ANÁLISE HARMÔNICA DE CAVIDADES ACÚSTICAS PELO MÉTODO DOS ELEMENTOS DE CONTORNO DIRETO

\author{
ÁLVARO CAMPOS FERREIRA
}

DISSERTAÇÃO DE MESTRADO EM ENGENHARIA MECÂNICA

DEPARTAMENTO DE ENGENHARIA MECÂNICA 

UNIVERSIDADE DE BRASÍLIA

FACULDADE DE TECNOLOGIA

DEPARTAMENTO DE ENGENHARIA MECÂNICA

\title{
ANÁLISE HARMÔNICA DE CAVIDADES ACÚSTICAS PELO MÉTODO DOS ELEMENTOS DE CONTORNO DIRETO
}

\author{
ÁLVARO CAMPOS FERREIRA \\ ORIENTADOR: MARCUS VINÍCIUS GIRÃO DE MORAIS
}

DISSERTAÇÃO DE MESTRADO EM

CIÊNCIAS MECÂNICAS

PUBLICAÇÃO: ENM.DM - 226 A/14

BRASÍLIA/DF: DEZEMBRO - 2014. 

UNIVERSIDADE DE BRASÍLIA

FACULDADE DE TECNOLOGIA

DEPARTAMENTO DE ENGENHARIA MECÂNICA

\section{ANÁLISE HARMÔNICA DE CAVIDADES ACÚSTICAS PELO MÉTODO DOS ELEMENTOS DE CONTORNO DIRETO}

\section{ÁLVARO CAMPOS FERREIRA}

DISSERTAÇÃO DE MESTRADO SUBMETIDA AO DEPARTAMENTO DE ENGENHARIA MECÂNICA DA FACULDADE DE TECNOLOGIA DA UNIVERSIDADE DE BRASÍLIA, COMO PARTE DOS REQUISITOS NECESSÁRIOS PARA A OBTENÇÃO DO GRAU DE MESTRE EM CIÊNCIAS MECÂNICAS.

APROVADA POR:

Marcus Vinicius Girão de Morais, PhD. (ENM-UnB)

(Orientador)

Éder de Lima Albuquerque, PhD. (ENM-UnB)

(Co-Orientador)

Carla Tatiana Anflor, PhD. (FGA-UnB)

(Examinador Interno)

Lineu José Pedroso, PhD. (ENC-UnB)

(Examinador Externo)

BRASÍLIA/DF, 12 DE DEZEMBRO DE 2014. 


\section{FICHA CATALOGRÁFICA}

FERREIRA, ÁLVARO CAMPOS

Análise Harmônica De Cavidades Acústicas Pelo Método Dos Elementos

De Contorno Direto

em Ciências Mecânicas. [Distrito Federal] 2014.

xiv, 94p., 297mm (ENM/FT/UnB, Mestre, Ciências Mecânicas, 2014).

Dissertação de Mestrado - Universidade de Brasília.

Faculdade de Tecnologia.

Departamento de Engenharia Mecânica.

1. Acústica

3. Métodos Numéricos

I. ENM/FT/UnB
2. Análise harmônica

4. Método dos Elementos de Contorno

II. Título (série)

\section{REFERÊNCIA BIBLIOGRÁFICA}

FERREIRA, A.C. (2014). Análise Harmônica De Cavidades Acústicas Pelo Método Dos Elementos De Contorno Direto. Dissertação de Mestrado em Ciências Mecânicas, Publicação ENM.DM - 226 A/14, Departamento de Engenharia Mecânica, Universidade de Brasília, Brasília, DF, 94p.

\section{CESSÃO DE DIREITOS}

NOME DO AUTOR: Álvaro Campos Ferreira.

TÍTULO DA DISSERTAÇÃO DE MESTRADO: Análise Harmônica De Cavidades Acústicas Pelo Método Dos Elementos De Contorno Direto.

GRAU / ANO: $\quad$ Mestre / 2014

É concedida à Universidade de Brasília permissão para reproduzir cópias desta dissertação de mestrado e para emprestar ou vender tais cópias somente para propósitos acadêmicos e científicos. O autor reserva outros direitos de publicação e nenhuma parte desta dissertação de mestrado pode ser reproduzida sem a autorização por escrito do autor.

\footnotetext{
Álvaro Campos Ferreira

SQN 409 Bloco J apartamento 208, Asa Norte

70.857-100 Brasília - DF - Brasil.
} 



\section{RESUMO}

\section{ANÁLISE HARMÔNICA DE CAVIDADES ACÚSTICAS PELO MÉTODO DOS ELE- MENTOS DE CONTORNO DIRETO}

\section{Autor: Álvaro Campos FERREIRA}

\section{Orientador: Marcus Vinícius Girão DE MORAIS}

Programa de Pós-graduação em Ciências Mecânicas

\section{Brasília, Novembro de 2014}

O estudo de cavidades acústicas é uma área de grande interesse em diversas áreas da industria. Em aplicações automotivas, o projeto de abafadores reativos ou dissipativos tem uso em diversas aplicações na admissão e na exaustão de motores de combustão interna. Em aplicações petrolíferas, o controle de ruído é uma necessidade em dutos para redução de ações acústicas gerados por máquinas ou pelo próprio fluxo ou sua interação com acidentes (curvas, junções T, válvulas, reduções, entre outros). Ou ainda em aplicações biomecanicas, o estudo do trato vocal repercute em domínios da fonoaudiologia, síntese da voz, e no ensino/treinamento de cantores líricos. Inúmeras são as aplicações práticas quando as soluções permitem a avaliações de cavidades tão complexas e diferentes.

Uma das formas de prever numericamente o comportamento acústico é com o Método de Elementos de Contorno. Este método possui características interessantes para a solução de problemas acústicos sem poluição numérica em altas frequências. O presente trabalho aborda a acústica de cavidades através do método dos Elementos de Contorno Direto. A implementação numérica é realizada em MATLAB devido as possibilidades de solução computacional e de visualização dos resultados. A construção de malhas em elementos de contorno usa o programa GiD. O código implementado é utilizado para obter o comportamento acústico de cavidades de geometria simples e esse resultado é comparado com soluções analíticas (soluções fechadas e matriz de transferência) e resultados numéricos de modelos do Método de Elementos Finitos obtidos utilizando o software comercial Ansys 14.5.

O código implementado é então utilizado para obter o comportamento acústico de cavidades de geometria complexa em colaboração com o Laboratório de Vibrações (UnB FT/EnM/GDS). 


\section{ABSTRACT}

\section{ANÁLISE HARMÔNICA DE CAVIDADES ACÚSTICAS PELO MÉTODO DOS ELE- MENTOS DE CONTORNO DIRETO}

\section{Autor: Álvaro Campos FERREIRA}

\section{Orientador: Marcus Vinícius Girão DE MORAIS}

Programa de Pós-graduação em Ciências Mecânicas

\section{Brasília, Novembro de 2014}

The study of acoustic cavities is a highly interesting area for numerous industry segments. The design of reactive or dissipative mufflers in the admission or exhaustion of internal combustion engines is a concern in the automotive industry. In petrochemical applications, the noise control is a necessity for the reduction of acoustic effects generated by the machinery or the flow inside the duct itself (curves. T junctions, valves, reductions, for example). There are even biomechanical applications, the study of the vocal tract bounces in the domain of phonoaudiology, voice synthesis and in the teaching/coaching of lyrical singers. There are countless applications for the evaluation of solutions of cavities with complex geometries.

One of the ways to numerically predict the acoustic behavior is using the Boundary Element Method. This method possesses interesting characteristics for the solution of acoustic problems with no numeric pollution in the high frequencies.

The present work assesses cavity acoustics by means of the Direct Boundary Element Method. The numerical implementation is performed in the MATLAB programing environment for its capacity of computational solution and results visualisation. Mesh construction in boundary elements is carried out using commercial program GiD. The implemented code is used to obtain the acoustic behavior of simple geometry cavities and this result is compared with analytical solutions (closed solutions and transfer matrix) and numerical results of Finite Element Method models obtained using commercial software Ansys 14.5.

The implemented code is then used to obtain the acoustic behavior of complex geometry cavities in collaboration with the Laboratório de Vibrações (UnB - FT/EnM/GDS). 



\section{ÍNDICE}

Capítulo

Página

INTRODUÇÃO 1

1.1 Contexto Industrial $\ldots \ldots \ldots \ldots \ldots$

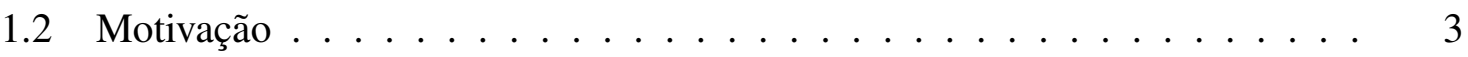

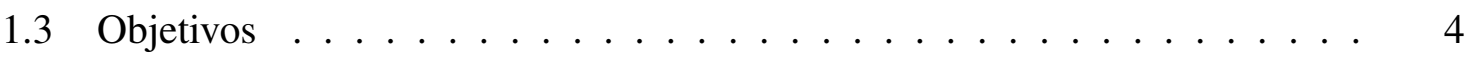

1.4 Metodologia . . . . . . . . . . . . . . . . 4

1.5 Organização dos capítulos ................... 5

MÉTODOS NUMÉRICOS

2.1 Métodos Numéricos aplicados em Acústica . . . . . . . . . . . 7

2.2 Método de Elementos de Contorno em Acústica . . . . . . . . . . . . . . . 11

O MÉTODO DE ELEMENTOS DE CONTORNO APLICADO A ACÚSTICA 16

3.1 Formulação Teórica . . . . . . . . . . . . . . . . . . . . . 16

3.2 Soluções Fundamentais da Equação da Onda . . . . . . . . . . . . . . 22

3.2.1 Tipos de Elementos de Contorno . . . . . . . . . . . . . . . . . 27

3.2.2 Aplicação de Condições de Contorno . . . . . . . . . . . . . 27

3.2.3 Obtenção de Valores em Pontos Internos . . . . . . . . . . . . . 28

3.2.4 Rotina para Carga Concentrada . . . . . . . . . . . . . . . . 29

3.2.5 Solução Fundamental e Discretização de Contorno no caso 3D . . . 30

IMPLEMENTAÇÃO MATLAB 32

4.1 Subrotinas e fluxo de informação no programa . . . . . . . . . . . . 32

4.2 Exemplo do fluxo de informações para o programa bidimensional . . . . . 35

VALIDAÇÃO DO CÓDIGO IMPLEMENTADO 40 
5.1 Cavidades 1D . . . . . . . . . . . . . . . 40

5.1.1 Cavidade 1D fechada-fechada - Caso (i) . . . . . . . . . . . . . 40

5.1.2 Cavidade 1D fechada-aberta - Caso (ii) . . . . . . . . . . . . 42

5.2 Cavidades $2 \mathrm{D} \ldots \ldots \ldots \ldots \ldots$. . . . . . . . . . . . . . . . . . 44

5.2.1 Cavidade 2D fechada-fechada - Caso (iii) . . . . . . . . . . 45

5.2.2 Cavidade 2D fechada-aberta - Caso (iv) . . . . . . . . . . 48

5.3 Cavidades 3D . . . . . . . . . . . . . . . . . . . . 49

5.3.1 Cavidade 3D cúbica aberta-fechada - Caso (v) . . . . . . . . 51

5.3.2 Cavidade 3D longa fechada-fechada - Caso (vi) . . . . . . . . 52

CASOS ESTUDADOS

6.1 Cavidade de Auralização . . . . . . . . . . . . . . . . 54

6.2 Acústica do trato vocal . . . . . . . . . . . . . . . 58

6.3 Cavidade de um Motor de Foguete Híbrido . . . . . . . . . . . . . . . 68

CONCLUSÕES E PERSPECTIVAS

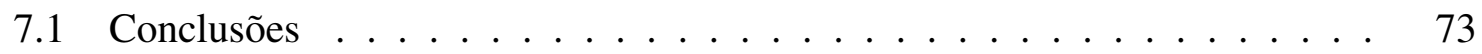

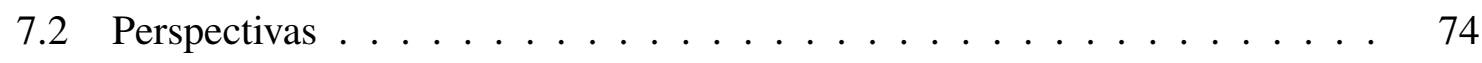

REFERÊNCIAS BIBLIOGRÁFICAS

$\begin{array}{ll}\text { APÊNDICES } & 78\end{array}$ 


\section{ÍNDICE DAS TABELAS}

Tabela

Página

2.1 Principais diferenças entre o MEF e o MEC . . . . . . . . . . . . . 10

4.1 Descrição de cada vetor criado na subrotina dad i.m . . . . . . . . . . . 34

4.2 Descrição de cada matriz criada na subrotina format_dad.m . . . . . . . . 34

4.3 Exemplo da matriz PONTOS para um problema bidimensional . . . . . . 36

4.4 Exemplo da matriz SEGMENTOS para um problema bidimensional . . . . 36

4.5 Exemplo da matriz MALHA para um problema bidimensional . . . . . . . 36

4.6 Exemplo da matriz CCSeg para um problema bidimensional. O tipo de condição de contorno é atribuído através do valor da célula "Tipo de CDC", em que um valor nulo indica que a pressão é conhecida no segmento e um valor diferente de zero indica que o gradiente de pressão é conhecido. . . . 37

5.1 Frequências de ressonância para o caso (i) 1D fechada-fechada . . . . . . . 41

5.2 Frequências de ressonância para a cavidade (ii) 1D fechada-aberta . . . . . 44

5.3 Frequências de ressonância para a cavidade (iii) 2D fechada-fechada . . . . 46

5.4 Frequências de ressonância para a cavidade (iv) . . . . . . . . . . . . . 49

6.1 Dimensões da Cavidade de Auralização . . . . . . . . . . . . . . 55

6.2 Frequências de Ressonância da Cavidade de Auralização $(\mathrm{Hz})$. . . . . . . 56

6.3 Área da seção transversal do trato vocal para diferentes vogais $\left[\mathrm{cm}^{2}\right] \ldots$. . . 62

6.4 Frequências Naturais para os modos de Ressônancia do trato vocal para diferentes vogais ............................ 63

6.5 Primeiras três frequências naturais do motor híbrido . . . . . . . . . . 72

7.1 Relações necessárias para encontrar as frequências de ressonância utilizando a matriz de transferência . . . . . . . . . . . . . . . 83 


\section{ÍNDICE DAS FIGURAS}

Figura

Página

1.1 Simulação da radiação acústica de um submarino por MEC (Liu, 2009) . . 2

1.2 Simulação da radiação acústica de rodovia em edificações por MEC (Liu,

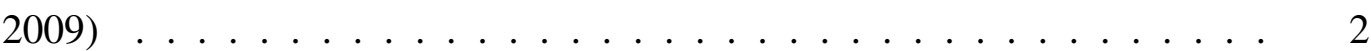

2.1 Estrutura em célula para um exemplo simples com dez pontos de colocação. Uma grande distância entre os pontos de colocação resulta em uma grande diferença entre o número de equações para aproximá-la (Kurz et al., 2002) .

2.2 A matriz permutada para o exemplo dado pela figura 2.1 possui grandes blocos fora da diagonal que descrevem interação remota entre os pontos de colocação e podem ser aproximadas por matrizes de baixo posto matricial (Kurz et al., 2002) . . . . . . . . . . . . . . . . . . 13

2.3 Uma estrutura hierarquica em células cobrindo todos os elementos do contorno (O pequeno quadrado ao lado mostra o esquema de numeração para as células filhas de qualquer célula pai) (Liu and Nishimura, 2006) . . . . . . 14

2.4 A hierarquia ramificada em células obtida para o FMM (Liu and Nishimura,

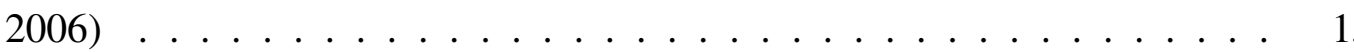

3.1 Contorno Discretizado . . . . . . . . . . . . . . . . . 20

3.2 Solução Fundamental para a pressão mostrada em Dominguez (1993) para um domínio circular unitário e número de onda $k=10 \ldots \ldots$. . . . .

3.3 Solução Fundamental para a pressão mostrada em Kirkup (2007) para um domínio circular unitário e número de onda $k=10 \ldots 24$

3.4 Comparação entre as Soluções Fundamentais para a Pressão Acústica . . . 24

3.5 Comparação entre a parte real das Soluções Fundamentais para a Pressão Acústica . . . . . . . . . . . . . . . . . . . . . . 
3.6 Comparação entre a parte imaginária das Soluções Fundamentais para o gradiente de Pressão Acústica . . . . . . . . . . . . . . . . . . . . 25

3.7 Gradiente de Pressão - Discrepância da parte imaginária da Solução Fundamental para o gradiente de pressão . . . . . . . . . . . . . . . . 26

3.8 Comparação entre a parte real das Soluções Fundamentais para a Pressão

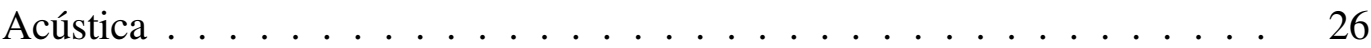

3.9 Comparação entre a parte imaginária das Soluções Fundamentais para o gradiente de Pressão Acústica . . . . . . . . . . . . . . . . . . . . . . . . 27

3.10 Tipos de Elementos: (a) Elementos Constantes, (b) Elementos Lineares, (c) Elementos Quadráticos (Braga, 2012) . . . . . . . . . . . . .

3.11 Direção da normal e numeração dos elementos nos casos: (a) Domínio Interno, (b) Domínio Externo (Dominguez, 1993) . . . . . . . . . . . . .

4.1 Geometria e Condições de Contorno de uma cavidade Bidimensional . . . . 35

4.2 Distribuição de pressão da cavidade 4.1 para a frequência $\omega_{b}=26.21[\mathrm{rad} / \mathrm{s}] \quad 38$

5.1 Condições de contorno para o caso (i) 1D fechada-fechada . . . . . . . . . 41

5.2 Resposta em frequência para a cavidade (i) 1D fechada-fechada . . . . . . 42

5.3 Quatro primeiras formas modais operacionais para a cavidade (i) 1D fechadafechada ............................ 43

5.4 Condições de contorno para o caso (ii) $1 \mathrm{D}$ fechada-aberta . . . . . . . . . . 43

5.5 Resposta em frequência para a cavidade (ii) 1D fechada-aberta . . . . . . . 44

5.6 Duas primeiras formas modais para a cavidade (ii) $1 \mathrm{D}$ fechada-aberta . . . 45

5.7 Condições de contorno para o caso (iii) 2D fechada-fechada . . . . . . . . 46

5.8 Resposta em frequência para a cavidade (iii) 2D fechada-fechada . . . . . . 47

5.9 Quatro primeiras formas modais para a cavidade (iii) 2D fechada-fechada . $\quad 47$

5.10 Forma modal mista para a frequência $\omega_{b}=254[\mathrm{rad} / \mathrm{s}]$ para a cavidade (iii) 2D fechada-fechada . . . . . . . . . . . . . . . . . 48

5.11 Condições de contorno para o caso (iv) 2D fechada-aberta . . . . . . . . 49

5.12 Resposta em frequência para a cavidade (iv) 2D fechada-aberta . . . . . . . 50

5.13 Quatro primeiras formas modais para a cavidade (iv) 2D fechada-aberta . . 50

5.14 Resposta em frequência para a cavidade (v) 3D cúbica aberta-fechada . . . 51

5.15 Modo identificado para a cavidade (v) 3D cúbica aberta-fechada . . . . . . 52 
5.16 Resposta em frequência para a cavidade (vi) 3D longa fechada-fechada . . .

5.17 Duas primeiras formas modais para a cavidade (vi) 3D longa fechada-fechada 53

6.1 Cavidade de auralização $\ldots \ldots \ldots \ldots$. . . . . . . . . . . . 54

6.2 Resposta em frequência da cavidade de auralização discriminando os quatro primeiros modos de ressonância . . . . . . . . . . . . 56

6.3 Malha em elementos de contorno para a cavidade de auralização . . . . . . 56

6.4 Primeira forma modal acústica da cavidade de auralização obtida por MEC $\quad 57$

6.5 Segunda forma modal acústica da cavidade de auralização obtida por MEC 57

6.6 Modelo esquemático para o aparelho fonador (Cataldo et al., 2004) . . . . . 58

6.7 Distribuição de pressão normalizada para o primeiro modo das vogais $\backslash o \backslash \mathrm{e}$ $\backslash a \backslash$ obtidas respectivamente por Hannukainen et al. (2007) e Takemoto et al.

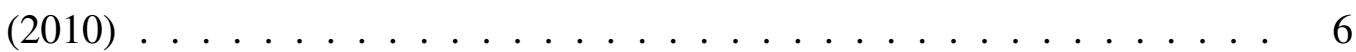

6.8 Malha desenvolvida para a cavidade do trato vocal durante a fonação da

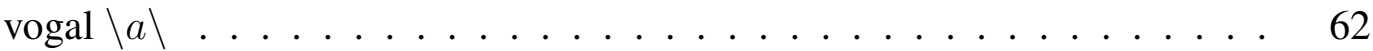

6.9 Malha desenvolvida para a cavidade do trato vocal durante a fonação da

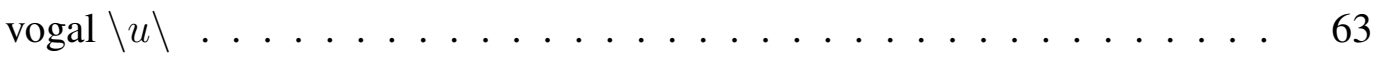

6.10 Resposta em frequência para a cavidade do trato vocal durante a fonação da vogal $\backslash a \backslash$ identificando os três primeiros modos de ressonância . . . . . . . 64

6.11 Primeira forma modal para a cavidade do trato vocal durante a fonação da

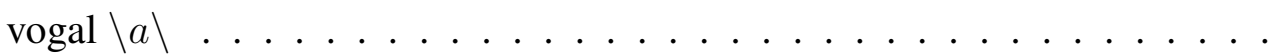

6.12 Segunda forma modal para a cavidade do trato vocal durante a fonação da vogal $\backslash a \backslash \ldots \ldots \ldots \ldots \ldots \ldots \ldots \ldots \ldots \ldots \ldots \ldots \ldots \ldots \ldots \ldots \ldots$

6.13 Terceira forma modal para a cavidade do trato vocal durante a fonação da

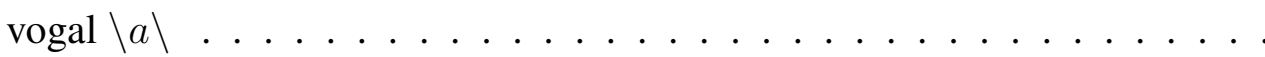

6.14 Primeira forma modal para a cavidade do trato vocal durante a fonação da

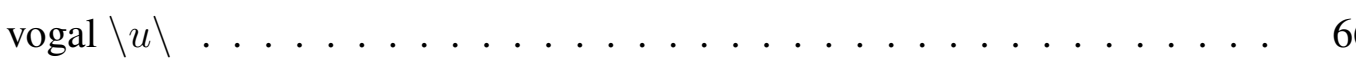

6.15 Segunda forma modal para a cavidade do trato vocal durante a fonação da

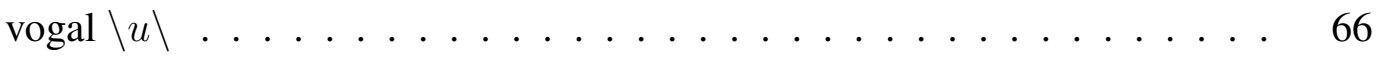

6.16 Terceira forma modal para a cavidade do trato vocal durante a fonação da

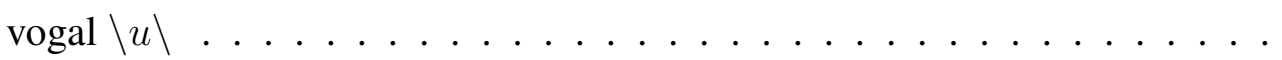

6.17 Resposta em frequência para a cavidade do trato vocal durante a fonação da

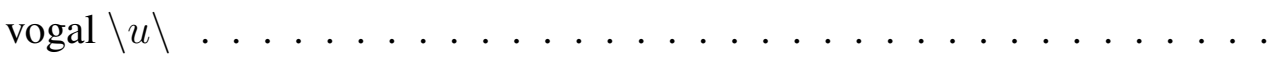


6.18 Dimensões principais do motor híbrido estudado . . . . . . . . . . . . . 69

6.19 Vista explodida mostrando os componentes principais do motor híbrido estudado . . . . . . . . . . . . . . . . . . . 70

6.20 Resposta em frequência para a cavidade do motor de foguete híbrido . . . . 70

6.21 Primeira forma modal para a cavidade do motor de foguete híbrido . . . . . 71

6.22 Segunda forma modal para a cavidade do motor de foguete híbrido . . . . . 71

6.23 Terceira forma modal para a cavidade do motor de foguete híbrido . . . . . 72

7.1 Esquema do conduto reto (Morais, 2000) . . . . . . . . . . . . . 80

7.1 Transformação da integral de domínio em integral de contorno. . . . . . . . 89

7.2 Posição dos pontos no domínio. . . . . . . . . . . . . . . 93

7.3 Condições de contorno do exemplo $1 \ldots \ldots$. . . . . . . . . . . . . . . 94

7.4 Primeira forma modal para o exemplo 1, obtido utilizando o RIM . . . . . . 95 


\section{LISTA DE SÍMBOLOS, NOMENCLATURA E ABREVIAÇÕES}

$i$ : unidade imaginária, $i=\sqrt{-1}$.

$p$ : pressão acústica, perturbação do campo de pressão observado em $[P a]$ (Kinsler, 1982).

$\partial_{n} p$ : gradiente de pressão acústica na direção $n, \partial_{n} p=\frac{\partial p}{\partial n}$.

$q$ : vazão acústica na direção $x, q=\frac{i S}{\omega} \frac{\partial p}{\partial x}$

$t$ : tempo medido em segundos $[s]$.

$c$ : velocidade de propagação da onda acústica no meio físico $[\mathrm{m} / \mathrm{s}]$

$\frac{\partial f}{\partial b}$ : derivada parcial da função $f$ com relação à variável $b$.

$\dot{f}$ : notação reduzida da derivada parcial da função $f$ com relação à variável $t$.

$\nabla:$ Laplaceano, operador adimensional de Laplace. $\nabla=\left(\frac{\partial}{\partial x}, \frac{\partial}{\partial y}, \frac{\partial}{\partial z}\right)$ no espaço.

S: domínio.

$\Gamma$ : contorno.

$\xi$ : posição no espaço geométrico.

$n$ : vetor normal ao contorno.

$\delta\left(x-x_{d}\right)$ : função delta de Dirac aplicada ao ponto $x_{d}$.

T: período de oscilação.

$f$ : frequência. 
$\omega$ : frequência circular, $\omega=2 \pi / T=2 \pi f$.

$k$ : número de onda, $k=\omega / c$.

$\mu$ : módulo de elasticidade do meio físico.

$K_{n}$ : função modificada de Bessel de ordem $n$.

$H_{n}^{(m)}$ : função de Hankel de ordem $n$ e tipo $m$.

MEC : Método dos Elementos de Contorno.

MEF : Método dos Elementos Finitos.

SEA : Análise Estatística de Energia (ing. - Statistical Energy Analysis). 


\section{Capítulo 1 INTRODUÇÃO}

\subsection{Contexto Industrial}

Níveis baixos de ruído são uma demanda majoritária em veículos e máquinas industriais. Isso é especialmente evidente em veículos motorizados de transporte de passageiros. A redução sistemática de massa para um aumento da eficiência de combustível em automóveis e aeronaves podem levar a um aumento de ruído e níveis de vibração.

O acoplamento fluido-estrutura torna-se mais pronunciado a medida que a rigidez dessas estruturas é reduzida, particularmente com a introdução de novos materiais mais leves como materiais compósitos (Dhandole and Modak, 2007). O aumento do acoplamento fluidoestrutura assim como o aumento nos níveis de vibração geral do veículo gera, também, um aumento do ruído nas redondezas do veículo. Tais problemas podem ser encontrados em veículos transitando em diferentes meios acústicos, principalmente água e ar.

Um dos casos em que a propagação acústica e o acoplamento de placas de metal finas e o meio torna-se evidente é o de submarinos (Figura 1.1), em que o ruído gerado pelo motor e pela maquinária interna são propagados pelo meio quase infinito do oceano. Conhecer as características dessa propagação é importante para sermos capazes de prever o comportamento acústico no campo distante (far-field) e podermos controlar essa geração de ruído.

Outro caso evidente é de carros transitando em vias próximas de residências ou centros comerciais (Figura 1.2). Nesse caso, o ruído gerado pelo motor, pela aerodinâmica do veículo devem ser minimizados para que o som propagado até o local habitado seja inferior a níveis pré-estabelecidos. A previsão do nível de ruído propagado a uma determinada distância pode ser um fator importante na decisão de alterar o veículo para a redução desse ruído propagado. Ser capaz de prever também o ruído propagado por uma indústria que se encontra próxima de centros habitados é também importante para garantir o conforto dos habitantes.

O mesmo ocorre no caso de fazendas de energia eólica, em que o ruído gerado pelas carac- 


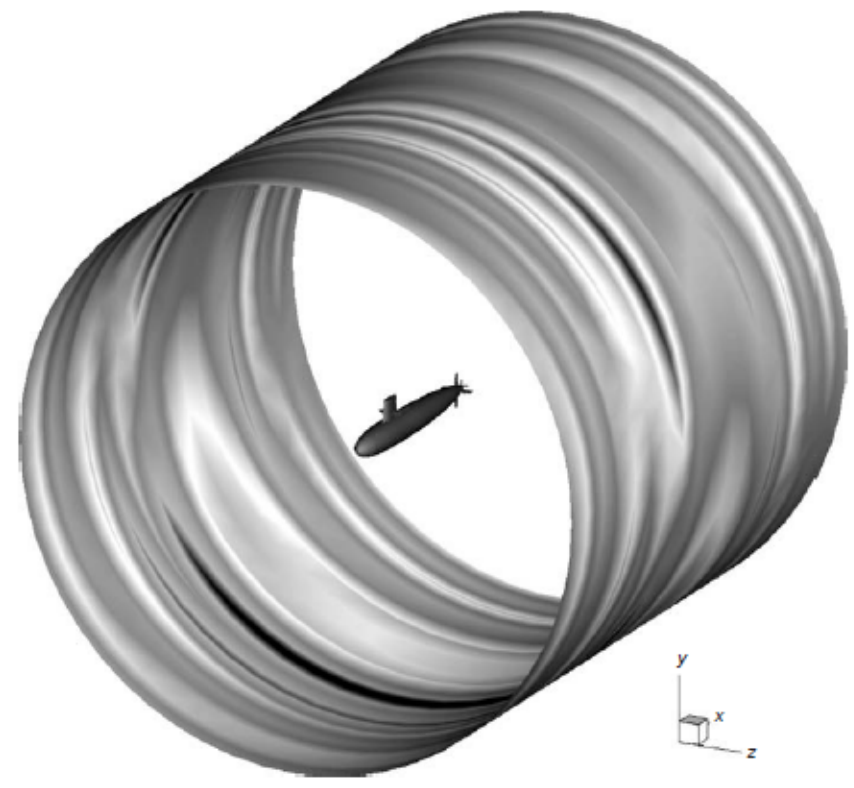

Figura 1.1: Simulação da radiação acústica de um submarino por MEC (Liu, 2009)

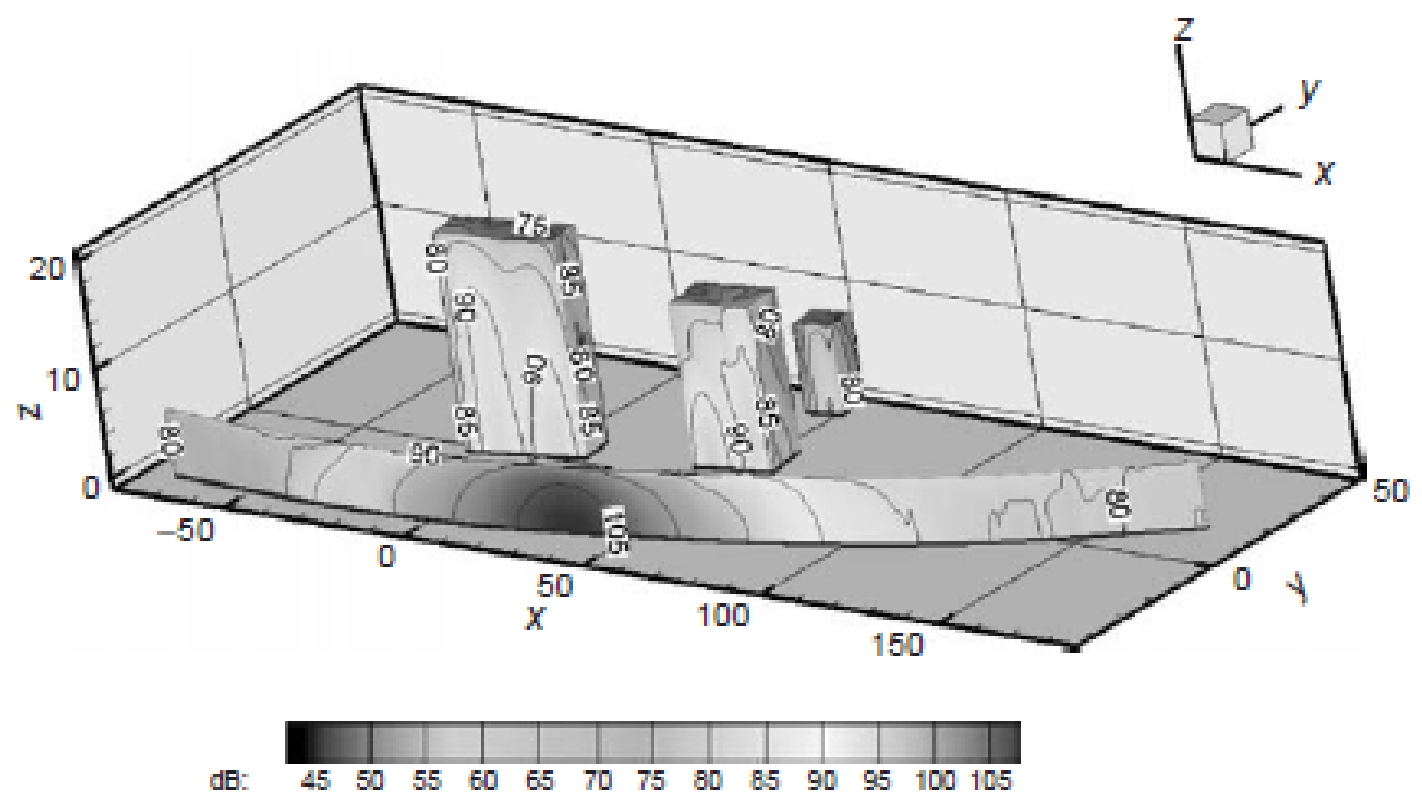

Figura 1.2: Simulação da radiação acústica de rodovia em edificações por MEC (Liu, 2009) 
terísticas aerodinâmicas e pelo gerador é propagado, possivelmente até áreas em que esse ruído deve ser minimizado, como reservas naturais ou centros de convivência. Ser capaz de prever o comportamente acústico dessas turbinas pode ajudar a mudar seu design e diminuir drasticamente o impacto ambiental causado por ela.

No caso de veículos motorizados é importante também preocupar-se com o ruído existente na cavidade interna do veículo, também chamada de habitáculo veicular. Nessas cavidades, em que se encontram os passageiros, o nível de ruído deve ser o menor possível para garantir o máximo de conforto aos passageiros e não influenciar a inteligibilidade da fala. Nesse caso, o ruído interno percebido pelo passageiro é o fator de design mais importante do ponto de vista acústico. Devemos concentrar os esforços para que o design minimize o ruído, principalmente na faixa de frequência média ([300 - 3000] [Hz]), que é responsável por $90 \%$ da inteligibilidade (Melo et al., 2012).

\subsection{Motivação}

A previsão do comportamente acústico desses modelos é geralmente um trabalho complexo. Devido à geometria complexa das cavidades e a caracterização das fontes acústicas, a construção de protótipos para realizar ensaios experimentais deve ser planejada em virtude do alto custo. Soluções analíticas são difíceis de se obter para geometrias complexas.

Métodos numéricos vem sendo empregados como uma ferramenta para baratear os custos da prototipagem de geometrias complexas em problemas de acústica e vibro-acústica. Diversos métodos para a previsão das características acústicas de cavidades e meios infinitos foram propostas, cada uma com suas vantagens e desvantagens.

Para baixas e médias frequências, métodos baseados em elementos, como o Método de Elementos de Contorno (MEC) e o Método de Elementos Finitos (MEF), são muito utilizados por serem capazes em obter bons resultados a um custo relativamente baixo. No caso em que o interesse acústico seja na faixa de alta frequência, as incertezas relacionadas às propriedades do material resultam em um efeito significativo na resposta dinâmica esperada da estrutura. Abordagens baseadas da Análise Estatística Energética (SEA) devem ser empre- 
gadas (Estorff, 2008).

\subsection{Objetivos}

Implementar um algoritmo para a solução de problemas acústicos e fornecer uma ferramenta numérica para o GDS - Grupo de Dinâmica de Sistemas da Universidade de Brasília (UnB). O código MEC implementado vai auxiliar no estudo de cavidades acústicas para resolver problemas de engenharia e realizar pesquisa básica.

O código deve ser implementado de forma que possa ser utilizado para o ensino do Método de Elementos de Contorno na UnB. Com a validação do código, os resultados obtidos podem ser comparado com resultados experimentais obtidos no Laboratório de Vibrações da UnB para aumentar a robustez e confiabilidade desses resultados.

Os objetivos específicos deste trabalho são:

- realizar uma revisão bibliográfica da formulação MEC direto.

- implementar os códigos das formulações bidimensional e tridimensional do MEC direto na linguagem de programação MATLAB a partir de códigos existentes em outras linguagens na literatura (Dominguez, 1993).

- validar o código implementado a partir da solução de casos que possuam soluções analíticas.

- utilizar o programa implementado para prever o comportamento acústico de cavidades de geometria complexa e comparar os resultados obtidos com resultados da literatura.

\subsection{Metodologia}

Realizar uma pesquisa bibliográfica sobre o Método de Elementos de Contorno aplicado em acústica assim como sobre soluções analíticas disponíveis para cavidades unidimensionais, bidimensionais e tridimensionais. 
Inicialmente o código bidimensional do Método de Elementos de Contorno (MEC) direto será utilizado para resolver problemas de cavidades acústicas unidimensionais que possuem soluções analíticas disponíveis na literatura. Os resultados obtidos serão comparados com as soluções analíticas para validar os resultados numéricos. O código correspondente ao MEC tridimensional será então utilizado para resolver problemas de cavidades acústicas unidimensionais e bidimensionais, em que soluções analíticas estão disponíveis. Resultados experimentais obtidos no laboratório de vibrações de uma cavidade tridimensional serão utilizados para realizar comparações entre as soluções analítica e numérica. Por fim, o código implementado será utilizado para resolver problemas de cavidades tridimensionais com geometrias arbitrárias, em que soluções analíticas não estão disponíveis. Esses casos serão comparados com resultados experimentais, encontrados na literatura ou obtidos no Laboratório de Vibrações da UnB utilizando soluções analíticas aproximadas (Método da Matriz de Transferência).

\subsection{Organização dos capítulos}

A presente dissertação encontra-se dividida em seis capítulos.

O capítulo 2 apresenta uma introdução aos métodos numéricos aplicados à resolução de problemas de acústica. Métodos determinísticos e estatísticos diversos são abordados. Em virtude dos objetivos da dissertação, uma introdução ao Método de Elementos de Contorno como objeto de estudo principal do trabalho é desenvolvido. Um curto histórico do Método de Elementos de Contorno é apresentado, incluindo as principais vantagens e desvantagens do método e técnicas para aumentar sua eficiência computacional.

O capítulo 3 apresenta a formulação básica para o Método de Elementos de Contorno (MEC) Direto. Os pontos principais para a compreensão do código implementado são salientados a fim de ajudar na compreensão dos resultados obtidos posteriormente.

O capítulo 4 descreve a implementação do código MEC Direto para a solução de cavidades internas no ambiente de programação escolhido, o programa comercial MatLab. O MatLab é um programa comercial que possui uma linguagem de alto nível e é utilizada por engenhei- 
ros e matemáticos no mundo inteiro por ter sintaxe simples e possuir recursos de linguagens de baixo nível facilmente utilizáveis. É possível desenvolver programas com diversas subrotinas independentes em um mesmo programa além da maior vantagem do programa que é sua poderosa capacidade gráfica, o que permite visualizar os resultados facilmente. Em cada caso, o programa desenvolvido consiste em um programa principal em que as subrotinas serão iniciadas e em que as variáveis serão controladas. As características do sistema estudado serão incluídas no sistema através de uma subrotina contida no programa principal.

O capítulo 5 apresenta os resultados de alguns casos estudados nos domínios $2 \mathrm{D}$ e 3D que serviram a validação do programa. Os programas utilizados são semelhantes aos programas desenvolvidos por Dominguez (1993), com a diferença da linguagem de programação escolhida, MatLab. Esses casos correspondem a cavidades unidimensionais, bidimensionais e tridimensionais de geometria simples. Estes casos possuem soluções analíticas para as condições de contorno escolhidas.

O capítulo 6 apresenta os resultados obtidos em casos complexos utilizando a implementação numérica. Essas outras cavidades acústicas foram colaborações do autor em outros estudos do Laboratório de Vibrações (UnB - FT/ EnM/GDS) ou casos presentes na literatura. Os resultados obtidos são comparados com soluções analíticas e resultados experimentais.

O capítulo 7 apresenta a conclusão da presente dissertação e resume os resultados do trabalho desenvolvido de forma a elucidar as principais dificuldades encontradas. Apresenta-se as oportunidades para trabalhos futuros. Os resultados obtidos são revisados de forma a reapresentar a metodologia desenvolvida. Ao final do texto, perspectivas de continuidade do trabalho são apresentadas de forma a traçar um possível caminho para trabalhos futuros. 


\section{Capítulo 2 MÉTODOS NUMÉRICOS}

Esse capítulo apresenta uma introdução aos principais métodos numéricos mais evidentes para a resolução de problemas em acústica. Métodos determinísticos e estatísticos diversos são abordados. Uma introdução do Método de Elementos de Contorno, conforme o objeto de estudo principal do trabalho é desenvolvido. Um curto histórico do Método de Elementos de Contorno é apresentado incluindo suas principais vantagens e desvantagens, bem como algumas técnicas para aumentar sua eficiência computacional.

\subsection{Métodos Numéricos aplicados em Acústica}

Métodos numéricos para solução de equações diferenciais em problemas de engenharia tornaram-se lugar comum em laboratórios no mundo inteiro nas últimas décadas. Desde a popularização do computador e dos primeiros métodos numéricos comerciais, diversas técnicas numéricas foram desenvolvidas e aprimoradas. Esses métodos são capazes de construir modelos discretos a partir de um modelo contínuo e, portanto, simplificar o problema que almeja-se resolver (Gilat, 2008; Azevedo, 2007). Os métodos de maior popularidade e versatilidade entre os métodos numéricos são o Método de Elementos Finitos (MEF), o Método de Diferenças Finitas e o Método de Elementos de Contorno (MEC).

O Método de Elementos Finitos é o método mais populares e é capaz de resolver uma grande gama de problemas de engenharia. Contudo, o MEF possui como característica a utilização de um número muito grande de variáveis, além de ter uma entrada e saída de dados trabalhosos para um problema complexo (Azevedo, 2007).

A Análise Estatística Energética (Statistical Energy Analysis - SEA) é um poderoso método para a predição e análise do comportamento vibro-acústico de sistemas de acoplamento fluido-estrutura (Estorff, 2008). O modelo produz uma representação estatística para o comportamento vibro-acústico médio de uma população de sistemas físicos similares, onde cada 
amostra individual pode se desviar da média obedecendo uma estimativa de variância (Gerges, 2001).

O método é executado através de uma divisão do sistema original em subsistemas e o comportamento médio do conjunto desses subsistemas físicos é obtido, juntamente com a variância assosciada. Cada subsistema representa um mecanismo de armazenamento de energia. $\mathrm{O}$ fluxo de potência entre subsistemas é proporcional aos fatores de perda por acoplamento e à diferença de energia modal média. A potência é dissipada devido aos efeitos de amortecimento. A inclusão de uma fonte de energia com alta frequência gera um sistema de equações lineares a partir do balanço de energia entre os subsistemas em que os níveis de energia são as variáveis desconhecidas. Ao resolver o sistema, obtemos os níveis de resposta médios, que informam o comportamento estatístico do sistema.

A razão mais importante para empregar o SEA quando tratamos de problemas no domínio da alta frequência são as variações aleatórias e incertezas inerentes às propriedades materiais e do sistema. As características dos modos de altas frequências são mais sensíveis a variações dessas propriedades materiais e aos parâmetros do sistema. Junta-se a isso o aumento da densidade modal na alta frequência, conclui-se que é vantajoso conhecer o comportamento médio através de uma análise estatística do sistema nessas condições Gerges (2001). Ainda assim, o SEA não é uma metodologia substituta para os métodos determinísticos, mas sim um complemento para a análise dos sistemas no domínio da alta frequência, em que o comportamento será melhor descrito por suas características médias.

Dentre os métodos determinísticos para a solução de equações diferenciais parciais, o método Wave Based e o Método de Trefftz são dignos de menção por sua importância no desenvolvimente de técnicas para integração numérica. O Método de Trefftz é baseado em um método proposto por Walter Ritz, conhecido hoje em dia como o Método de Ritz, que procura aproximar a solução de equações integrais através do método variacional e funções estimadas (Cheng and Cheng, 2005). Esse método permite aproximar a solução da equação integral utilizando uma série finita de funções estimadas para a solução da equação integral. Envolve a integração sobre o domínio da solução e é considerado um método de domínio e não de contorno. Baseado na mesma idéia, Erich Trefftz elaborou o método de contorno conhecido como o Método de Trefftz. Utilizando a a primeira identidade de Green, é possível aplicar 
o Método de Ritz utilizando apenas funções que são soluções para a equação diferencial. Esse procedimento permite que a equação seja resolvida solucionando apenas integrais de contorno evitando erros de poluição relacionados às aproximações polinomiais relacionadas aos elementos (Bergen et al., 2012). Essa classe de métodos procuram diminuir os erros associados a métodos de discretização de domínio ou contorno eliminando a necessidade de polinômios de funções de forma que não são a solução exata da equação diferencial governante. Dessa forma, tanto no Método de Elementos de Contorno quanto no Método de Elementos Finitos, uma discretização muito fina é necessária para suprimir o erro de poluição associado e aumentar a precisão da solução. A solução dessas equações resulta nos fatores de contribuição das funções de onda utilizadas na expansão das variáveis dinâmicas do campo. Através da implementação do método Wave Based em problemas de dinâmica estrutural em regime permanente, acústica e vibro-acústica de sistemas interiores e exteriores, é mostrado que, devido ao pequeno tamanho do modelo e as características aprimoradas de convergência, o método Wave Based possui um desempenho numérico superior comparado com métodos baseados em elementos. Como resultado, problemas na faixa de frequência superior devem ser atacados utilizando essa técnica (Bergen et al., 2012).

O Método Wave Based é outra técnica determinística alternativa para analisar problemas acústicos. O método é baseado na abordagem indireta de Trefftz, onde a resposta dinâmica das variáveis são descritas usando funções de onda (wave functions) que satisfaçam a equação diferencial exatamente. Utilizando essa abordagem, nenhum erro de aproximação é cometido dentro do domínio. Entretanto, essas funções de onda podem violar as condições de contorno e de continuidade. Forçando os erros residuais associados para zero em um esquema de resíduos ponderados resulta em um pequeno sistema de equações algébricas.

Seguindo o mesmo espírito do Método de Trefftz, é possível utilizar a solução fundamental da equação diferencial governante como a função estimada para a solução da equação diferencial. A partir da formulação obtida dessa forma e utilizando pontos de colocação para determinar a posição dos pontos fonte da solução fundamental, a solução da equação integral pode ser obtida sem a necessidade de resolver integrais de contorno. Esse método é chamado Método das Soluções Fundamentais (Fundamental Solutions Method).

O Método de Elementos de Contorno possui uma vantagem entre os métodos determinísticos 
citados pois ele reduz efetivamente uma ordem de grandeza do problema. Ou seja, apenas o contorno do problema é discretizado. Assim, segundo Azevedo (2007) com o MEC é possível obter soluções mais precisas, uma vez que esse trabalha com soluções de equações integrais sem aproximação no domínio. Apenas considerações no contorno e a geometria são aproximados. Uma boa aplicação do MEC são simulações em que requerem alteração constante na malha da estrutura para aperfeiçoar a solução do problema. Outra característica do MEC é a obtenção das informações do domínio a partir das variáveis do contorno, pois os valores das variáveis no interior do domínio podem ser escritos como uma função das variáveis externas presentes no contorno. Isso também é válido para um problema externo, em que o domínio externo ao contorno discretizado pode ser infinito, nessa característica o MEC é superior ao MEF, uma vez que são necessárias técnicas complexas para modelar esta classe de problemas em MEF. Enquanto no MEC, mesmo para casos em que o domínio é infinito, apenas o contorno dele deve ser discretizado. A utilização comercial do MEC é menor que a do MEF pois a aplicação do MEC é limitada a problemas que apresentam as chamadas soluções fundamentais ou funções de Green. Uma função de Green é um tipo de função usada para resolver equações diferenciais homogêneas não sujeitas a condições de contorno. A existência de uma solução fundamental é necessária para fazermos a transformação da equação diferencial que governa o problema para uma equação integral de contorno. Essa transformação é feita utilizando a solução fundamental do problema com o Teorema GaussGreen. O livro Liu (2009) apresenta um diagrama útil das vantagens e desvantagens do MEC em comparação ao MEF, que pode ser visto na Tabela 2.1.

Tabela 2.1: Principais diferenças entre o MEF e o MEC

\begin{tabular}{|l|l|}
\hline$M E F$ & $M E C$ \\
\hline Funcionalidades & \\
- Abordagem baseada em derivadas (local) & - Abordagem baseada em integrais (global) \\
- Malha do Domínio: malhas 2D ou 3D & - Malha do Contorno: malhas 1D ou 2D \\
- Matrizes simétricas e esparsas & - Matrizes não-simétricas e cheias \\
- Muitos pacotes comerciais disponíveis & - Menos pacotes comerciais disponíveis \\
\hline $\begin{array}{l}\text { Vantagens } \\
\text { - Solução rápida }\end{array}$ & - Geração da malha é rápida \\
- Adequado para análise geral de estruturas, \\
$\begin{array}{l}\text { sistemas mecânicos complexos } \\
\text { - Problemas não-lineares }\end{array}$ & $\begin{array}{l}\text { - Adequado para problemas de concentração de } \\
\text { - Materiais compósitos (análise na }\end{array}$ \\
macro-escala) & - Adequado para problemas de domínio infinito \\
\hline
\end{tabular}




\subsection{Método de Elementos de Contorno em Acústica}

O Método de Elementos de Contorno é um método numérico para resolver euqações diferenciais parciais lineares. Apesar de sua base poder ser traçada até o século XVIII, o método começou a ser implementado computacionalmente apenas no início e meio do século XX, quando computaddores eletrônicos tornaram-se disponíveis e a comunidade acadêmica começou a publicar artigos utilizando o MEC para resolver problemas potenciais. Apesar de existirem formulações para problemas potenciais e até de elasticidade na primeira década do século XX, não foi até 1967 que a sorte começou a mudar para os métodos de solução de equações diferenciais de contorno, da qual o MEC faz parte. Apenas com a publicação do artigos: Integral Equation Methods in Potential Theory e An integral equation approach to boundary value problems of classical elastostatics pelos pesquisadores Maurice Jaswon e Frank Joseph Rizzo, respectivamente, funções de Green foram utilizadas para resolver problemas de integral de contorno pela primeira vez, dando o pontapé inicial necessário para o desenvolvimento do chamado Método de Elementos de Contorno Direto (Cheng and Cheng, 2005). O problema atacado por Rizzo era o da elastoestática mas o uso da função de Green para resolver a equação governante do problema numericamente pode ser utilizada para qualquer equação em que uma função de Green possa ser utilizada como uma solução na forma de impulso da equação diferencial parcial. Foi na década de 1970 que o desenvolvimento do MEC recebeu suas maiores contribuições e o termo Boundary Element Method foi cunhado. Com uma história rica e complexa, é impossível reduzir os criadores do MEC a apenas um grupo de pessoas ou a apenas um período no tempo.

A equação da onda possui funções de Green que podem ser utilizadas como soluções fundamentais no Método de Elementos de Contorno. A implementação de algoritmos para resolver problemas de acústica utilizando o MEC foi realizada na segunda metade do século XX, após a implementação do MEC para problemas potenciais. Logo tornou-se evidente a vantagem de utilizar o MEC para resolver problemas de acústica. O MEC apresenta uma solução interessante para problemas de acústica em meios infinitos. Outros métodos numéricos capazes de resolver problemas de acústica necessitam da discretização de todo o domínio estudado, o que impossibilitava o estudo de meios infinitos, por exemplo em casos de radiação acústica. O MEC não necessita da discretização da totalidade do domínio, mas apenas seu contorno e 
sua formulação já garante a condição de Sommerfeld para radiação, necessária para estudar radiação em meios infinitos.

Apesar dessa característica, o MEC não conseguiu atingir a popularidade de seus concorrentes por um motivo simples: sua formulação gera matrizes cheias e não-simétricas. O sistema linear gerado pode ser facilmente resolvido, porém seu custo computacional para montar a a matriz do problema é de ordem $O\left(N^{2}\right)$ e necessita de $O\left(N^{3}\right)$ operações para resolver o sistema linear usando solvers diretos, onde $O(a)$ indica ordem de grandeza do número $a$ e $N$ indica o número de graus de liberdade do sistema. Muitas formas de resolver o problema do custo do MEC foram propostas nas décadas seguintes. Os mais conhecidos métodos desenvolvidos são o Método de Multi Pólos Rápidos (Fast Multipole ou FMP) e o Adaptive Cross-Approximation. Ambos os métodos procuram reduzir o número de operações total para a obtenção da matriz do problema e cada um possui suas vantagens.

O método Adaptive Cross-Approximation conhecido como ACA procura diminuir o custo computacional de se resolver uma matriz cheia e não simétrica dividindo a matriz em questão em pequenos blocos de tamanhos variados. Esses blocos, que descrevem interações remotas da matriz, são estimados por aproximações adaptativas de matrizes de posto matricial baixo. Este procedimento reduz a complexidade do algoritmo para montar a matriz e fazer produtos de matriz $\times$ vetor para aproximadamente $O(N)$. A maior vantagem do ACA com relação a outros métodos rápidos de BEM, como o Método de Multi Pólos Rápidos (FMP), é que apenas as entradas originais da matriz do sistema são utilizadas para a aproximação. Isso significa que algoritmos já implementados para obter a matriz original podem ser facilmente adaptados para produzir a aproximação por ACA. O algoritmo necessário para o método não é de difícil implementação em contraste com os algorirmos para séries de Taylor ou para os harmônicos esféricos usados no FMP. Outra vantagem do ACA é que qualquer precisão arbitrária do método pode ser obtida muito facilmente. No pior dos casos, a matriz original vai ser gerada sem nenhum erro (Kurz et al., 2002).

As matrizes cheias e densas oriundas de equações integrais não possuem estrutura explícita em geral. Mas é possível fazer permutações da matriz original para que a matriz com linhas e colunas permutadas possuam blocos que se aproximam de matrizes de baixo posto matricial. Isso pode ser feito construindo uma estrutura ramificada que separe os pontos de colocação 
em células distintas. Um exemplo simples é mostrado na figura 2.1, em que uma distância arbitrária define o tamanho de cada célula. Com essa metodologia é possível separar pares de células admissíveis, como mostrado pelos pares $\{1,2,3,4,5\}$ e $\{6,7,8,9\}$. A partir dessa divisão, é possível montar a estrutura em bloco da matriz mostrada pela figura 2.2, em que interações remotas dos pontos de colocação estão posicionadas longe da diagonal e podem ser aproximados por matrizes de baixo posto matricial (Kurz et al., 2002).

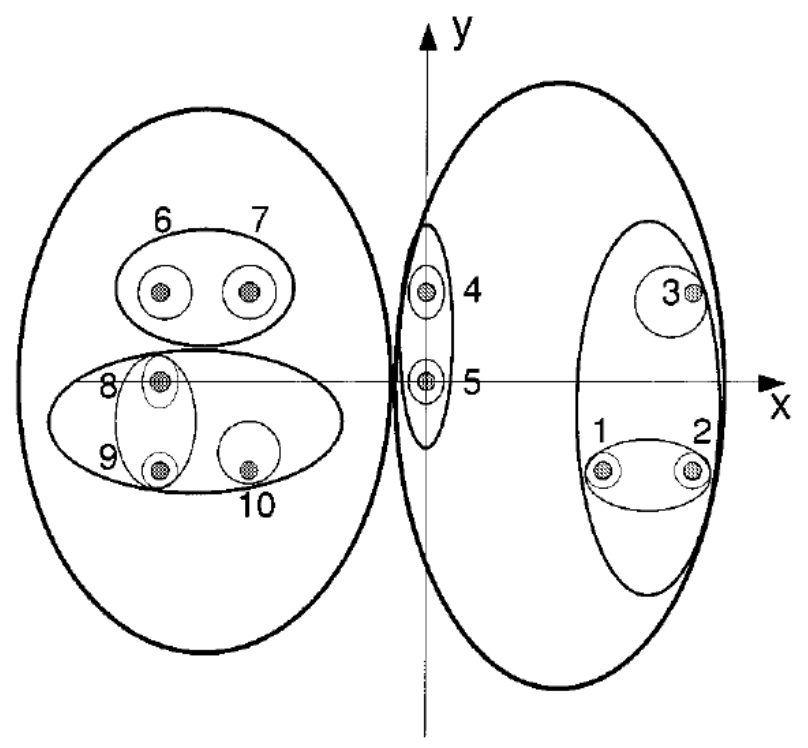

Figura 2.1: Estrutura em célula para um exemplo simples com dez pontos de colocação. Uma grande distância entre os pontos de colocação resulta em uma grande diferença entre o número de equações para aproximá-la (Kurz et al., 2002)

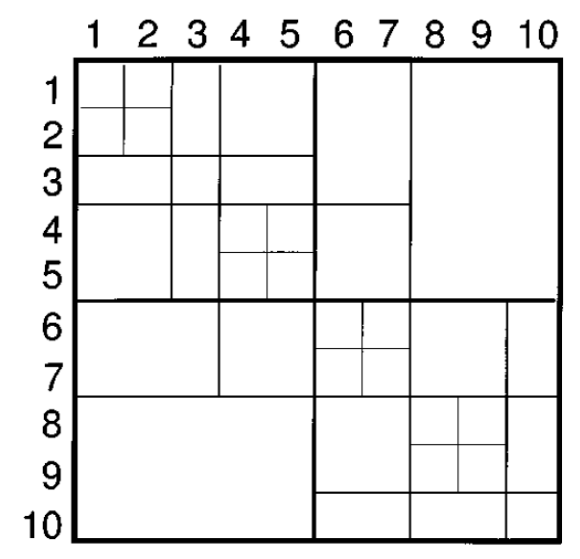

Figura 2.2: A matriz permutada para o exemplo dado pela figura 2.1 possui grandes blocos fora da diagonal que descrevem interação remota entre os pontos de colocação e podem ser aproximadas por matrizes de baixo posto matricial (Kurz et al., 2002)

O Método de Multi Pólos Rápidos (FMM) ataca o problema de uma forma diferente. Ao invés de tentar resolver a matriz principal do problema considerando a interação entre cada 
nó ou cada elemento, o método procura dividir o domínio em células que obedecem uma estrutura ramificada para a malha (tree structure of the mesh) e procura resolver a influência entre cada uma dessas células de diferentes tamanhos utilizando um método iterativo de solução de equações (como o GMRES). Isso é feito através do cálculo de uma nova variável chamada momento da célula e através de um método chamado translação momento-a-momento (moment-to-moment translation) entre cada uma das células. Esse procedimento é capaz de diminuir drasticamente o número de operações necessárias para encontrar as variáveis desconhecidas de $O\left(N^{2}\right)$ para $O(N)$. A desvantagem principal desse método é a implementação complexa dos algoritmos que produzem seus resultados. Apesar da base do método estar disponível desde a década de 1980 com os trabalhos de Rokhlin (1985) só na última década o FMM-MEC vem ganhando seu espaço entre os métodos numéricos mais famosos. A figura 2.3 mostra a hierarquia das celulas atribuídas para descrever o domínio em um problema potencial bidimensional (Liu and Nishimura, 2006). A figura 2.4 mostra a estrutura ramificada da hierarquia das células, as células preenchidas são células que contém um elemento.

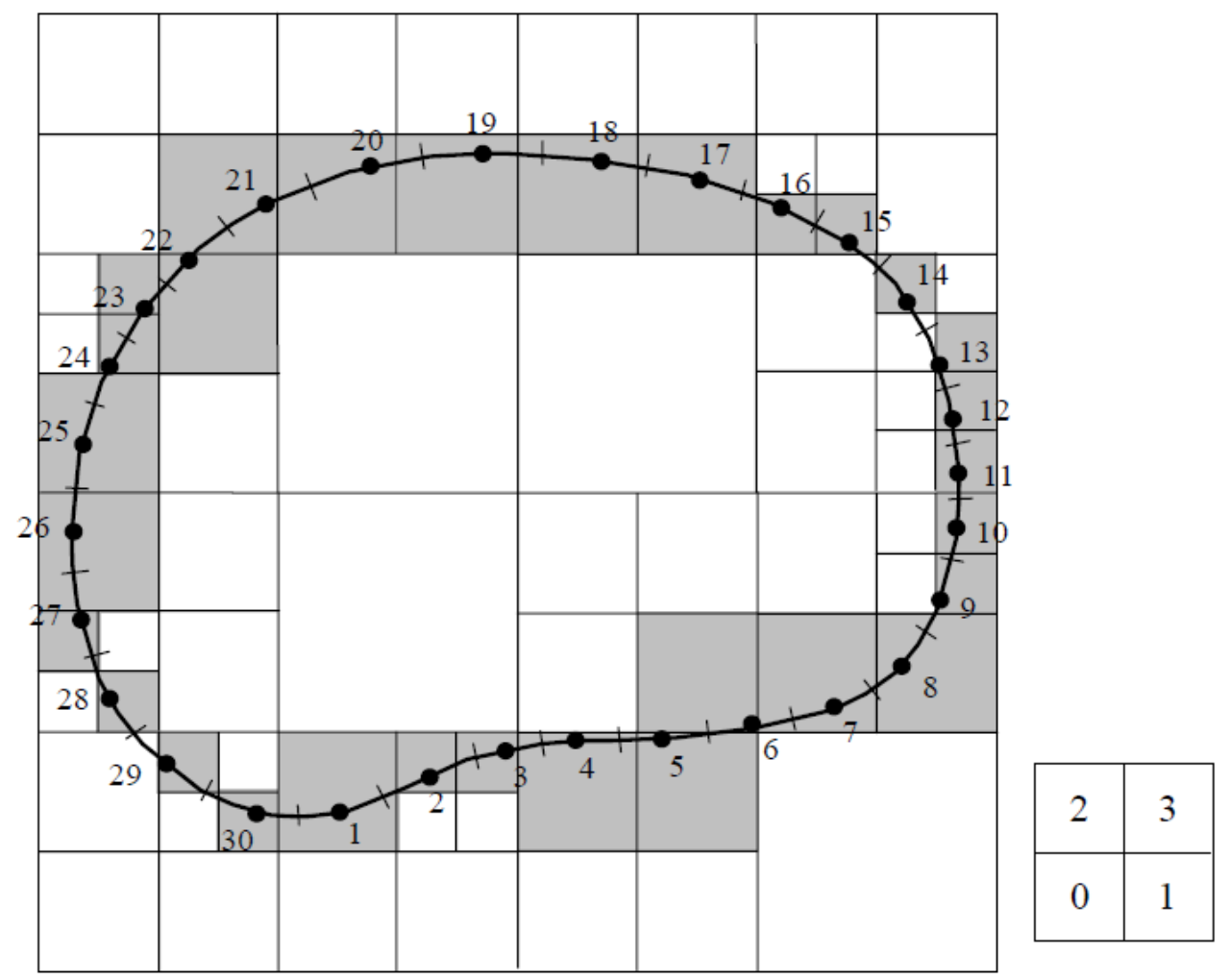

Figura 2.3: Uma estrutura hierarquica em células cobrindo todos os elementos do contorno (O pequeno quadrado ao lado mostra o esquema de numeração para as células filhas de qualquer célula pai) (Liu and Nishimura, 2006) 


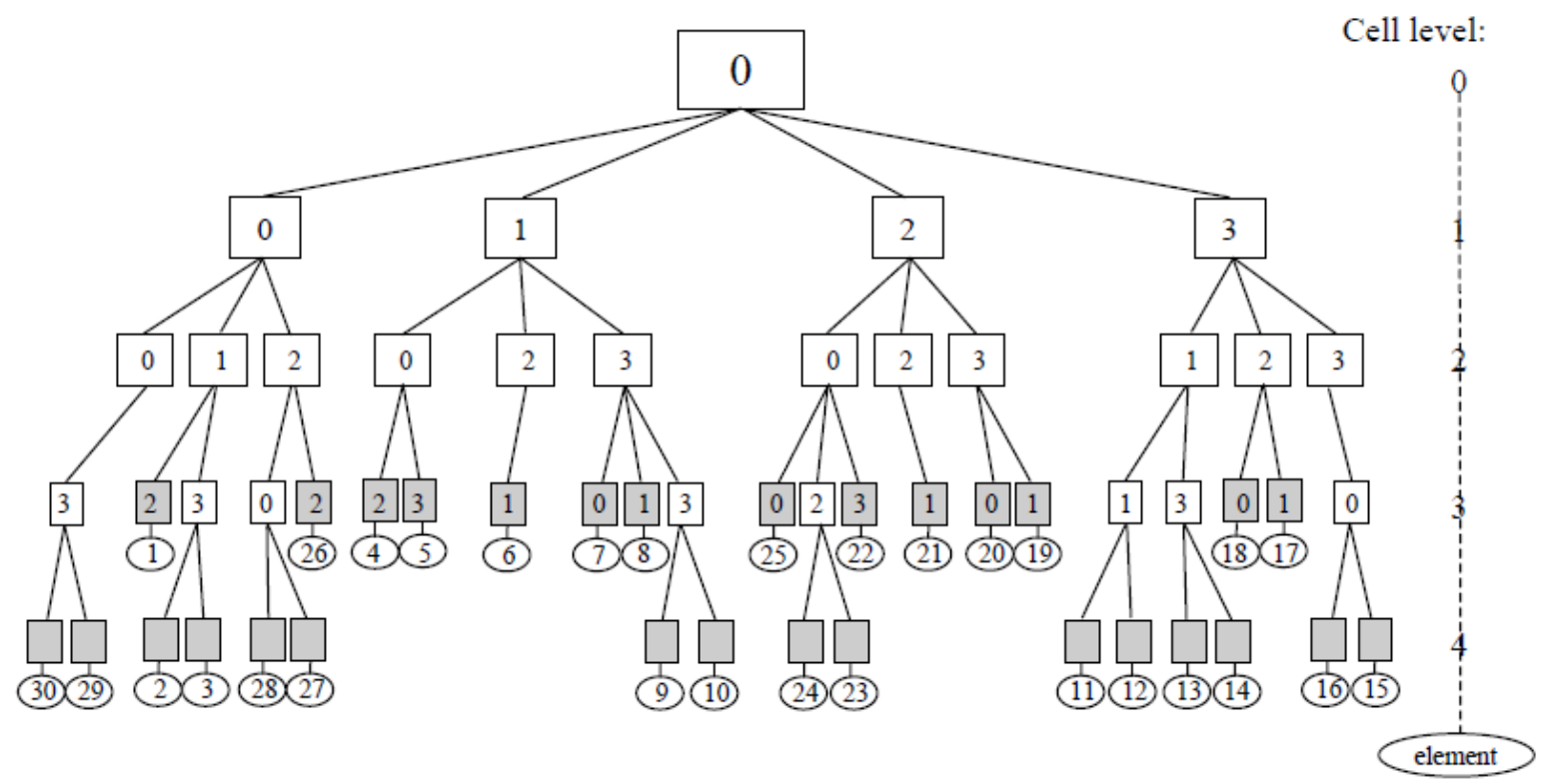

Figura 2.4: A hierarquia ramificada em células obtida para o FMM (Liu and Nishimura, 2006) 


\section{Capítulo 3 O MÉTODO DE ELEMENTOS DE CONTORNO APLICADO A ACÚSTICA}

Neste capítulo, a formulação para o Método de Elementos de Contorno Direto será sucintamente apresentada. Os pontos principais para a compreensão do código implementado são salientadas a fim de ajudar na compreensão dos resultados obtidos posteriormente. Toda a formulação apresentada provém da revisão bibliográfica e sua leitura é recomendada para estudo mais aprofundado dos conceitos apresentados.

\subsection{Formulação Teórica}

A formulação que será desenvolvida nessa sessão corresponde ao método direto descrito em Dominguez (1993) e Kirkup (2007), entre outros.

A equação da onda tridimensional, mostrada na equação 3.1, pode ser obtida a partir das equações da continuidade e de equilíbrio para pequenas perturbações (Kinsler, 1982; Dominguez, 1993).

$$
\nabla^{2} p=\frac{1}{c^{2}} \frac{\partial^{2} p}{\partial t^{2}}
$$

Em um domínio $\Omega$ de contorno $\Gamma$, considera-se um escalar governado pela equação da onda com forças de campos não nulas dadas por $\frac{1}{c^{2}} b$ no domínio $\Omega$ na Equação 3.2:

$$
\nabla^{2} p+\frac{1}{c^{2}} b=\frac{1}{c^{2}} \frac{\partial^{2} p}{\partial t^{2}}
$$

onde $c$ é a velocidade do som no meio e $p=p(\xi, t)$ é o campo de pressão para uma determinada posição espacial $\xi$ num instante temporal $t$. A partir da Relação Recíproca para problemas de propagação de ondas escalares podemos chegar à representação integral da 
equação da onda, como mostrado em Dominguez (1993) na Equação 3.3:

$$
\int_{\Gamma}\left(\frac{\partial p^{*}}{\partial n} * p^{*}\right) d \Gamma+\int_{\Omega} \frac{1}{c^{2}}\left(b * p^{*}+p_{0} \dot{p}^{*}+v_{0} p^{*}\right) d \Omega=\int_{\Gamma}\left(\frac{\partial p^{*}}{\partial n} * p\right) d \Gamma+\int_{\Omega} \frac{1}{c^{2}}\left(b^{*} * p+p_{0}^{*} \dot{p}+v_{0}^{*} p\right) d \Omega
$$

onde * é a convolução de Riemann, n é o vetor normal ao contorno $\Gamma$. O campo $p^{*}(x, t)$ é assumido como a solução da equação da onda escalar do domínio infinito sob a forma de uma fonte de impulso pontual unitária em (3.4):

$$
\frac{1}{c^{2}} b^{*}(x, t)=\delta(t) \delta(x-\xi)
$$

O $\delta(x-\xi)$ é o delta de Dirac, $\xi$ é o ponto de aplicação da fonte no instante $t$. A equação integral 3.3 pode ser reescrita utilizando as propriedades do delta de Dirac como:

$$
C(\xi) p(\xi, t)=\int_{\Gamma}\left(\frac{\partial p}{\partial n} * p^{*}-p * \frac{\partial p^{*}}{\partial n}\right) d \Gamma+\int_{\Omega} \frac{1}{c^{2}}\left(b * p^{*}\right) d \Omega+\int_{\Omega} \frac{1}{c^{2}}\left(p_{0} \dot{p}^{*}+v_{0} p^{*}\right) d \Omega
$$

onde $C(\xi)=\left\{\begin{aligned} & 1 \text { se } \xi \in \Omega \\ & 0 \text { se } \xi \ni \Omega \\ & \frac{1}{2} \text { se } \xi \in \Gamma \text { suave } \neq \text { contorno }\end{aligned}\right.$

Se $\xi \in \Gamma$, as integrais de contorno incluem uma singularidade que pode ser fraca ou forte. Quando involvem singularidade forte, as integrais são divergentes se calculadas no sentido tradicional. Nestes casos elas devem ser calculadas no sentido do valor principal de Cauchy (Dominguez, 1993).

Para problemas harmônicos, considera-se

$$
p(x, t)=p(x, \omega) e^{i \omega t}
$$

onde $\omega$ é a frequência de oscilação da pressão e $i$ é a unidade imaginária $(i=\sqrt{-1})$.

Nesse caso, a convolução de Riemann torna-se o produto escalar. A equação da onda linear 
com solução fundamental $p^{*}$ torna-se:

$$
\nabla^{2} p^{*}+\frac{\omega^{2}}{c^{2}} p^{*}+\frac{1}{\mu} \delta(x-\xi)=0
$$

Nesse caso, a solução fundamental para a formulação bidimensional obtida por Dominguez (1993) é

$$
p^{*}=\frac{1}{2 \pi \mu} K_{0}\left(\frac{i \omega r}{c}\right)
$$

onde $K_{0}$ é a função modificada de Bessel de ordem zero, $\mu$ é o módulo de elasticidade do meio, relacionado à velocidade do som através da relação (3.9), $r$ é a distância do ponto de observação (ponto campo) com relação ao ponto de aplicação da fonte pontual (ponto fonte), equação (3.10).

$$
\begin{gathered}
c=\sqrt{\frac{\mu}{\rho}} \\
r=|x-\xi|
\end{gathered}
$$

E a solução fundamental para a variação do campo de pressão acústica é dado por:

$$
\frac{\partial p^{*}}{\partial n}=\frac{\omega}{2 \pi c} \frac{\partial r}{\partial n} K_{1}\left(\frac{i \omega r}{c}\right)
$$

onde $K_{1}$ é a função modificada de Bessel de ordem um.

A partir da equação (3.5), a representação integral completa da equação da onda linearizada harmônica para MEC considerando as propriedades do delta de Dirac resulta na equação:

$$
C(\xi) p(\xi, t)+\int_{\Gamma} p \frac{\partial p^{*}}{\partial n} d \Gamma=\int_{\Gamma} \frac{\partial p}{\partial n} p^{*} d \Gamma
$$


Essa equação contém singularidades quando o ponto de integração estiver localizado no elemento que está sendo integrado. Porém para elementos retílineos comos os usados neste trabalho, $\frac{\partial r}{\partial n}=0$ quando o ponto fonte pertence ao elemento, o que dispensa o tratamento da singularidade.

Para qualquer ponto $i=\xi$ em que a superfície seja suave, $C(\xi)=\frac{1}{2}$. Como neste trabalho é utilizado elementos constantes (descritos mais adiante), o ponto de colocação $\xi$ estará sempre em uma região suave do contorno.

Os pontos de colocação são chamados nós físicos ou simplesmente nós. Os pontos iniciais e finais dos elementos são chamados de nós geométricos pois definem a geometria do elemento que é retilíneo. No caso de elementos constantes, estes elementos possuem geometria retilínea e tanto pressão quanto sua derivada são assumidos constantes ao longo do elemento. O nó (ponto de colocação) é o ponto médio do elemento. O uso de elementos constantes facilitam a implementação pois a pressão e o gradiente de pressão são considerados constantes ao longo do elemento, o que simplifica a formulação. Entretanto, esta simplicidade tem um custo na precisão dos resultados, sendo necessário usar um número maior de elementos que no caso de elementos de mais alta ordem (lineares ou quadráticos, por exemplo). Caso o elemento seja composto de dois nós e o valor da incógnita no elemento sofra essa linearização, diz-se que o elemento é linear. Caso o elemento seja composto de três nós, gerando uma parábola entre eles, diz-se que o elemento é quadrático.

Para os elementos constantes, o valor de cada incógnita em cada elemento é considerado constante e igual ao valor da incógnita no nó pertencente ao elemento. Nesse caso, o número de nós é igual ao número de elementos.

Para uma discretização do contorno $\Gamma=\sum_{i=1}^{N} \Gamma_{i}$ em que o contorno $\Gamma$ é dividido em $N$ partes tal que o i-ésimo elemento de contorno é chamado $\Gamma_{i}$. Podemos reescrever a equação conforme equação (3.13) abaixo.

$$
C(\xi) p_{j}(\xi, t)+\sum_{i=1}^{N} \int_{\Gamma_{i}} p \frac{\partial p^{*}}{\partial n} d \Gamma=\sum_{i=1}^{N} \int_{\Gamma_{i}} \frac{\partial p}{\partial n} p^{*} d \Gamma
$$




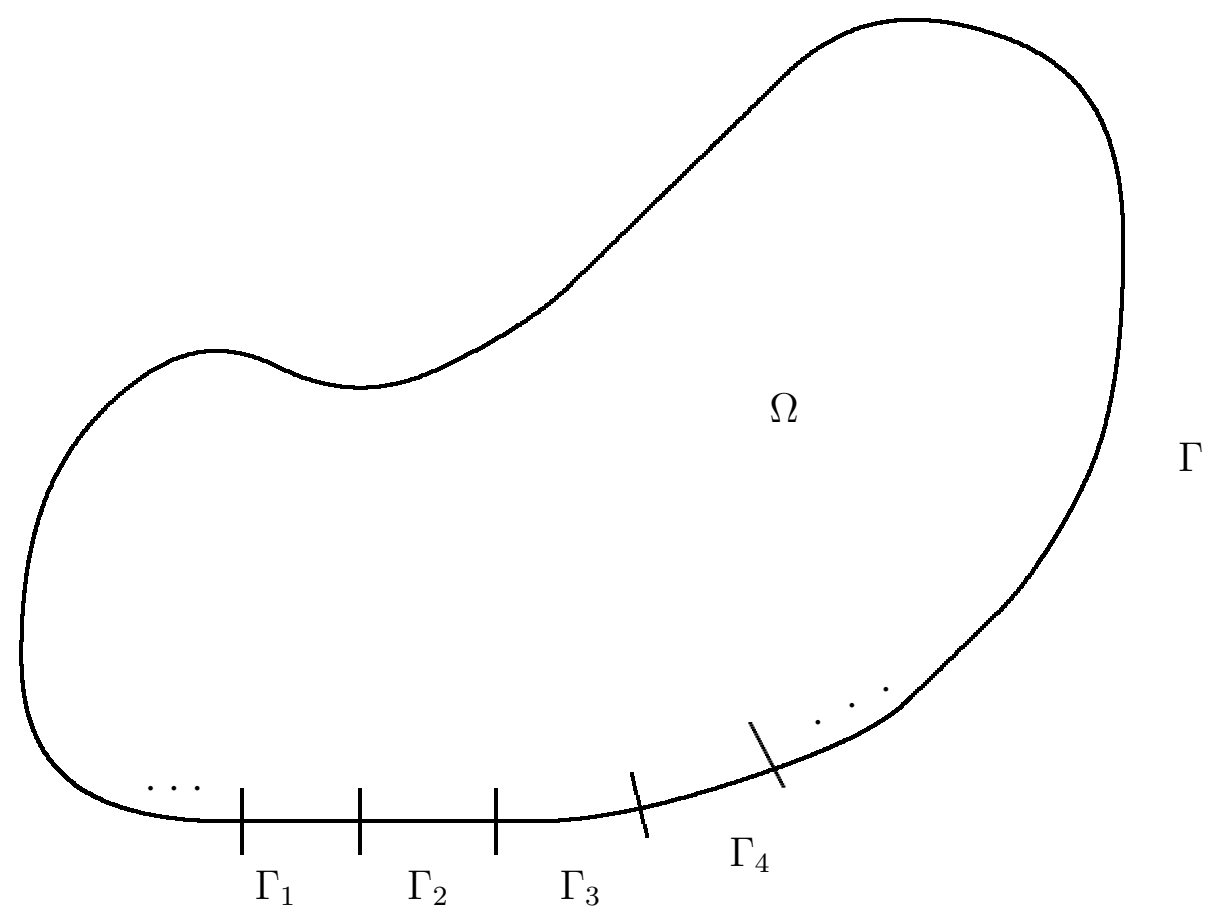

Figura 3.1: Contorno Discretizado

Cada valor da integral no contorno $\Gamma_{i}$ é aproximado pela integral nesse elemento. O ponto médio do elemento $i$ é um dos nós no contorno. Essa integral, por sua vez, pode ser calculada utilizando métodos numéricos, tal como a quadratura de Gauss. Conforme observado anteriormente para elementos constantes, o nó $i$ estará sempre presente em uma parte suave do contorno e, portanto, o valor da constante $C(\xi)$ é igual a $\frac{1}{2}$. Os valores de $p$ e $\frac{\partial p}{\partial n}$ podem ser retirados da integral, pois eles serão constantes em cada elemento. Estes fatos simplificam a formulação. É possível, portanto, escrever

$$
C(\xi) p_{j}(\xi, t)+\sum_{i=1}^{N}\left(\int_{\Gamma_{i}} \frac{\partial p^{*}}{\partial n} d \Gamma\right) p_{i}=\sum_{i=1}^{N}\left(\int_{\Gamma_{i}} p^{*} d \Gamma\right) \frac{\partial p_{i}}{\partial n}
$$

onde $p_{i}$ e $\frac{\partial p_{i}}{\partial n}$ são os valores de pressão $p$ e gradiente de pressão $\frac{\partial p}{\partial n}$ para o elemento $i$. Podemos, agora, reescrever a equação de forma matricial.

$$
H_{i j}=C(\xi)+\sum_{i=1}^{N}\left(\int_{\Gamma_{i}} \frac{\partial p^{*}}{\partial n} d \Gamma\right), C(\xi)=\left\{\begin{array}{l}
\frac{1}{2} \text { se } i=j \\
0 \text { se } i \neq j
\end{array}\right.
$$




$$
G_{i j}=\sum_{i=1}^{N}\left(\int_{\Gamma_{i}} p^{*} d \Gamma\right)
$$

E a equação (3.14) toma a seguinte forma

$$
\sum_{i=1}^{N} H_{i j} p_{i}=\sum_{i=1}^{N} G_{i j} \frac{\partial p_{i}}{\partial n}
$$

A equação (3.12) pode ser vista como um sistema de equações em que em parte do contorno a pressão acústica é definida e, na outra, o gradiente de pressão é definido. Isso garante que tenhamos um total de equações igual ao número total de incógnitas e podemos resolver o problema definido como em Kirkup (2007) pela equação (3.18).

$$
[H]\{p\}=[G]\{q\}
$$

onde $[H]$ é uma matriz quadrada com as informações referentes às características do campo de pressão e $[G]$, do gradiente de pressão normal ao contorno.

A equação (3.18) é obtida escrevendo o problema na forma matricial. Em que $[H]$ é a matriz $N \times N$ com as informações referentes à pressão, $\{p\}$ é o vetor de tamanho $N$ com os valores da pressão para cada elemento, $[G]$ é a matriz $N \times N$ com as informações referentes à variação de pressão no contorno na direção $n$ e $\{q\}$ é o vetor com os valores do gradiente de pressão na direção $n$. Esse problema pode ser rearranjado de tal forma que obtemos a equação (3.19):

$$
[A]\{x\}=\{b\}
$$

Nesse caso, todos os valores de variáveis desconhecidas no contorno foram levados para o lado esquerdo da equação, de tal forma que o lado direito torna-se um vetor que possui apenas valores conhecidos. Essa manobra gera um sistema mixto de equações, em que a matriz $[A]$ possui valores correspondentes à pressão assim como ao gradiente de pressão, diferentemente do MEF (Dominguez, 1993). Após a montagem do sistema da equação (3.19), po- 
demos resolver o problema para encontrar $\{x\}$ e todos os valores desconhecidos de pressão e de gradiente de pressão serão determinados. Uma manobra reversa à utilizada na equação (3.19) é atribuída ao sistema $[A]\{x\}=\{b\}$ e obtemos o sistema original $[H]\{p\}=[G]\{q\}$.

Uma vez que os valores são determinados no contorno, o valor da pressão e do gradiente de pressão em pontos internos são facilmente obtidos aplicando as equações (3.20) e (3.21).

$$
\begin{gathered}
p_{j}(\xi, t)=\int_{\Gamma} \frac{\partial p}{\partial n} p^{*} d \Gamma-\int_{\Gamma} p \frac{\partial p^{*}}{\partial n} d \Gamma \\
\frac{\partial p_{j}}{\partial \xi}(\xi, t)=\int_{\Gamma} \frac{\partial p}{\partial n} \frac{\partial p^{*}}{\partial \xi} d \Gamma-\int_{\Gamma} p \frac{\partial^{2} p^{*}}{\partial n \partial \xi} d \Gamma
\end{gathered}
$$

onde $p_{j}$ é o valor da pressão no ponto interno $j$ e os valores de $p$ e $\frac{\partial p}{\partial n}$ já foram determinados anteriormente.

\subsection{Soluções Fundamentais da Equação da Onda}

As integrais que precisam ser estimadas na equação normalmente o são através de um método de integração numérica, como uma quadratura de Gauss. Nesse caso, devemos computar a solução fundamental no pontos, que incluem funções de Bessel. É necessário criar uma rotina que seja capaz de calcular com a devida precisão os valores das funções de Bessel envolvidas no cálculo da solução fundamental. Kirkup (2007) mostra outra forma para a solução fundamental em duas dimensões na equação (3.22) e em três dimensões na equação (3.23).

$$
\begin{gathered}
p^{*}=-\frac{i}{4 \pi} H_{0}^{(1)}(k r) \\
p^{*}=\frac{1}{4 \pi r} e^{i k r}
\end{gathered}
$$

Em que $k=\frac{\omega}{c}$ é o número de onda e $H_{0}^{(1)}$ é a função de Hankel esférica de tipo 1 e ordem 0.

A solução fundamental pode ser obtida para um domínio circular e um número de onda dado. As soluções fundamentais dadas pelas equações (3.8) e (3.22) foram obtidas para um mesmo domínio circular de raio unitário e número de onda $k=10$. Os resultados podem ser 
observados nas figuras 3.2 e 3.3, que mostram a solução fundamental para a pressão obtidas utilizando as equações (3.8) e (3.22), respectivamente. Podemos perceber que a solução obtida utilizando a equação (3.22) produz o mesmo valor para a pressão que a equação (3.8) porém com o sinal invertido.

Para o ponto fonte e pontos campo mostrados na figura 3.4, as duas soluções fundamentais são comparadas nas figuras 3.5 e 3.6. No caso da solução fundamental para o gradiente da pressão desenvolvida por Dominguez (1993), obtém-se um valor nulo para a parte imaginária, o que não ocorre para a solução apresentada por Kirkup (2007). Em todos os casos, observamos que consistentemente obtém-se para a equação (3.8) o conjugado complexo da solução fundamental para a pressão acústica, dada pela equação (3.22). Essas diferenças mostram que uma implementação de ambas as soluções seria desejável. Todas as funções especiais de Bessel e Hankel são calculadas através de funções internas do MatLab.

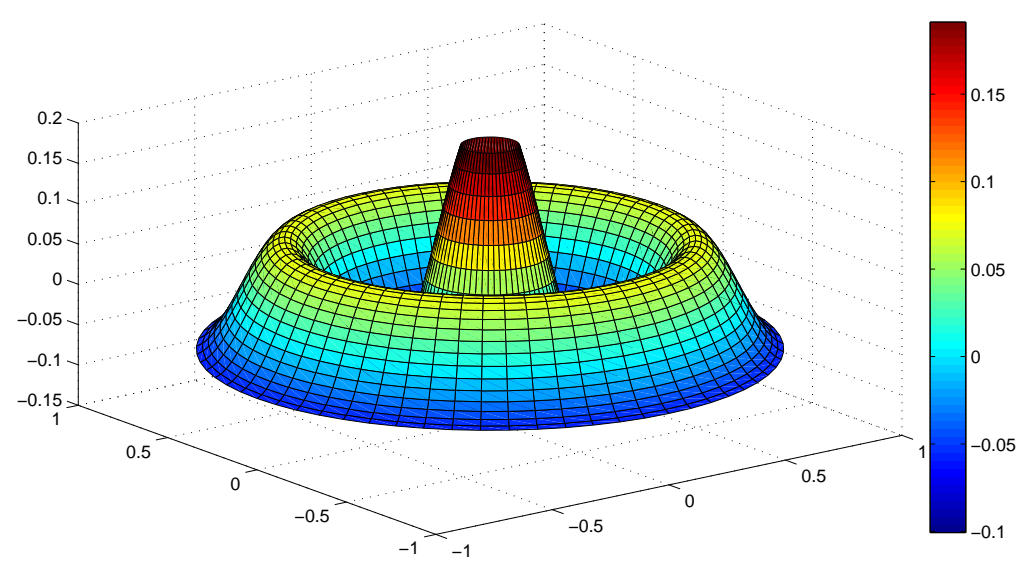

Figura 3.2: Solução Fundamental para a pressão mostrada em Dominguez (1993) para um domínio circular unitário e número de onda $k=10$

É possível observar na Figura 3.7 que a parte imaginária do gradiente da pressão apresenta uma maior discrepância entre as soluções fundamentais e que essa discrepância ocorre com maior amplitude quando o ponto campo se aproxima do ponto fonte. Mesmo a solução fundamental apresentada por Dominguez (1993) na equação (3.8) apresentando valor nulo para a parte imaginária da solução do gradiente de pressão, a solução equivalente dada pela equação (3.23) apresenta parte imaginária não nula consistentemente para todos os pontos campo. 


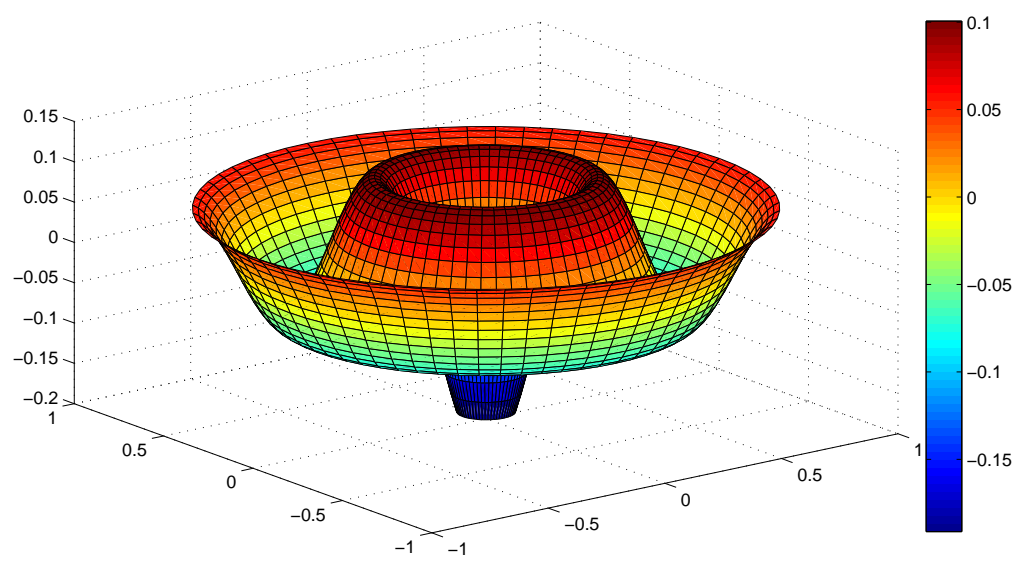

Figura 3.3: Solução Fundamental para a pressão mostrada em Kirkup (2007) para um domínio circular unitário e número de onda $k=10$

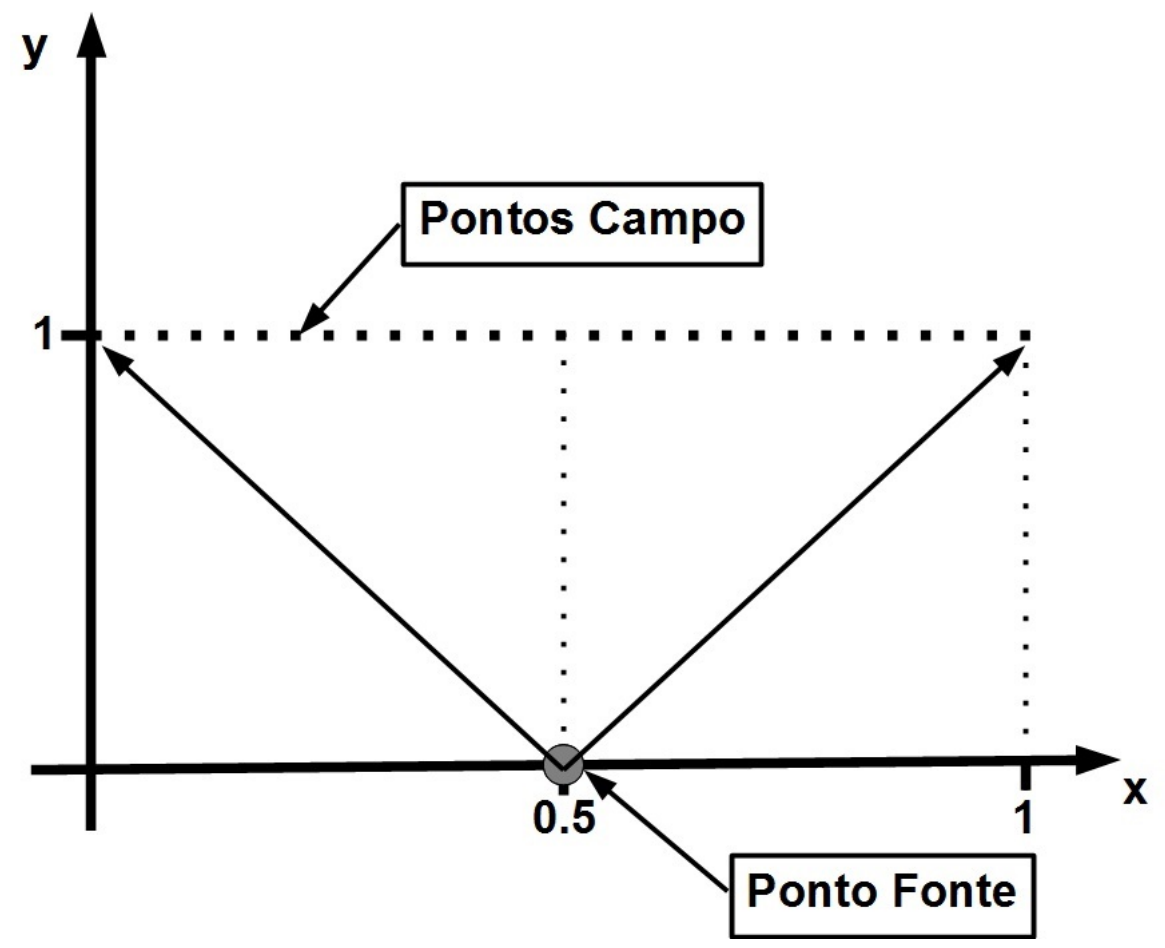

Figura 3.4: Comparação entre as Soluções Fundamentais para a Pressão Acústica 


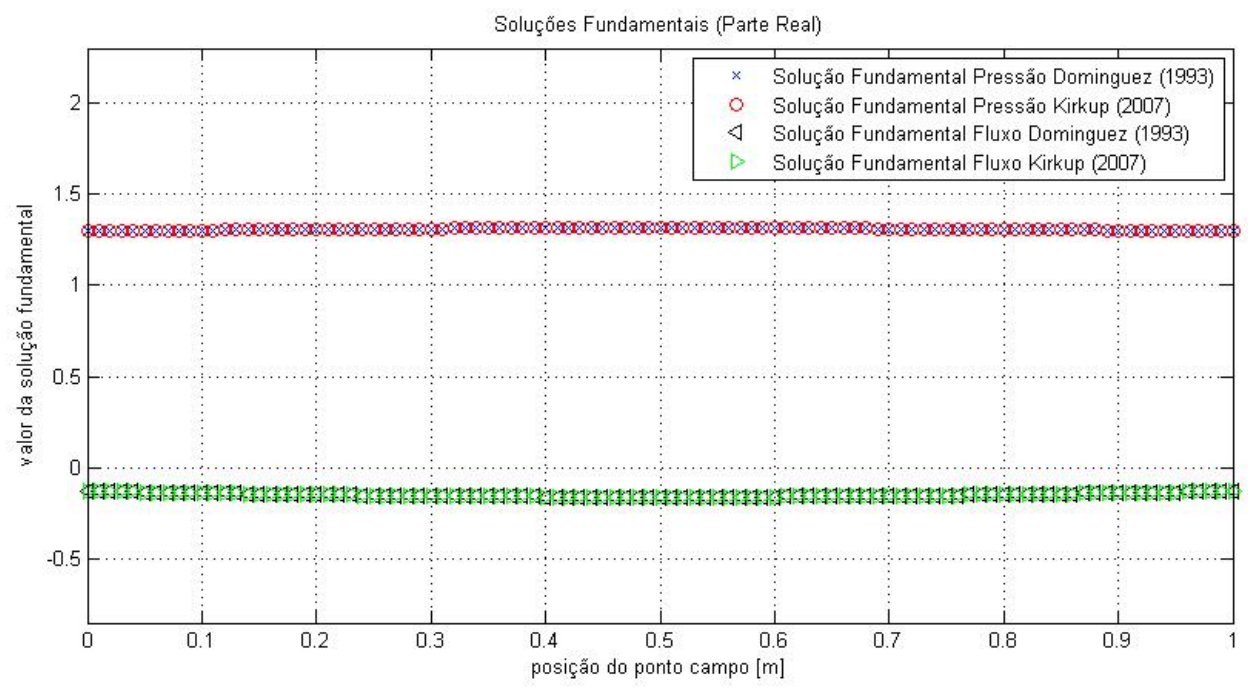

Figura 3.5: Comparação entre a parte real das Soluções Fundamentais para a Pressão Acústica

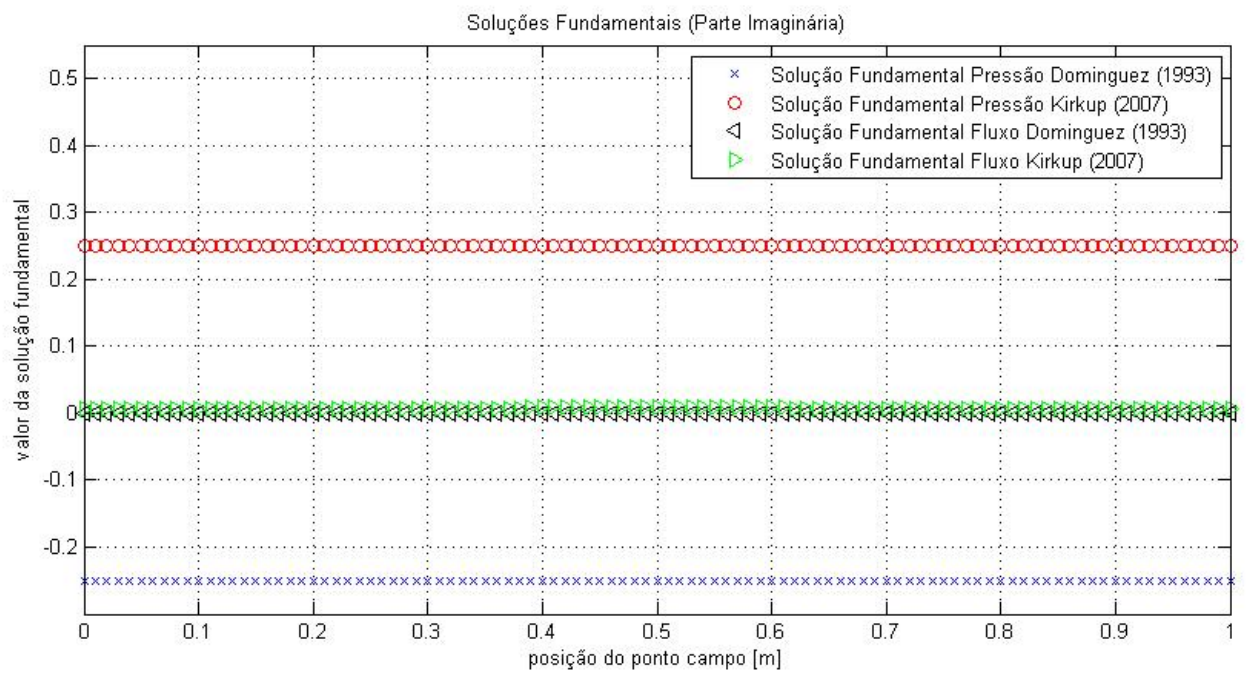

Figura 3.6: Comparação entre a parte imaginária das Soluções Fundamentais para o gradiente de Pressão Acústica 


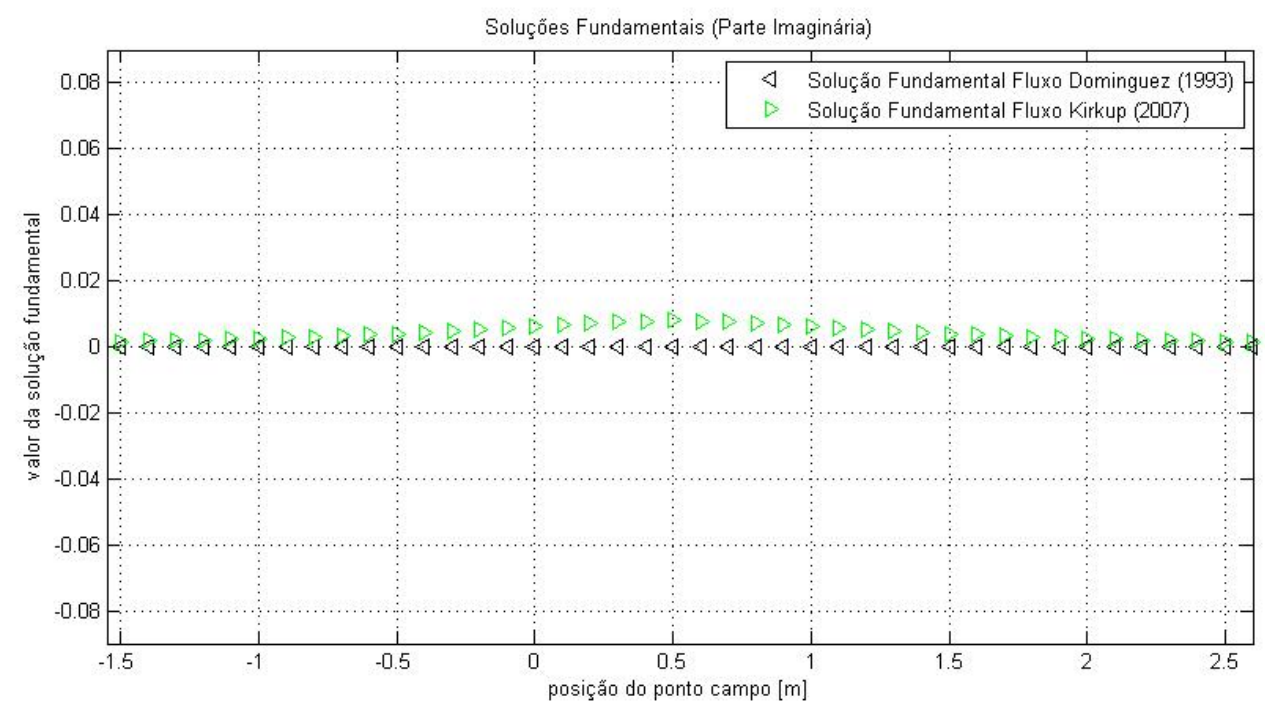

Figura 3.7: Gradiente de Pressão - Discrepância da parte imaginária da Solução Fundamental para o gradiente de pressão

É importante notar que essa discrepância só ocorre quando a parte imaginária da velocidade de propagação de onda não é nula. Caso a velocidade de propagação de onda seja completamente real, as duas soluções são equivalentes, ou seja, obtém os mesmos valores para os pontos campo e fonte estudados, mas ainda obtém-se para a equação (3.8) o conjugado complexo da solução fundamental para a pressão acústica, dada pela equação (3.22). Podemos observar esses resultados nas Figuras 3.8 e 3.9.

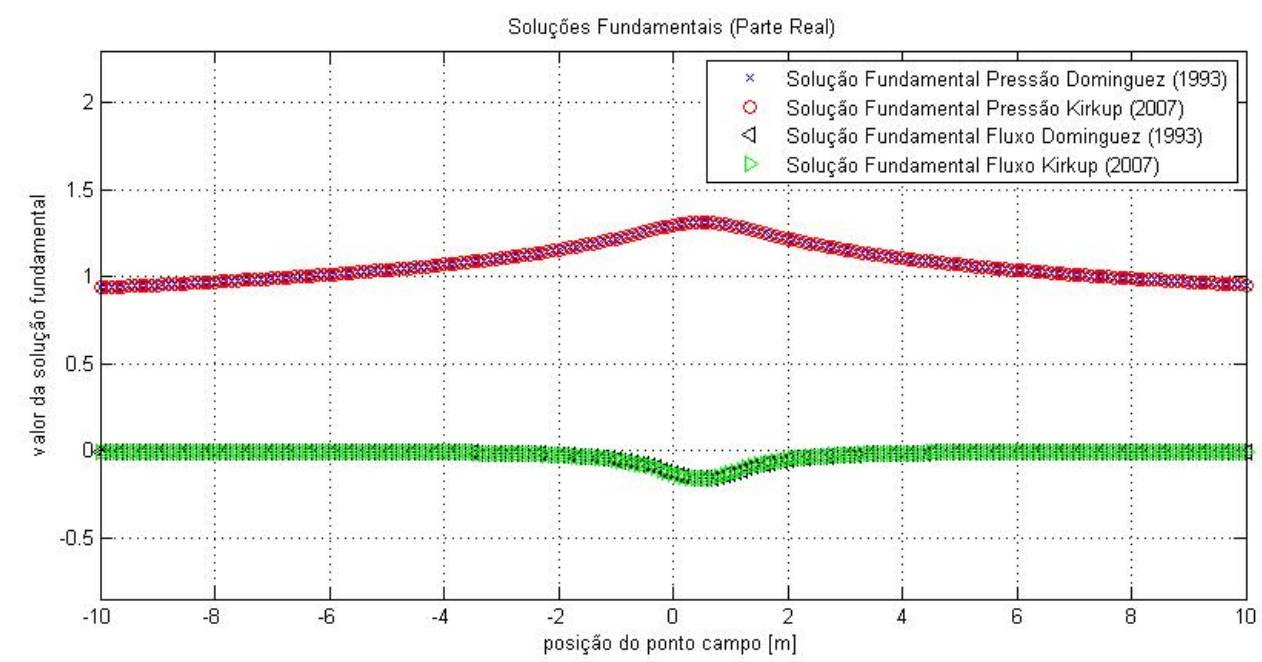

Figura 3.8: Comparação entre a parte real das Soluções Fundamentais para a Pressão Acústica

Em ambos os casos é necessário fazer uma mudança de variáveis e realizar a integração com uma quadratura de Gauss. Ambas as soluções fundamentais possuem uma singularidade 


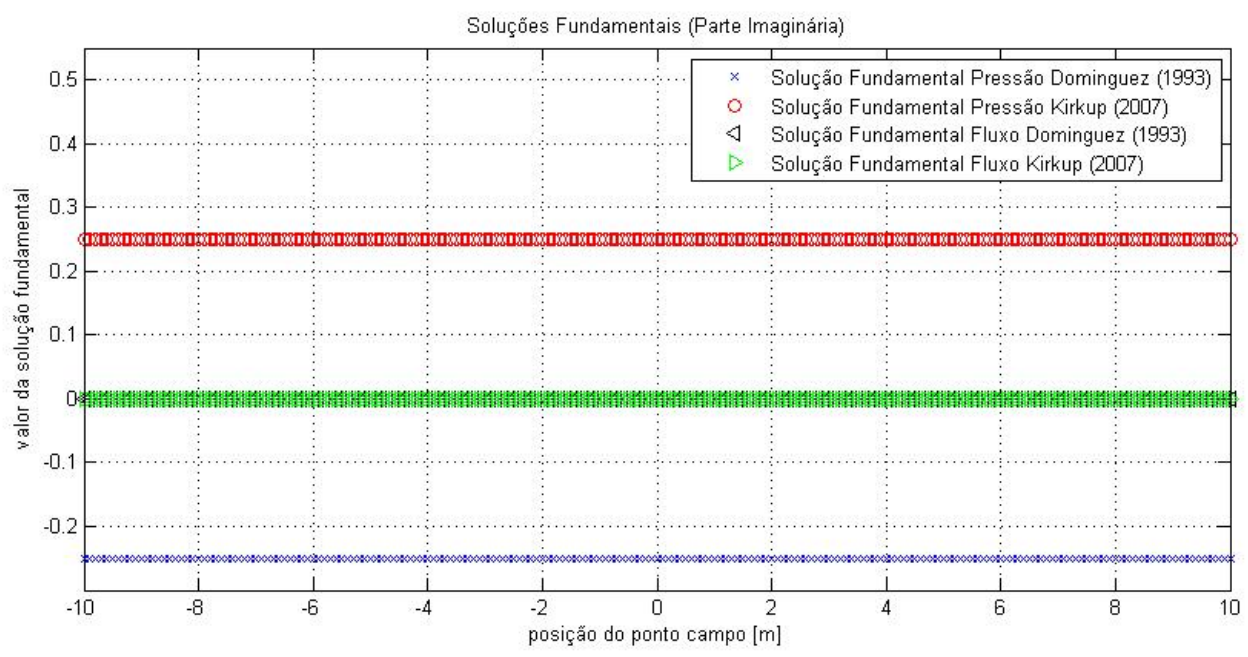

Figura 3.9: Comparação entre a parte imaginária das Soluções Fundamentais para o gradiente de Pressão Acústica

quando o ponto de integração coincide com o ponto fonte. Nesse caso, a solução fundamental para o gradiente de pressão torna-se singular e a função não pode ser calculada diretamente.

\subsubsection{Tipos de Elementos de Contorno}

Para definir os nós que serão utilizados na discretização do contorno do domínio é necessário desenvolver elementos que os contenham, definam as características geométricas e recebam as condições de contorno do problema. Esses elementos podem ser definidos com diferentes números de nós, dependendo da geometria que procuramos aproximar com cada um deles. Elementos Constantes e Lineares são elementos que contém, respectivamente, um e dois nós por elemento retilíneos que procuram aproximar o contorno do domínio utilizando linhas retas. Elementros quadráticos são elementos de três nós que são capazes de aproximar cada elemento a uma parábola, sendo mais eficientes no caso de um contorno mais curvilíneo. Nesse trabalho consideraremos os elementos sempre constantes, como mostrado na figura 3.10 .

\subsubsection{Aplicação de Condições de Contorno}

No MEC as condições de contorno são aplicadas diretamente nos elementos. O valor das condições de contorno são atribuídas aos elementos diretamente, que definem a geometria do problema de tal forma que o pré-processamento é simplificado pois precisamos apenas 


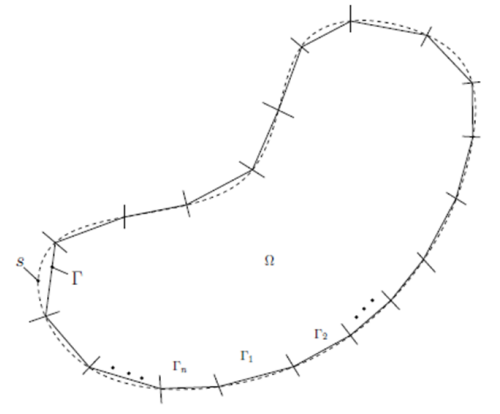

(a)

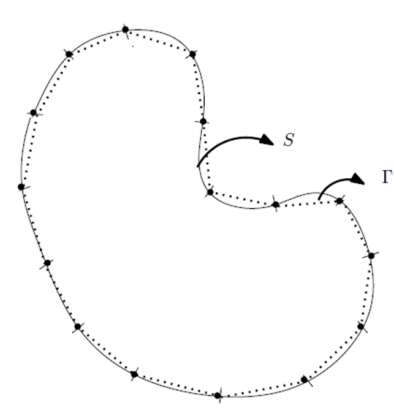

(b)

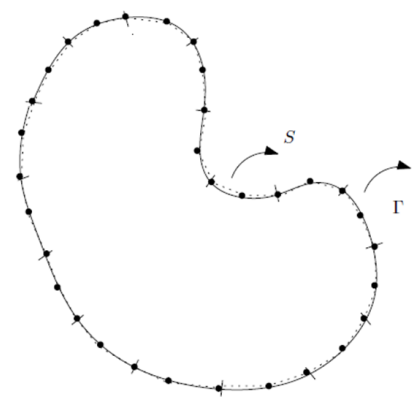

(c)

Figura 3.10: Tipos de Elementos: (a) Elementos Constantes, (b) Elementos Lineares, (c) Elementos Quadráticos (Braga, 2012)

identificar as linhas ou áreas em que as condições de contorno são aplicadas e os elementos, por sua vez, aplicam os valores das condições de contorno nos nós que os definem.

Como a equação que queremos resolver se encontra na forma dada pela equação (3.17), percebe-se que para cada valor de pressão, temos um valor correspondente de gradiente de pressão. Ao determinarmos o valor da variável em um dos pontos, resolvemos o sistema linear e encontramos o valor da segunda variável correspondente.

\subsubsection{Obtenção de Valores em Pontos Internos}

Após a obtenção dos valores das variáveis de pressão e gradiente de pressão no contorno do domínio estudado, é necessário obter os valores dessas variáveis em pontos internos ao domínio. Esses valores são obtidos de maneira direta no MEC, utilizando uma única equação para determinar cada valor de pressão e outra para o gradiente de pressão. A obtenção desses valores é computacionalmente barata, pois utilizamos apenas valores da pressão e do gradiente de pressão já conhecidos e as matrizes de influência $\mathrm{G}$ e $\mathrm{H}$ considerando como ponto fonte o ponto interno para encontrar o valor da pressão e do gradiente em pontos internos. Devemos lembrar que para a obtenção do valor da pressão e do gradiente de pressão em pontos externos ao domínio, como em casos de radiação em domínio infinito, consideramos o domínio infinito como pontos internos, facilitando a obtenção de valores em quaisquer pontos distantes do contorno estudado. Essa é a característica que leva o MEC a ser o método mais indicado para estudar casos em que o domínio é infinito. 
O valor da pressão e do gradiente de pressão em pontos internos são facilmente obtidos aplicando as equações (3.20) e (3.21).

$$
\begin{gathered}
p_{j}(\xi, t)=\int_{\Gamma} \frac{\partial p}{\partial n} p^{*} d \Gamma-\int_{\Gamma} \frac{\partial p^{*}}{\partial n} p d \Gamma \\
\frac{\partial p_{j}}{\partial \xi}(\xi, t)=\int_{\Gamma} \frac{\partial p}{\partial n} \frac{\partial p^{*}}{\partial \xi} d \Gamma-\int_{\Gamma} p \frac{\partial^{2} p^{*}}{\partial n \partial \xi} d \Gamma
\end{gathered}
$$

Em que $p_{j}$ é o valor da pressão no ponto interno $j$ e os valores de $p$ e $\frac{\partial p}{\partial n}$ já foram determinados anteriormente.

Para obter os valores de pressão e de gradiente de pressão para pontos externos utilizando o MEC, devemos considerar que a normal da superfície estudada está na direção contrária ao caso interno. No caso interno, a normal da superfície aponta para fora e a numeração dos elementos ocorre de forma horária. No caso externo, a normal aponta para dentro e a numeração dos elementos ocorre no sentido anti-horário como mostrado na Figura 3.11. Nota-se que independente de considerarmos o caso interno ou externo, a normal da superfície sempre estará apontando para fora do domínio estudado.

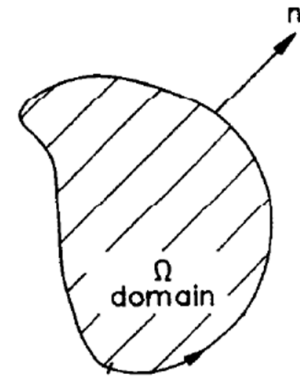

(a)

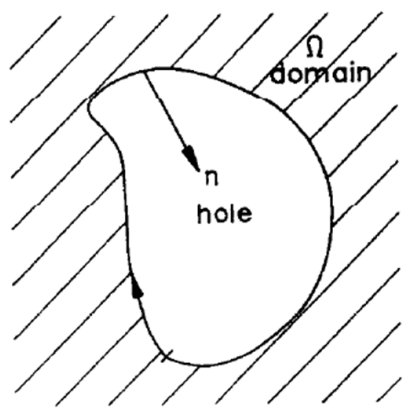

(b)

Figura 3.11: Direção da normal e numeração dos elementos nos casos: (a) Domínio Interno, (b) Domínio Externo (Dominguez, 1993)

\subsubsection{Rotina para Carga Concentrada}

É possível resolvermos a equação 3.12 com a inclusão de uma fonte acústica, mostrada na equação 3.26 . 


$$
C(\xi) p(\xi, t)+\int_{\Gamma} p \frac{\partial p^{*}}{\partial n} d \Gamma=\int_{\Gamma} \frac{\partial p}{\partial n} p^{*} d \Gamma+f_{c}
$$

Em que $f_{c}$ é um termo de fonte concentrada. Para que essa carga concentrada atue como um monopolo, a equação 3.27 nos mostra a forma para $f_{c}$, dada por Brancati (2010).

$$
f_{c}=f_{0} \cdot p^{*}\left(r_{s}\right)
$$

Em que $f_{0}$ é o força da fonte concentrada, $p^{*}\left(r_{s}\right)$ é a solução fundamental para a pressão acústica para a distância entre a fonte concentrada e cada ponto campo $r_{s}$. Nota-se que um sistema montado dessa forma será capaz de resolver um problema mesmo se o valor das condições de contorno para a pressão ou para o gradiente de pressão for zero. Isso se dá pois o termo $f_{c}$ é adicionado à matriz $b$, na equação 3.19 , produzindo uma resposta para o sistema linear.

\subsubsection{Solução Fundamental e Discretização de Contorno no caso 3D}

Neste trabalho também foi implementada a formulação tridimensional do MEC. Neste caso, é preciso calcular uma nova solução fundamental que corresponda ao problema da equação da onda tridimensional. Uma solução fundamental adequada, apresentada por diversos autores (Brancati, 2010; Dominguez, 1993; Kirkup, 2007), é apresentada nas equações (3.28) e (3.29).

$$
\begin{gathered}
p^{*}=\frac{1}{4 \pi r} e^{-i k r} \\
\frac{\partial p^{*}}{\partial n}=-\frac{\partial r}{\partial n} \frac{1}{4 \pi r}\left(i k+\frac{1}{r}\right) e^{-i k r}
\end{gathered}
$$

onde $r$ é a distância do ponto campo ao ponto fonte e $k=\frac{\omega}{c}$ é o número de onda. A singularidade existente na solução fundamental pode ser tratada de tal forma que, para elementos constantes, as matrizes $[H]$ e $[G]$ sejam calculadas de forma eficiente como descrito 
em Brancati (2010).

A implementação computacional no caso $3 \mathrm{D}$ será muito semelhante ao caso $2 \mathrm{D}$, com a diferença principal que agora os elementos vão corresponder a áreas limitadas por linhas e o domínio será o volume formado pelos elementos. O contorno será discretizado em elementos de superfície com um nó no centro de cada elemento, formando elementos constantes. A posição de cada nó vai depender da posição do elemento que o contém. 


\section{Capítulo 4 IMPLEMENTAÇÃO MATLAB}

O programa escolhido para implementar os códigos existentes na literatura foi o MatLab R2010a (MATLAB, 2010). O MatLab é um programa que possui uma linguagem de alto nível e é utilizada por engenheiros e matemáticos no mundo inteiro por ser simples e possuir recursos de linguagens de baixo nível sem precisar ser compilada. É possível desenvolver programas com diversas subrotinas independentes em um mesmo programa além da maior vantagem do programa que é sua poderosa capacidade gráfica, o que permite visualizarmos os resultados facilmente.

Em cada caso, o programa desenvolvido consiste em um programa principal em que as subrotinas serão iniciadas e em que as variáveis serão controladas. As características do sistema estudado serão incluídas no sistema através de uma subrotina contida no programa principal.

Conforme já foi citado em capítulo anteriores, dois programas foram desenvolvidos neste trabalho: um para a formulação bidimensional e outro com a formulação tridimensional, ambos em MatLab baseados nos programas em Fortran disponíveis em Dominguez (1993). Para não ser repetitivo, apenas o programa bidimensional será discutido em detalhes neste capítulo. Entretanto, o programa tridimensional apresenta a mesma estrutura do bidimensional com subrotinas equivalentes, exceto a rotina formata _dad que gera a malha e a matriz de condições de contorno CDC. Esta rotina está disponível apenas no programa bidimensional. No programa tridimensional, a geração da malha e da matriz CDC deve ser feita em um outro programa. Neste trabalho, optou-se por usar o programa comercial GiD 12.0 para esta etapa.

\subsection{Subrotinas e fluxo de informação no programa}

O programa desenvolvido com o código MatLab utiliza uma rotina principal que inicia uma série de subrotinas secundárias para o processamento de dados com um fluxo determinado de manipulação de dados. A primeira subrotina iniciada tem como objetivo definir as características do problema. Os dados inseridos na primeira subrotina são formatados por uma 
outra subrotina que também cria os pontos da malha do contorno. Outras subrotinas são especifícas para a visualização gráfica do problema e para a montagem das matrizes $[H]$ e $[G]$. O problema é resolvido da maneira descrita anteriormente e a matriz $[A]$ e os vetores $\{b\}$ e $\{x\}$ são montados de tal forma que todos os valores desconhecidos estão alocados no vetor $\{x\}$. As matrizes originais depois da solução do problema linear descrito por (3.19) são montadas por uma subrotina diferente e todos os resultados podem ser visualizados através de subrotinas específicas para a visualização de formas modais ou resposta em frequência.

As soluções fundamentais são calculadas para cada ponto fonte e pontos campo através de uma subrotina denominada calc_solfund.m. Essa subrotina utiliza a solução fundamental adequada, $2 \mathrm{D}$ ou $3 \mathrm{D}$, no caso do programa tridimensional, quando o ponto fonte e campo não são coincidentes. No caso em que eles sejam, uma rotina específica para tratar da singularidade da solução fundamental é aplicada. O programa diferencia as duas situações tratando os casos em que os pontos coincidem como casos singulares, e todos os outros como não-singulares.

\section{Entrada de dados - dad_i.m}

A subrotina de entrada de dados para o programa bidimensional define as características do problema, sua geometria, informações para a construção da malha, condições de contorno para cada segmento da malha definido, características do material estudado e número de pontos internos a serem definidos. É essa subrotina que apresenta cada ponto que define a geometria, sua indexação e posição no espaço. Essas informações são acumuladas na matriz PONTOS. A matriz SEGMENTOS mostra como estes pontos serão ligados, seja por linhas retas ou por arcos de círculo. Em ambos os casos, a matriz realiza a conectividade entre os pontos de tal forma que a normal formada esteja de acordo com a condição do problema externo ou interno. A matriz MALHA define quantos elementos serão criados em cada segmento. A matriz CCSEG apresenta as condições de contorno para cada segmento.

É essa subrotina que define o problema estudado, e cada problema diferente é definido por uma subrotina diferente. Portanto o sub-índice $i$ é um número inteiro que determina qual problema será estudado. 
Tabela 4.1: Descrição de cada vetor criado na subrotina dad i.m

\begin{tabular}{ll}
\hline Subrotina & Descrição \\
\hline PONTOS & Enumeração dos pontos que determinam a geometria e sua posição \\
SEGMENTOS & A partir dos pontos criados, são criados segmentos que determinam a geometria. \\
ne & Número de elementos por segmento. \\
MALHA & Define o número de elementos que cada segmento conterá. \\
CCSEG & Condições de contorno do problema por segmento. \\
CW & Velocidade de propagação da onda. \\
freq_ini & Valor mínimo da faixa de frequência estudada. \\
freq_final & Valor máximo da faixa de frequência estudada. \\
nfreq & Número de divisões do intervalo determinado pela faixa de frequência. \\
AFR & Vetor com os valores discretos da faixa de frequência. \\
npi, NPX, NPY & Número de pontos internos a serem criados em X e em Y. \\
fc & Valor e posição de uma carga concentrada. \\
\hline
\end{tabular}

Formatação dos dados - format_dad.m

Essa subrotina formata os dados inseridos pela subrotina dad_i.m e cria as matrizes que serão manipuladas pelas subrotinas consequentes, descritas na tabela 4.2. Vale ressaltar mais uma vez que esta subrotina só existe no programa bidimensional.

Tabela 4.2: Descrição de cada matriz criada na subrotina format_dad.m

\begin{tabular}{ll}
\hline Subrotina & Descrição \\
\hline NOS_GEO & Matriz que contém as coordenadas dos nós geométricos por eles definidos. \\
NOS & Matriz contendo as coordenadas de cada nó físico. \\
ELEM & Matriz que enumera cada elemento e os nós contidos nele. \\
CDC & Matriz que define a condição de contorno de cada elemento. \\
\hline
\end{tabular}

Visualização Gráfica - mostra_geo.m e mostra_cdc.m

Essas duas subrotinas geram um gráfico que permite a identificação da geometria e das condições de contorno do problema definidos na subrotina dad_i.m. A geometria mostrada inclui divisões dos elementos criados e dos nós, exemplificada na figura 4.1. As condições de contorno são mostradas graficamente e não há indicação numérica do valor da pressão ou do gradiente de pressão no gráfico criado. As condições de contorno podem ser observadas na figura 4.1, em que as setas que terminam com um triângulo correspodem a áreas em que o gradiente de pressão é conhecido e setas que terminam com círculos são áreas em que a pressão é conhecida. A subrotina mostra _geo existe também no programa tridimensional. 


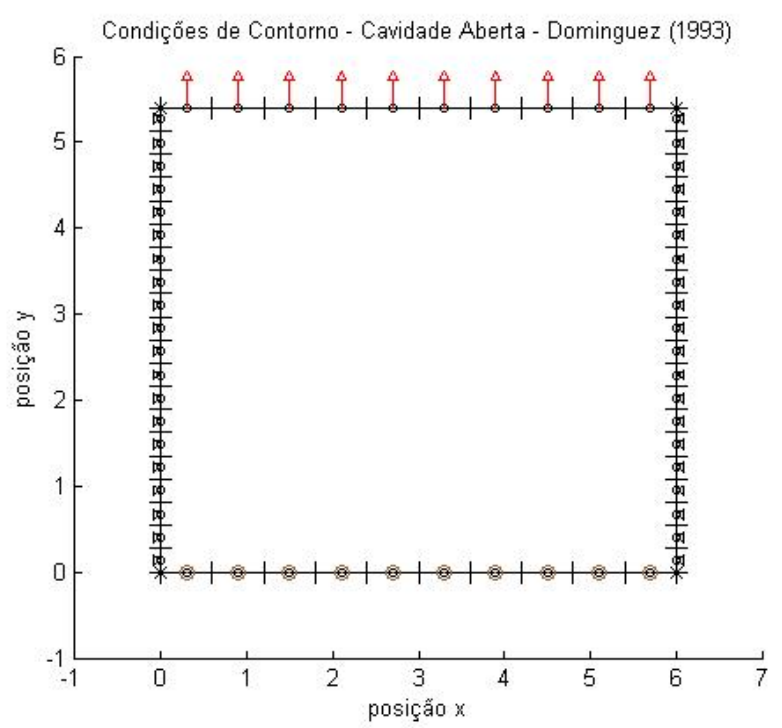

Figura 4.1: Geometria e Condições de Contorno de uma cavidade Bidimensional

Já a subrotina mostra _cdc existe apenas no programa bidimensional.

\subsection{Exemplo do fluxo de informações para o programa bidimensional}

Para ajudar na compreensão do funcionamento do programa bidimensional, um exemplo prático será desenvolvido nessa seção e cada matriz será apresentada para facilitar a compreensão das subrotinas utilizadas. O problema corresponde a uma cavidade quadrada aberta em um dos lados (Figura 4.1), conforme exemplo de Dominguez (1993). Para esse problema, a partir dos valores para a velocidade de propagação de onda $c=100[\mathrm{~m} / \mathrm{s}]$, massa específica

$\rho=100\left[\mathrm{~kg} / \mathrm{m}^{3}\right]$ e das condições de contorno, podemos calcular analiticamente a primeira frequência de ressonância da cavidade $\omega_{b}$. Vamos excitar a cavidade nessa frequência e analisar os resultados a partir dessa excitação.

O arquivo de entrada de dados fornece as informações necessárias para construir o modelo através da definição das matrizes PONTOS, SEGMENTOS, MALHA e CCSeg. Essas matrizes definem a geometria e condições de contorno do problema. Outras informações atribuídas na entrada de dados são a massa específica $(\rho) R O$ e a velocidade de propagação da onda (c) CW. Para o problema exemplo estudado, a matriz PONTOS é apresentada na tabela 4.3, a matriz SEGMENTOS na tabela 4.4, a matriz MALHA na tabela 4.5 e a matriz CCSeg na 
tabela 4.6. Essas matrizes vão gerar as matrizes $N O S \_G E O, N O S, E L E M$ e $C D C$, a partir da subrotina formata_dad.

Tabela 4.3: Exemplo da matriz PONTOS para um problema bidimensional

\begin{tabular}{rrr}
\hline Nó & Posição eixo x [m] & Posição eixo y [m] \\
\hline 1 & 0 & 0 \\
2 & 6 & 0 \\
3 & 6 & 6 \\
4 & 0 & 6 \\
\hline
\end{tabular}

Tabela 4.4: Exemplo da matriz SEGMENTOS para um problema bidimensional

\begin{tabular}{rrr}
\hline Segmento & Nó inicial & Nó final \\
\hline 1 & 1 & 2 \\
2 & 2 & 3 \\
3 & 3 & 4 \\
4 & 4 & 1 \\
\hline
\end{tabular}

Tabela 4.5: Exemplo da matriz MALHA para um problema bidimensional

\begin{tabular}{cc}
\hline Segmento & Número de Elementos no segmento \\
\hline 1 & 5 \\
2 & 5 \\
3 & 5 \\
4 & 5 \\
\hline
\end{tabular}

A partir dessas informações, é possível montar as matrizes de influência $H$ e $G$ do problema a ser resolvido. Se o problema estivesse sendo resolvido para uma faixa de frequência e não para apenas a frequência $\omega_{b}$, a partir desse ponto, uma coluna das matrizes de pressão e de gradiente de pressão será construída por vez, de tal forma que a matriz final será o resultado da obtenção do valor da pressão e gradiente de pressão de cada nó para todas as frequências analisadas na faixa de frequência. A subrotina $\mathrm{cal} H e \mathrm{H}$ constrói esssas matrizes a partir das matrizes informadas pela entrada de dados, referente à indexação e posição dos nós, conectividade dos elementos, velocidade de propagação da onda e frequência analisada. As matrizes $H$ e $G$ para a frequência estudada tem tamanho $n \times n$, em que o número de elementos $n=20$, e são muito extensas para serem apresentadas nesta seção. A partir das matrizes $H$ e $G$ e da matriz que define as condições de contorno (matriz $C D C$ ), a subrotina aplica_CDC constrói a matriz $A$ e o vetor $b$, que serão utilizados para resolver o sistema linear que define a física do problema para a frequência analisada. Após o cálculo do vetor $x$ obtido através da solução do sistema $A x=b$, a subrotina monta_Teq utiliza novamente a matriz que 
Tabela 4.6: Exemplo da matriz CCSeg para um problema bidimensional. O tipo de condição de contorno é atribuído através do valor da célula "Tipo de CDC", em que um valor nulo indica que a pressão é conhecida no segmento e um valor diferente de zero indica que o gradiente de pressão é conhecido.

\begin{tabular}{ccc}
\hline Segmento & Tipo de CDC & Valor da CDC \\
\hline 1 & 0 & 0 \\
2 & 1 & 0 \\
3 & 1 & 100 \\
4 & 1 & 0 \\
\hline
\end{tabular}

possui as informações de condição de contorno para separar os valores calculados de pressão e de gradiente de pressão, obtendo os vetores $T$ e $q$, que correspondem respectivamente aos valores da pressão e do gradiente de pressão para cada nó.

Com os valores de pressão e gradiente de pressão calculados para cada nó e para cada frequência analisada da faixa de frequência é possível visualizar o gráfico de resposta em frequência para a faixa analisada. A subrotina picos utiliza os valores da pressão e do gradiente de pressão para obter a resposta em frequência de um único nó e determinar se existem pontos de inflexão, que possivelmente podem determinar a existência de um modo de vibração. Após gerar a visualização da resposta em frequência, a subrotina gera uma visualização da distribuição de pressão ou gradiente de pressão no domínio do problema utilizando os valores da posição dos nós e dos elementos e uma escala de cor para o valor da variável analisada. Para a frequência $\omega_{b}=26.21[\mathrm{rad} / \mathrm{s}]$, a distribuição de pressão encontrada é mostrada na figura 4.2.

\section{Alguns comentários sobre a implementação tridimensional}

Para os algoritmos tridimensionais, a lógica de programação continuou a mesma do programa bidimensional. As maiores diferenças serão que os cálculos serão realizados considerando as três dimensões. Os vetores de posição dos nós vão incluir a posição na terceira dimensão, a visualização da malha será tridimensional e os elementos implementados serão quadrilaterais constantes. Os elementos quadrilaterais constantes possuem 4 nós geométricos (nós que definem a geometria do elemento) que correspondem aos vértices do quadrilátero e 1 nó físico (nó onde as variáveis físicas, ou seja, pressão e velocidade, são calculadas) que corresponde ao centróide do elemento. Os nomes dos vetores manipulados serão man- 


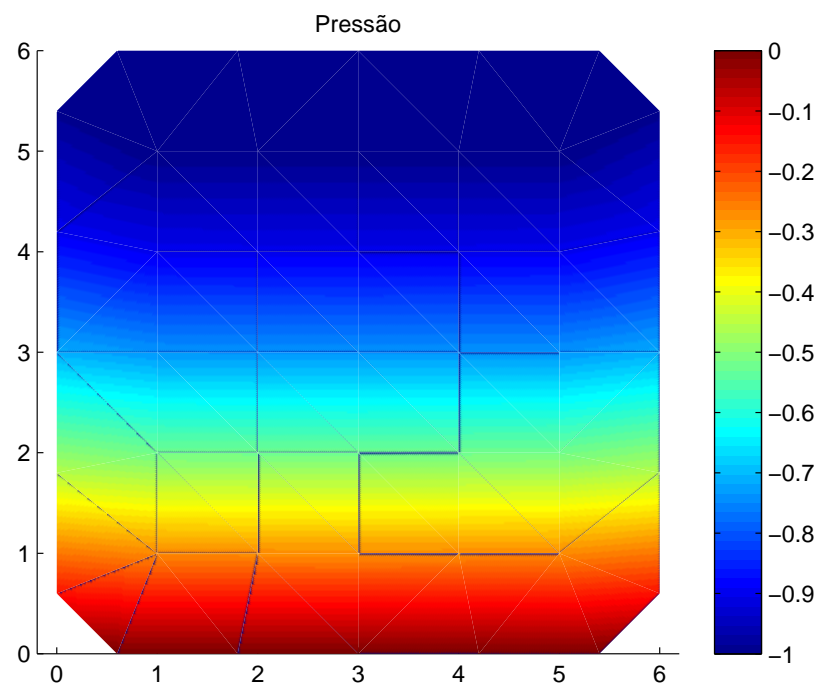

Figura 4.2: Distribuição de pressão da cavidade 4.1 para a frequência $\omega_{b}=26.21[\mathrm{rad} / \mathrm{s}]$

tidos o mais próximo possível de seus equivalentes bidimensionais para facilitar a leitura do programa por um usuário já familiarizado com o programa bidimensional. De uma maneira geral, o programa implementado para casos tridimensionais se aproxima muito do programa para casos bidimensionais.

\section{Fluxo de Informações no programa tridimensional}

O fluxo de informações do programa tridimensional implementado é simples, o que ajuda na compreensão geral do programa. Primeiramente todos os dados residuais que estejam guardados na memória do MATLAB são apagados para que eles não interfiram nos cálculos. A primeira subrotina utilizada pelo programa é a de entrada de dados. Ela define o problema que o programa vai resolver e define as matrizes de nós, conectividade dos elementos e condições de contorno, além de fornecer outras informações importantes como a velocidade de propagação da onda e a faixa de frequência analisada. A partir das informações inseridas pela subrotina de entrada de dados, é possível definir com a posição de cada nó e com a conectividade dos elementos, a geometria do problema. A próxima subrotina gera uma visualização gráfica da geometria definida pelas matrizes de nós e elementos e numera cada elemento de acordo com as informações da entrada de dados. Em seguida, o programa determina o número de divisões em que a faixa de frequência foi dividida e os vetores que conterão os valores da pressão e do gradiente de pressão de cada nó para cada frequência é criado. Vale a pena ressaltar que esses vetores terão dimensão de número de nós físicos $\times$ 
número de frequências analisadas, pois para cada valor da divisão da faixa de frequência vai gerar um valor de pressão e de gradiente de pressão em cada nó. 


\section{Capítulo 5 VALIDAÇÃO DO CÓDIGO IMPLEMENTADO}

Neste capítulo, alguns casos teste serão apresentados com o propósito de validar o código implementado por comparação com resultados conhecidos. Os casos correspondem a (i) cavidade fechada em todos os lados unidimensional, (ii) cavidade aberta em um dos lados unidimensional, (iii) cavidade fechada em todos os lados bidimensional, (iv) cavidade aberta em um dos lados bidimensional, (v) cavidade aberta em um dos lados tridimensional e (vi) cavidade fechada em todos os lados longa tridimensional. As formas operacionais apresentadas se aproximam da forma modal para uma frequência de excitação próxima à frequência de ressonância. Em todos os casos, a velocidade de propagação da onda é igual a $c=343 \mathrm{~m} / \mathrm{s}$. O método de integração radial RIM também foi validado dessa forma para casos bidimensionais, mas como esses resultados fogem do escopo deste trabalho, o método é apresentado nos apêndices.

\subsection{Cavidades 1D}

As cavidades apresentadas a seguir apresentam uma geometria que garante a hipótese de ondas planas em um dos sentidos. Dessa forma, a cavidade se comporta como uma cavidade unidimensional. Duas condições de contorno são consideradas: (i) cavidade 1D fechadafechada e (ii) cavidade 1D fechada-aberta.

\subsubsection{Cavidade 1D fechada-fechada - Caso (i)}

A cavidade em questão possui um lado de comprimento $10 \mathrm{~m}$ e largura de $1 \mathrm{~m}$ para que prevaleça a existência de ondas no sentido de lado maior. Dessa forma, a cavidade vai se comportar como uma cavidade unidimensional até o surgimento do primeiro modo transversal. Todos os lados da cavidade possuem condição de contorno de parede fechada, ou seja o gradiente de pressão é dado e a pressão é a incógnita a obter. As condições de contorno 
para o caso (i) são apresentadas na figura 5.1. Esse caso corresponde a uma condição de contorno fechada-pistão, onde o movimento do pistão é imposto. Portanto, a cavidade vai se comportar como uma cavidade fechada-fechada (Gibert, 1988). ${ }^{1}$

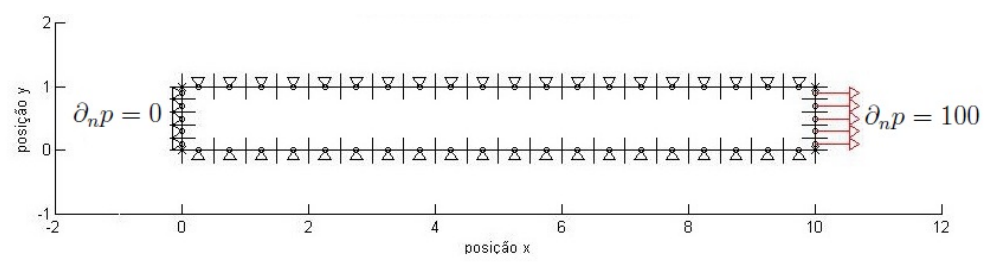

Figura 5.1: Condições de contorno para o caso (i) 1D fechada-fechada

A solução analítica para uma cavidade unidimensional fechada-fechada é dada por

$$
f_{\text {fechado-fechado }}=\frac{(2 \cdot \pi \cdot n) \cdot c}{2 \cdot L_{\text {tubo }}}, n=0,1,2,3, \ldots
$$

onde $c$ é a velocidade de propagação da onda, $n=0,1,2,3, \ldots$ são os números naturais e $L_{t u b o}$ é o comprimento do tubo estudado. A unidade de frequência é radianos por segundo $[\mathrm{rad} / \mathrm{s}]$. Neste trabalho, os modos de corpo rígido, que correspondem a $n=0$ não serão abordados.

As frequências numéricas por MEC são mostradas na tabela 5.1 para um modelo com 50 elementos constantes e a integração da solução fundamental foi realizada utilizando uma quadratura de Gauss-Legendre utilizando 4 pontos de Gauss. Os resultados são comparados com um modelo do software comercial Ansys 15 do MEF e possui 250 elementos e 306 nós.

Tabela 5.1: Frequências de ressonância para o caso (i) 1D fechada-fechada

\begin{tabular}{cccc}
\hline Modo & analítica & MEC & MEF \\
\hline 1 & 107,7 & 107,3 & 107,7 \\
2 & 215,5 & 215,5 & 215,6 \\
3 & 323,2 & 323,6 & 323,7 \\
4 & 431,0 & 431,8 & 432,2 \\
\hline
\end{tabular}

\footnotetext{
${ }^{1}$ De acordo com Gibert (1988), para cavidades acústicas acopladas a pistões dotados de uma rigidez $k$, o comportamento dinâmico do sistema vai depender da razão entre a rigidez do pistão e da compressibilidade do fluido. Seja $\alpha$ a razão entre a rigidez do pistão e a compressibilidade do fluido, é possível escrever a relação $\alpha=k L / \rho c^{2} S$, onde $L$ é o comprimento da cavidade, $S$ é a área transversal da cavidade que contém o fluido, $c$ é a velocidade de propagação de onda e $\rho$ é a massa específica do fluido. É possível mostrar que quando $\alpha \approx 1$ ou $\alpha>1$ a ressonância do sistema depende apenas da compressibilidade do fluido.
} 
A forma modal para as primeiras frequências de ressonância obtidas por MEC são mostradas na figura 5.3. A resposta em frequência é mostrada na figura 5.2.

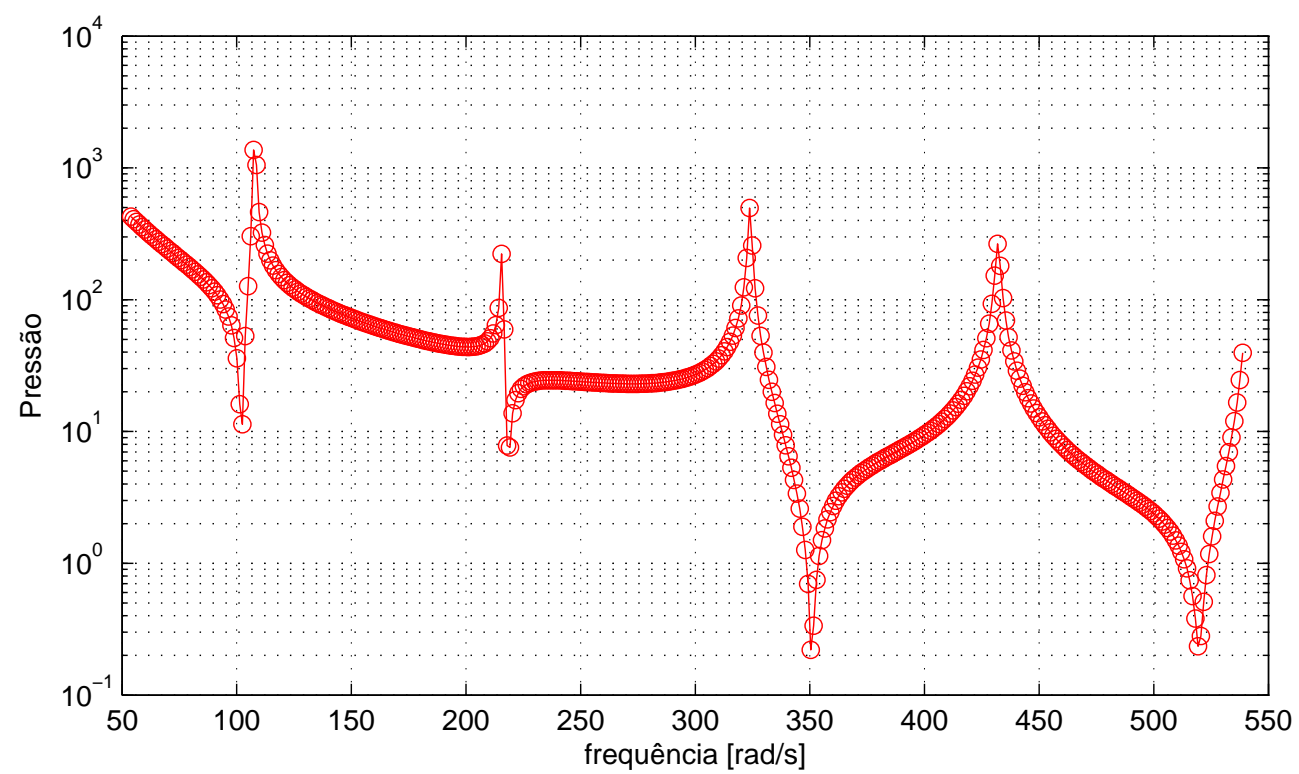

Figura 5.2: Resposta em frequência para a cavidade (i) 1D fechada-fechada

\subsubsection{Cavidade 1D fechada-aberta - Caso (ii)}

A cavidade estudada possui a mesma geometria descrita no caso (i). As condições de contorno para o gradiente de pressão são de parede fechada para todos os lados exceto um em que um valor da pressão é dado e seu gradiente de pressão é calculado. Dessa forma, a cavidade se comporta como uma cavidade aberta em um dos lados. As condições de contorno para o caso (ii) são apresentadas na figura 5.4.

A solução analítica para uma cavidade unidimensional fechada-aberta é dada por

$$
f_{\text {aberto-fechado }}=\frac{[2 \cdot \pi \cdot(2 \cdot n-1)] \cdot c}{4 \cdot L_{\text {tubo }}}, n=0,1,2,3, \ldots
$$

em que $c$ é a velocidade de propagação da onda, $n=0,1,2,3, \ldots$ são os números naturais e $L_{t u b o}$ é o comprimento do tubo estudado. Neste trabalho, os modos de corpo rígido, que correspondem a $n=0$ não serão abordados. 


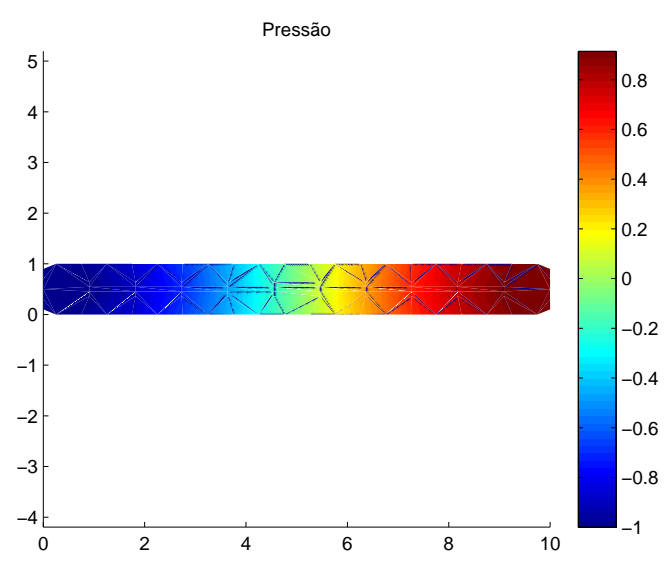

(a) Modo 1

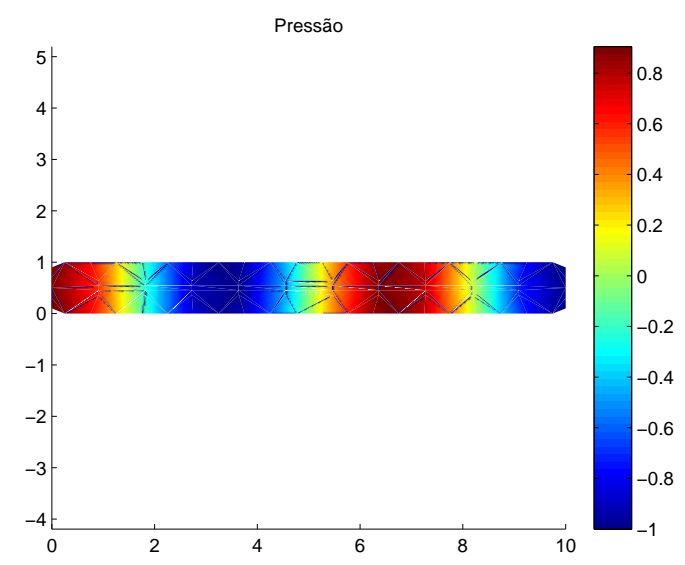

(c) Modo 3

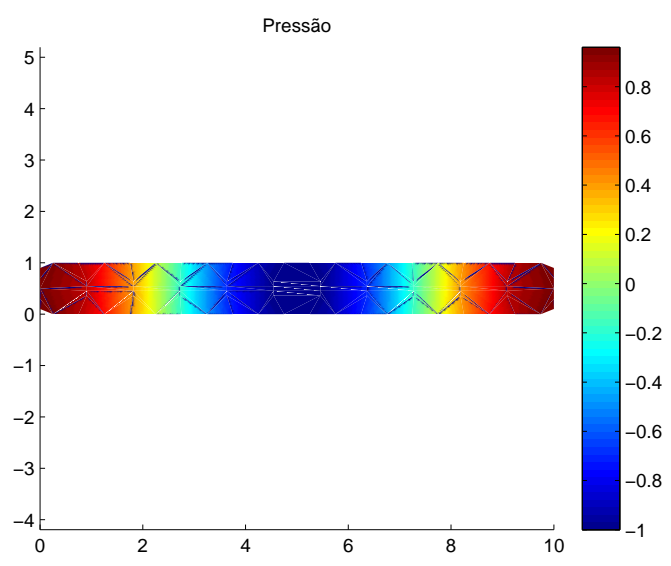

(b) Modo 2

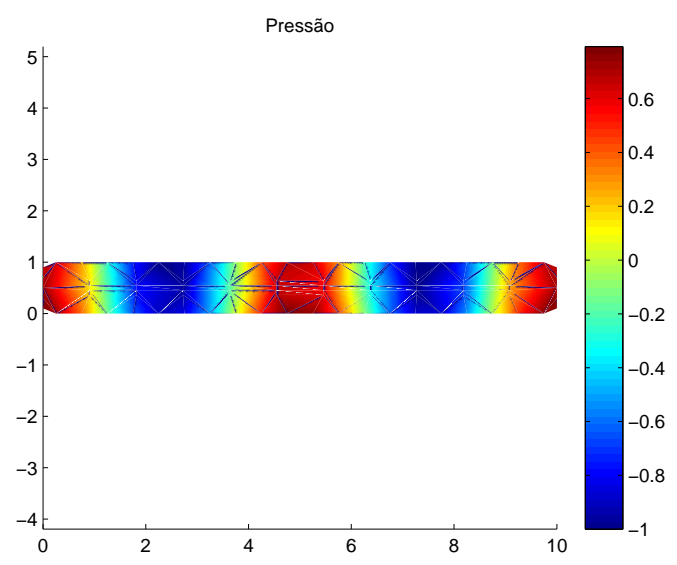

(d) Modo 4

Figura 5.3: Quatro primeiras formas modais operacionais para a cavidade (i) 1D fechadafechada

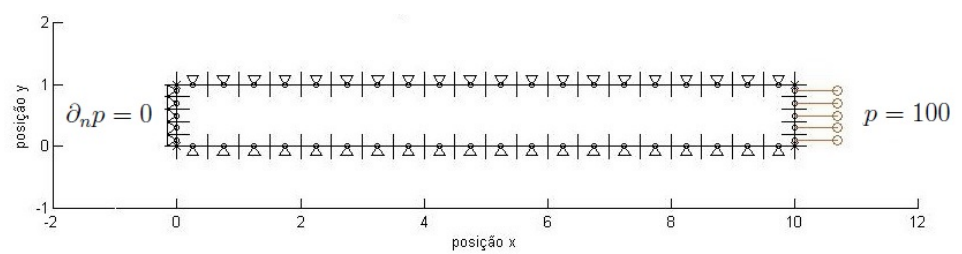

Figura 5.4: Condições de contorno para o caso (ii) 1D fechada-aberta 
As frequências obtidas por MEC são mostradas na tabela 5.2 para um modelo com 50 elementos constantes e 4 pontos de Gauss para a quadratura de Gauss-Legendre. O modelo MEF possui 250 elementos e 306 nós.

Tabela 5.2: Frequências de ressonância para a cavidade (ii) 1D fechada-aberta

\begin{tabular}{cccc}
\hline Modo & analítica & MEC & MEF \\
\hline 1 & 53,9 & 54,3 & 53,9 \\
2 & 161,6 & 162,4 & 161,7 \\
3 & 269,4 & 271,0 & 269,7 \\
4 & 377,2 & 378,8 & 377,9 \\
\hline
\end{tabular}

A resposta em frequência é mostrada na figura 5.5. A forma modal para as primeiras frequências de ressonância obtidas por MEC são mostradas na figura 5.6.

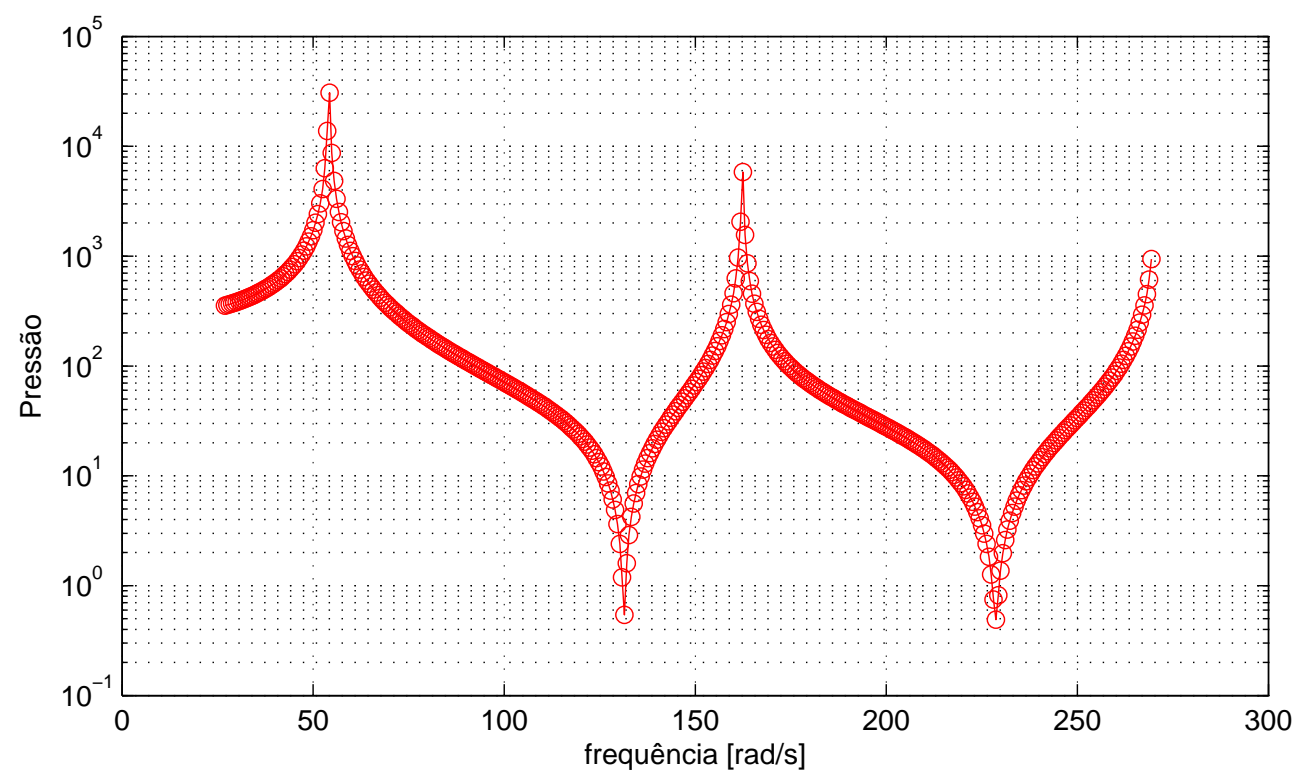

Figura 5.5: Resposta em frequência para a cavidade (ii) 1D fechada-aberta

\subsection{Cavidades 2D}

Essa seção apresenta resultados numéricos obtidos para cavidades bidimensionais de geometria simples. As condições de contorno correspondem a uma (iii) cavidade fechada-fechada e (iv) cavidade fechada-aberta. 


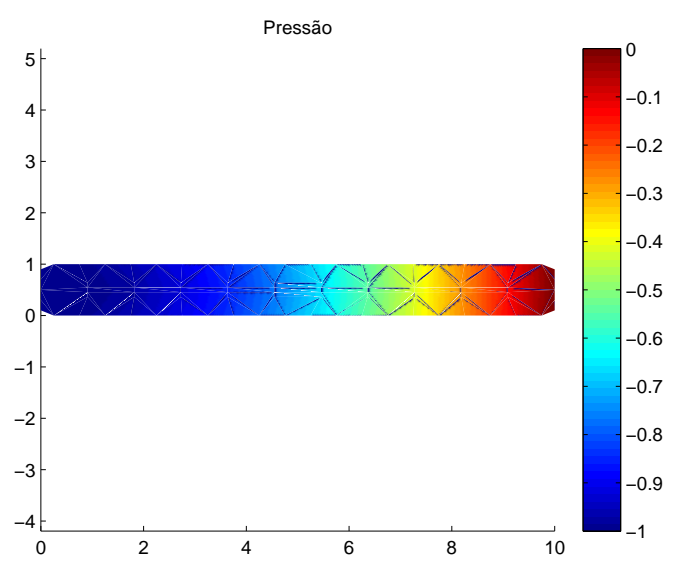

(a) Modo 1

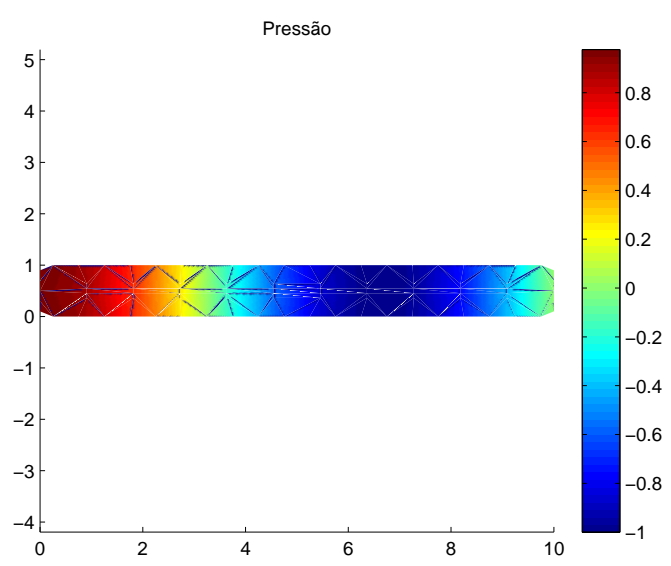

(b) Modo 2

Figura 5.6: Duas primeiras formas modais para a cavidade (ii) 1D fechada-aberta

\subsubsection{Cavidade 2D fechada-fechada - Caso (iii)}

Essa cavidade corresponde a um quadrado de lado $6 \mathrm{~m}$. A geometria não é uniforme pois deseja-se evitar ocorrência de simetria, em que o mesmo valor de frequência corresponda a dois modos diferentes. As características físicas do caso simétrica podem ser observadas em modelos numéricos e em soluções analíticas (Ferreira, 2012; Kinsler, 1982). As condições de contorno são determinadas para os lados como condições de gradiente de pressão conhecidas. Dessa forma, a cavidade se comporta como uma cavidade fechada. As condições de contorno para o caso (iii) são apresentadas na figura 5.7.

No caso (iii) 2D fechada-fechada, as frequências naturais são obtidas analiticamente aplicando a equação a seguir

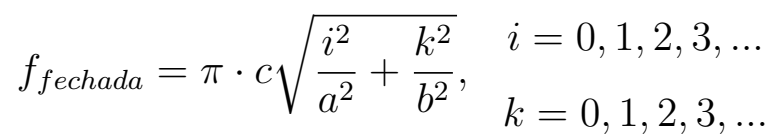

Em que $a$ e $b$ são as dimensões da cavidade bidimensional, $c$ é a velocidade de propagação de onda, $i=0,1,2,3, \ldots$ são os números naturais e determinam o modo na direção de $a$ e $k=0,1,2,3, \ldots$ são os números naturais e determinam o modo na direção de $b$. Neste trabalho, os modos de corpo rígido, que correspondem a $i=0$ e $k=0$ não serão abordados. 


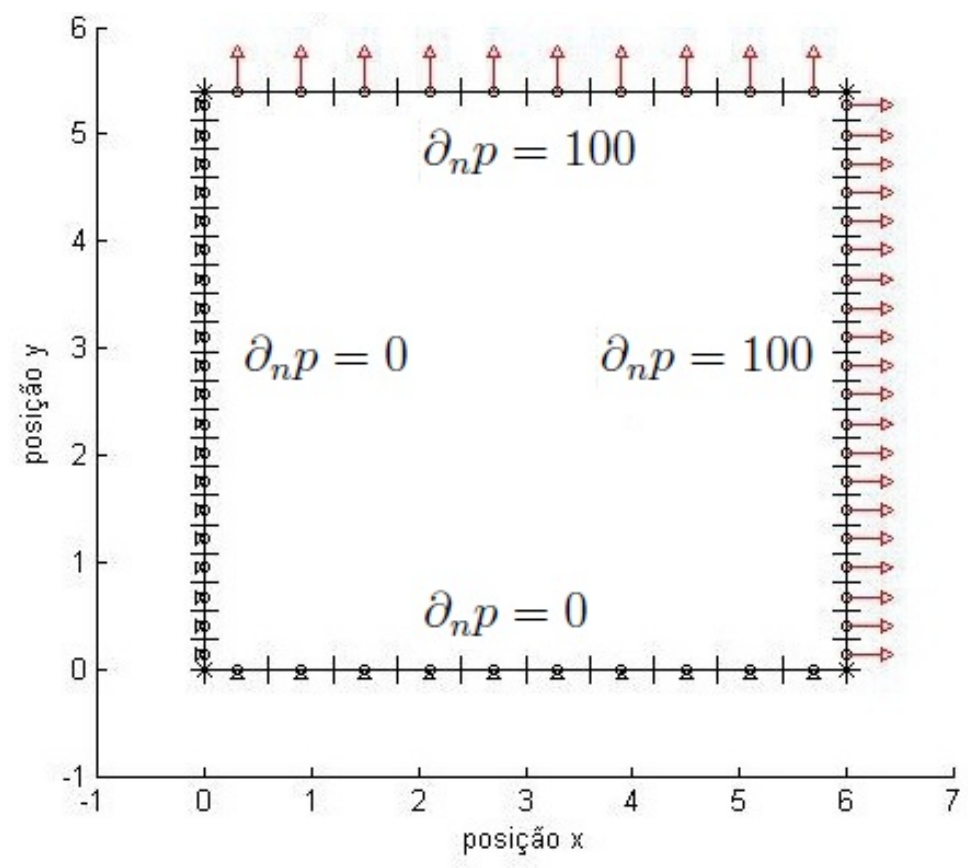

Figura 5.7: Condições de contorno para o caso (iii) 2D fechada-fechada

As frequências obtidas por MEC são mostradas na tabela 5.3 para um modelo com 50 elementos constantes e a integração da solução fundamental foi realizada utilizando uma quadratura de Gauss-Legendre utilizando 4 pontos de Gauss. O modelo MEF possui 2650 elementos e 2754 nós.

Tabela 5.3: Frequências de ressonância para a cavidade (iii) 2D fechada-fechada

\begin{tabular}{cccc}
\hline Modo & analítica & MEC & MEF \\
\hline 1 & 179,6 & 178,9 & 179,6 \\
2 & 189,0 & 189,0 & 189,1 \\
3 & 359,2 & 359,2 & 359,4 \\
4 & 378,1 & 377,4 & 378,3 \\
\hline
\end{tabular}

A resposta em frequência é mostrada na figura 5.8. A forma modal para as primeiras frequências de ressonância obtidas por MEC são mostradas na figura 5.9. O caso em que $i=k=1$ e modos mistos semelhantes não podem ser visualizados se as condições de contorno são colocadas da forma mostrada na figura 5.7. Para obter os modos dessas frequências, a rotina da carga concentrada deve ser utilizada. Para a frequência $\omega_{b}=254[\mathrm{rad} / \mathrm{s}]$, a forma modal obtida utilizando a rotina de carga concentrada no ponto $(0,0)$ é mostrada na figura 5.10 . 


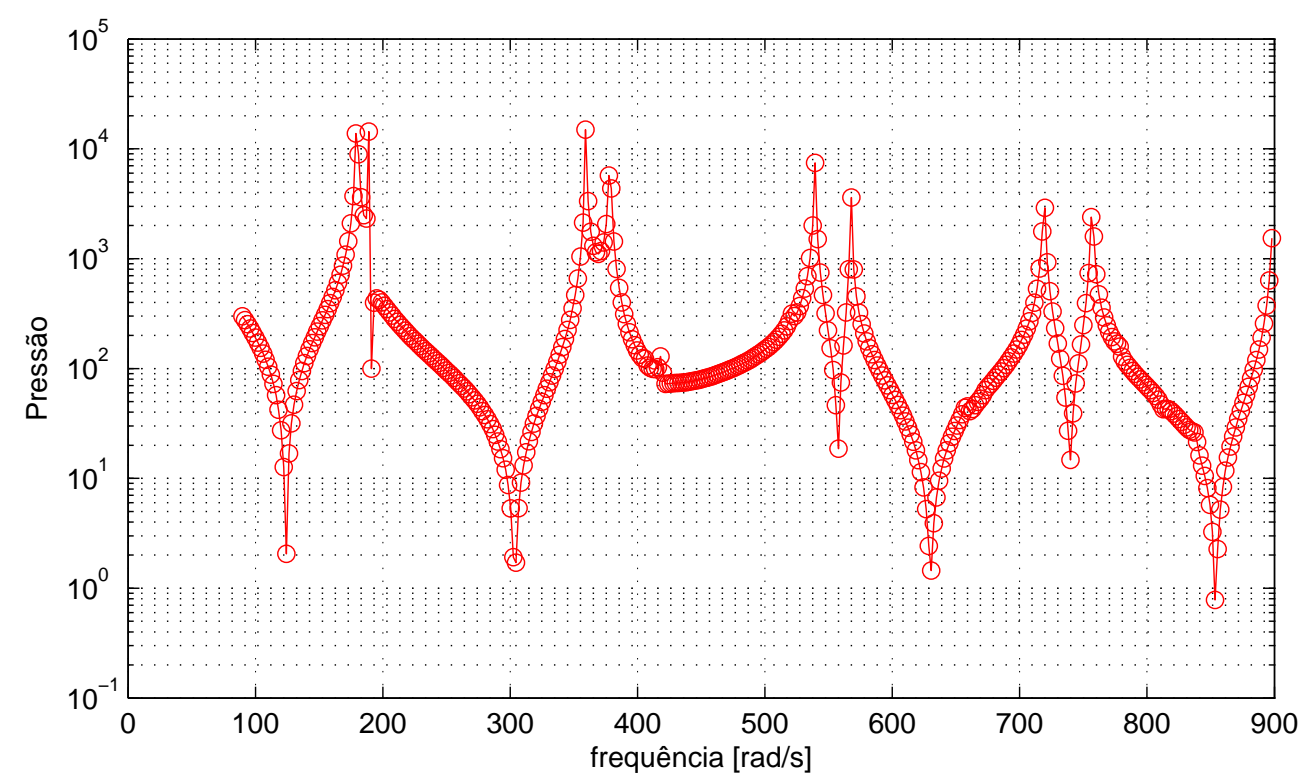

Figura 5.8: Resposta em frequência para a cavidade (iii) 2D fechada-fechada

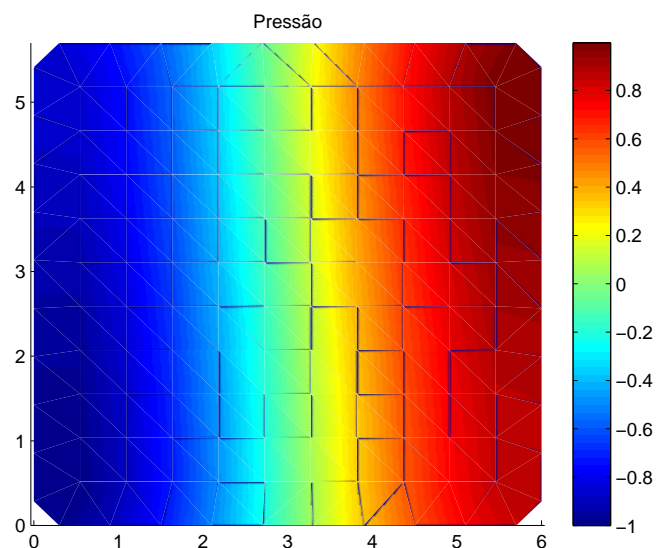

(a) Modo 1

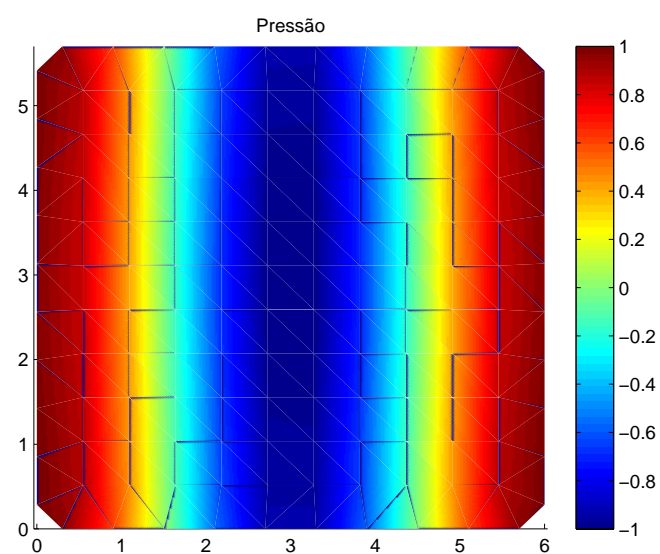

(c) Modo 3

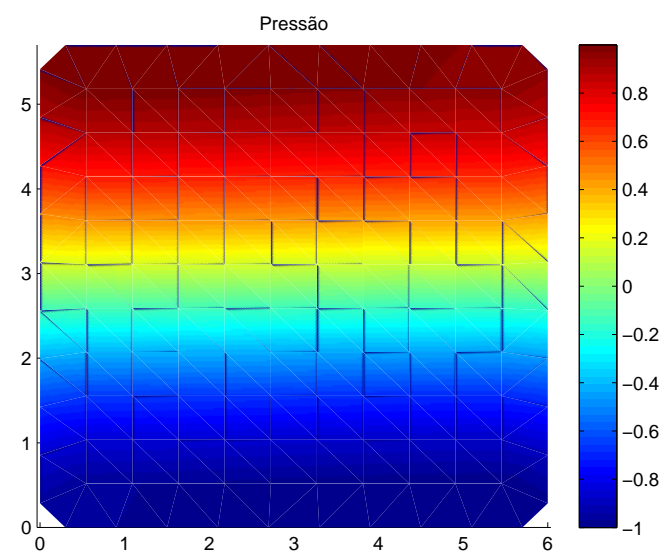

(b) Modo 2

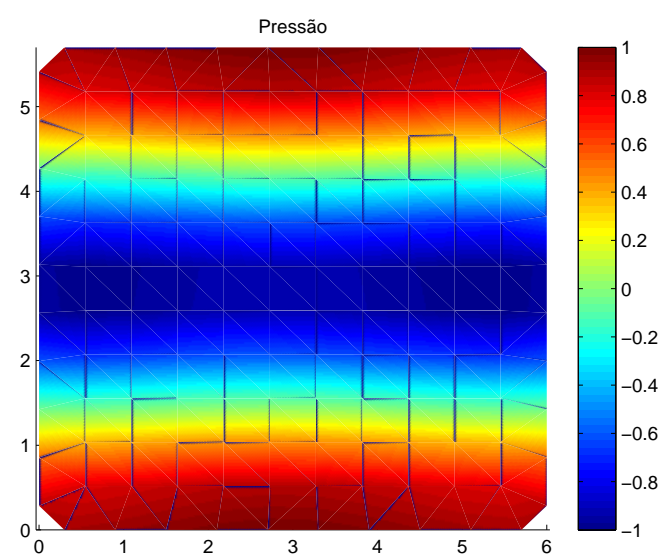

(d) Modo 4

Figura 5.9: Quatro primeiras formas modais para a cavidade (iii) 2D fechada-fechada 


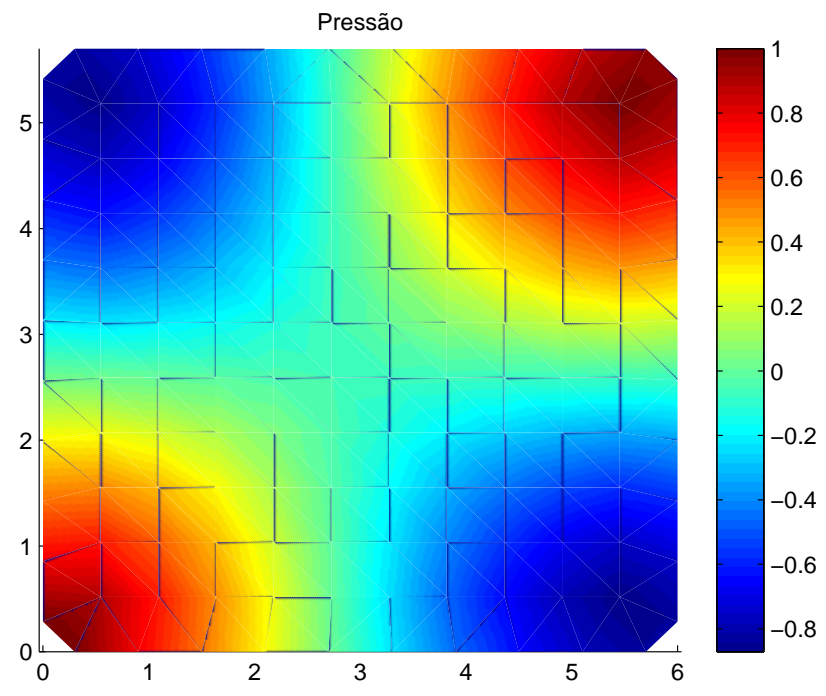

Figura 5.10: Forma modal mista para a frequência $\omega_{b}=254[\mathrm{rad} / \mathrm{s}]$ para a cavidade (iii) 2D fechada-fechada

\subsubsection{Cavidade 2D fechada-aberta - Caso (iv)}

A cavidade estudada possui a mesma geometria descrita no caso (iii). As condições de contorno para o gradiente de pressão são de parede fechada para todos os lados exceto um em que um valor da pressão é dado e seu gradiente de pressão é calculado. Dessa forma, a cavidade se comporta como uma cavidade aberta em um dos lados. As condições de contorno para o caso (iv) são apresentadas na figura 5.11.

No caso de uma cavidade aberta em apenas um dos lados e fechada nos demais, as frequências naturais são obtidas analiticamente aplicando a equação a seguir

$$
f_{\text {aberta }}=\pi \cdot c \sqrt{\frac{i^{2}}{a^{2}}+\frac{j^{2}}{4 \cdot b^{2}}}, \quad \begin{aligned}
& i=0,1,2,3, \ldots \\
& j=0,1,3,5, \ldots
\end{aligned}
$$

em que $a$ e $b$ são as dimensões da cavidade bidimensional, $c$ é a velocidade de propagação de onda, $i=0,1,2,3, \ldots$ são os números naturais e determinam o modo na direção de $a$, $j=0,1,3,5, \ldots$ são os números naturais ímpares e determinam o modo na direção de $b$. Neste trabalho, os modos de corpo rígido, que correspondem a $i=0$ e $j=0$ não serão abordados. 


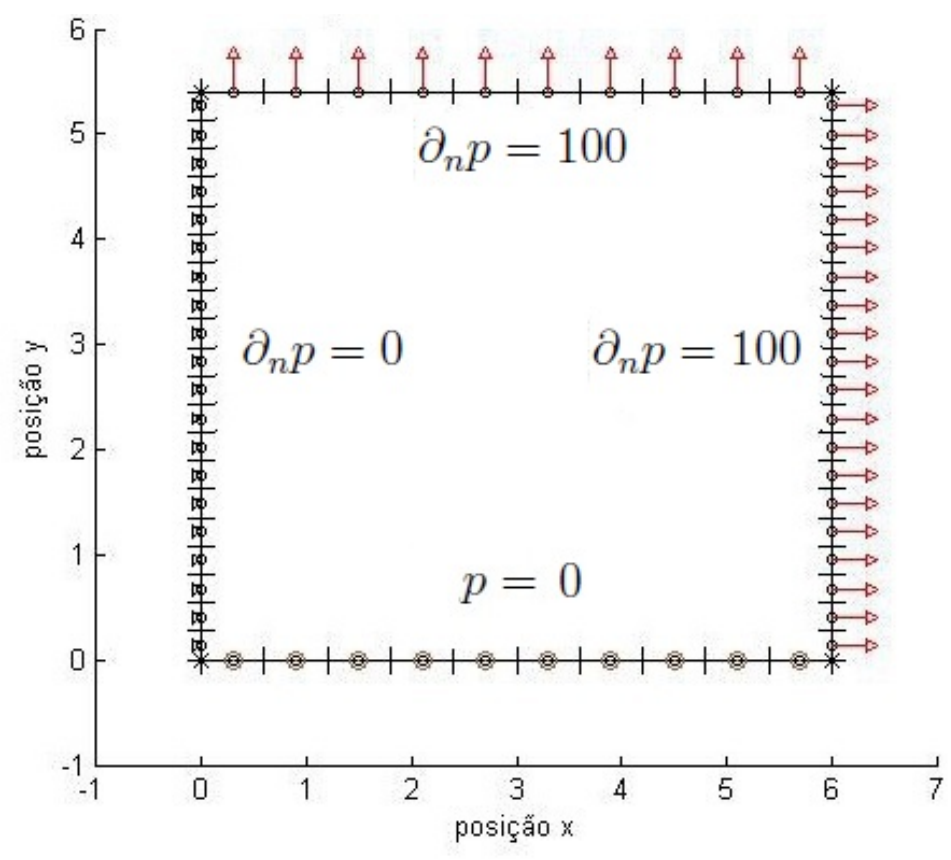

Figura 5.11: Condições de contorno para o caso (iv) 2D fechada-aberta

As frequências obtidas por MEC são mostradas na tabela 5.4 para um modelo com 50 elementos constantes e 4 pontos de Gauss para a quadratura de Gauss-Legendre. O modelo MEF possui 2650 elementos e 2754 nós.

Tabela 5.4: Frequências de ressonância para a cavidade (iv)

\begin{tabular}{cccc}
\hline Modo & analítica & MEC & MEF \\
\hline 1 & 94,5 & 94,5 & 94,5 \\
2 & 202,9 & 202,9 & 202,9 \\
3 & 283,6 & 283,9 & 283,7 \\
4 & 335,6 & 336,6 & 335,8 \\
\hline
\end{tabular}

A resposta em frequência é mostrada na figura 5.12. A forma modal para as primeiras frequências de ressonância obtidas por MEC são mostradas na figura 5.13.

\subsection{Cavidades 3D}

Essa seção trata de cavidades definidas em três dimensões físicas. Dois casos serão apresentados, o primeiro é (v) cavidade cúbica aberta-fechada e o segundo, (vi) cavidade longa fechada-fechada. Essas cavidades correspondem às versões tridimensionais dos casos (iv) e (i), respectivamente. 


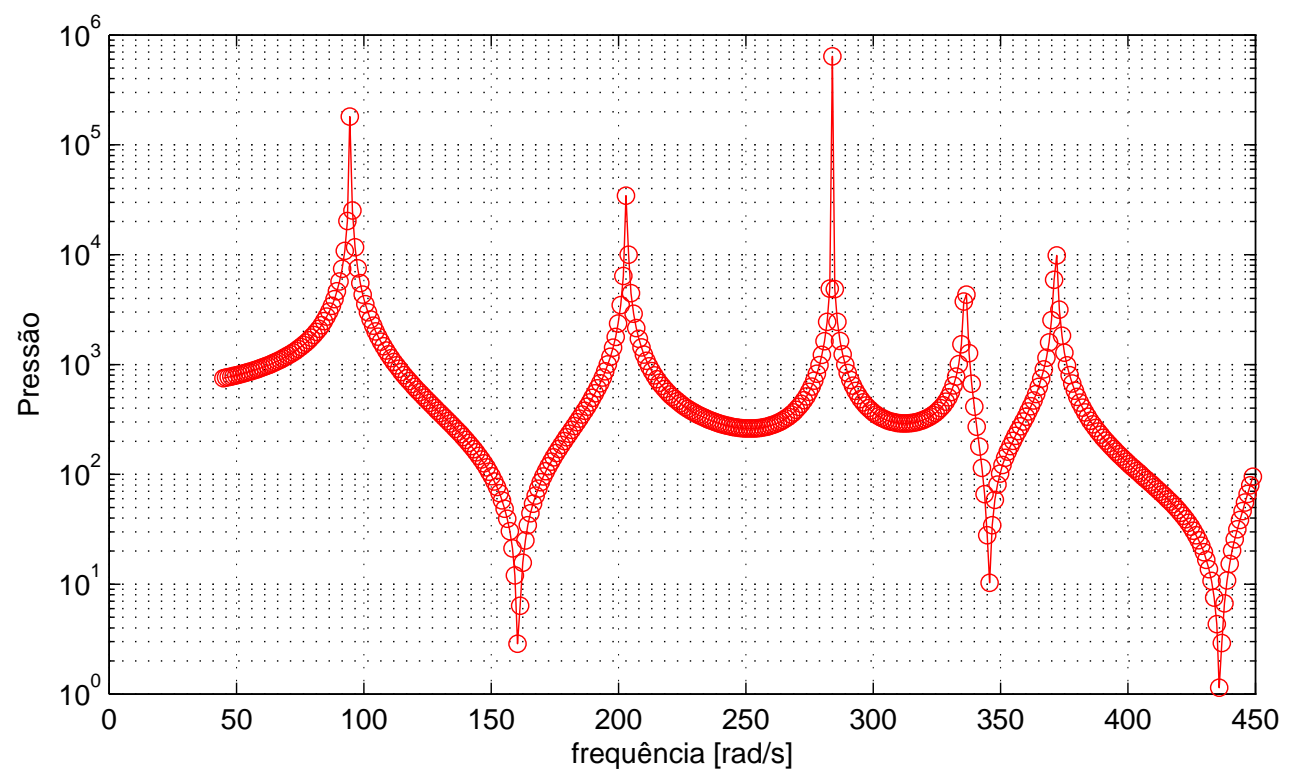

Figura 5.12: Resposta em frequência para a cavidade (iv) 2D fechada-aberta

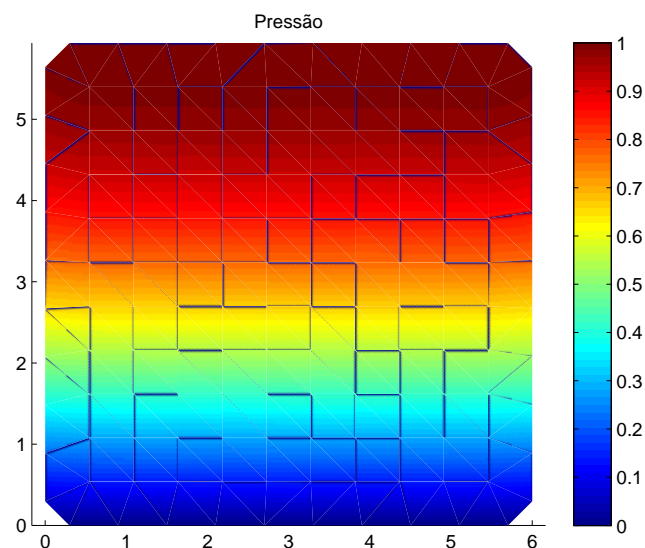

(a) Modo 1

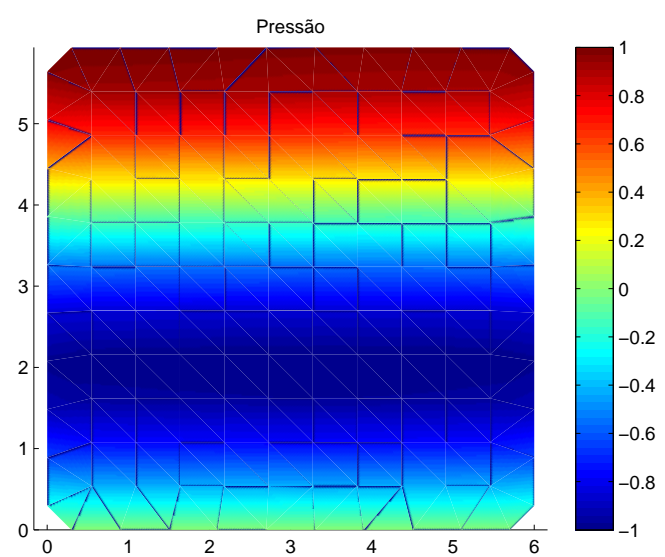

(c) Modo 3

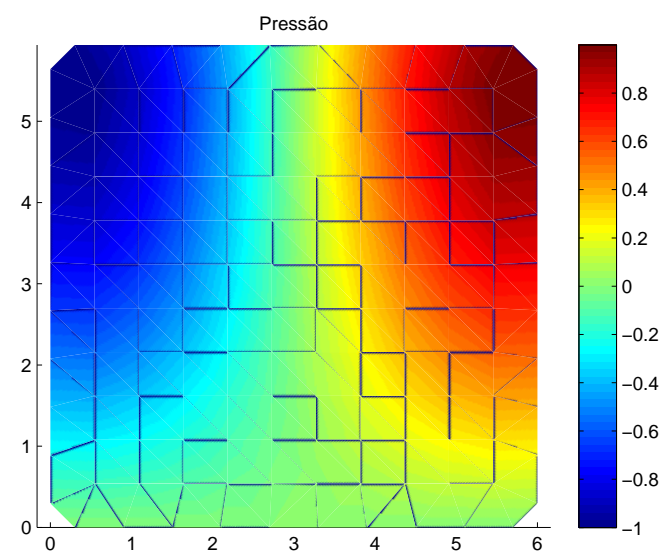

(b) Modo 2

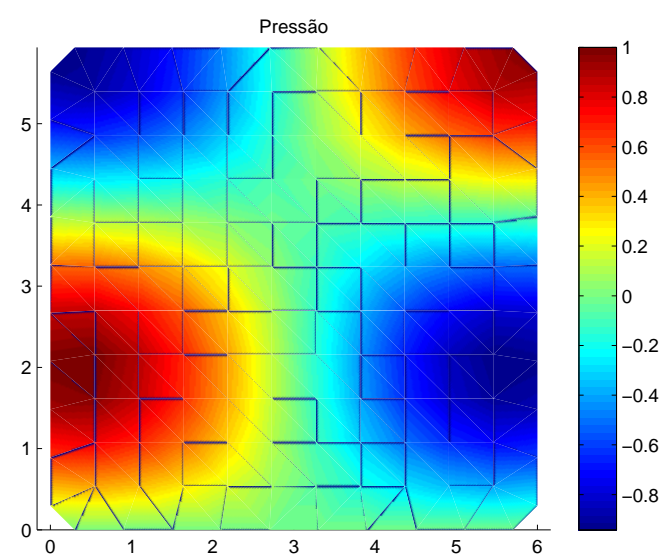

(d) Modo 4

Figura 5.13: Quatro primeiras formas modais para a cavidade (iv) 2D fechada-aberta 


\subsubsection{Cavidade 3D cúbica aberta-fechada - Caso (v)}

O caso corresponde a uma cavidade cúbica de lado $6 \mathrm{~m}$ aberta em um dos lados. As condições de contorno correspondem a parede fechada em todos os lados exceto um, em que a pressão é determinada e caracteriza um lado aberto. A solução analítica por separação de variáveis é dada por

$$
f_{\text {aberta }}=\pi \cdot c \sqrt{\frac{i^{2}}{a^{2}}+\frac{i^{2}}{d^{2}}+\frac{j^{2}}{4 \cdot b^{2}}}
$$

em que $a$ e $b$ são as dimensões da cavidade bidimensional, $c$ é a velocidade de propagação de onda, $i=0,1,2,3, \ldots$ e $k=0,1,2,3, \ldots$ são os números naturais e determinam o modo na direção de $a$ e $d, j=0,1,3,5, \ldots$ são os números naturais ímpares e determinam o modo na direção de $b$, em que está localizado o lado que apresenta condição aberta. Neste trabalho, os modos de corpo rígido, que correspondem a $i=0, k=0$ e $j=0$ não serão abordados.

A resposta em frequência mostrada a seguir corresponde a faixa de frequência do primeiro modo de vibração. Identifica-se o pico de amplitude do valor da pressão na frequência de ressonância. O modo identificado é mostrado na figura 5.15.

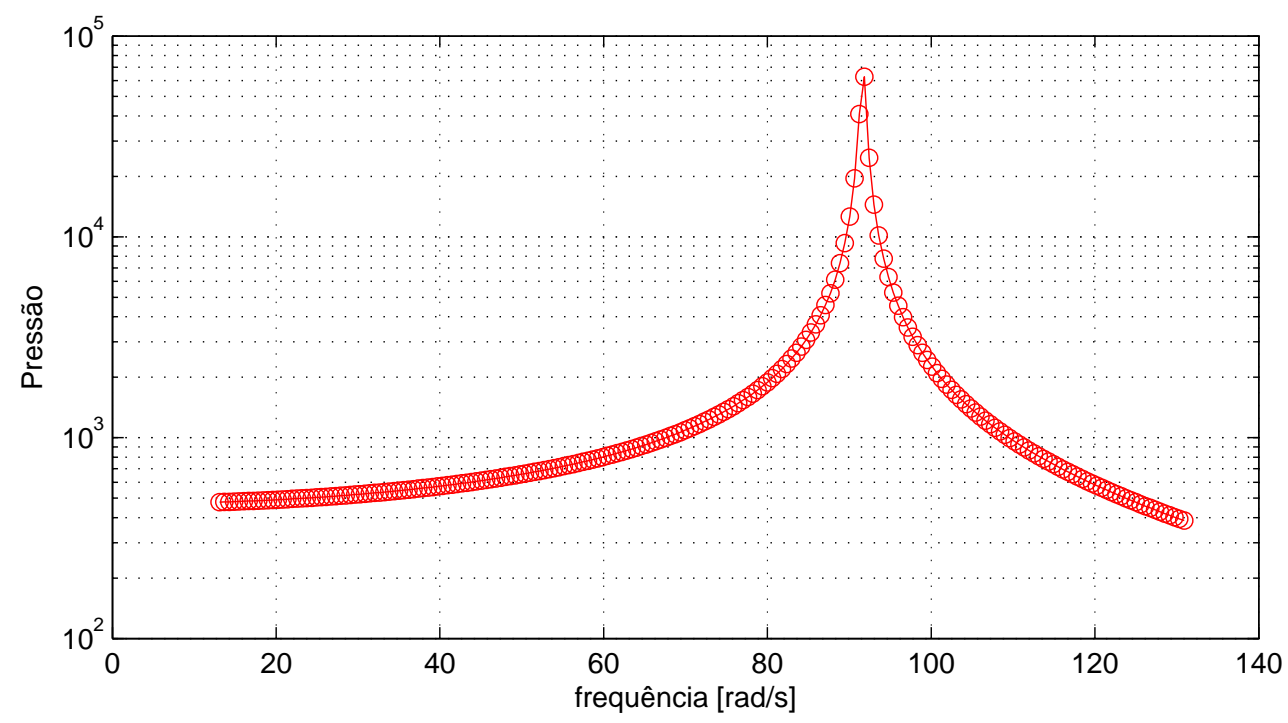

Figura 5.14: Resposta em frequência para a cavidade (v) 3D cúbica aberta-fechada 


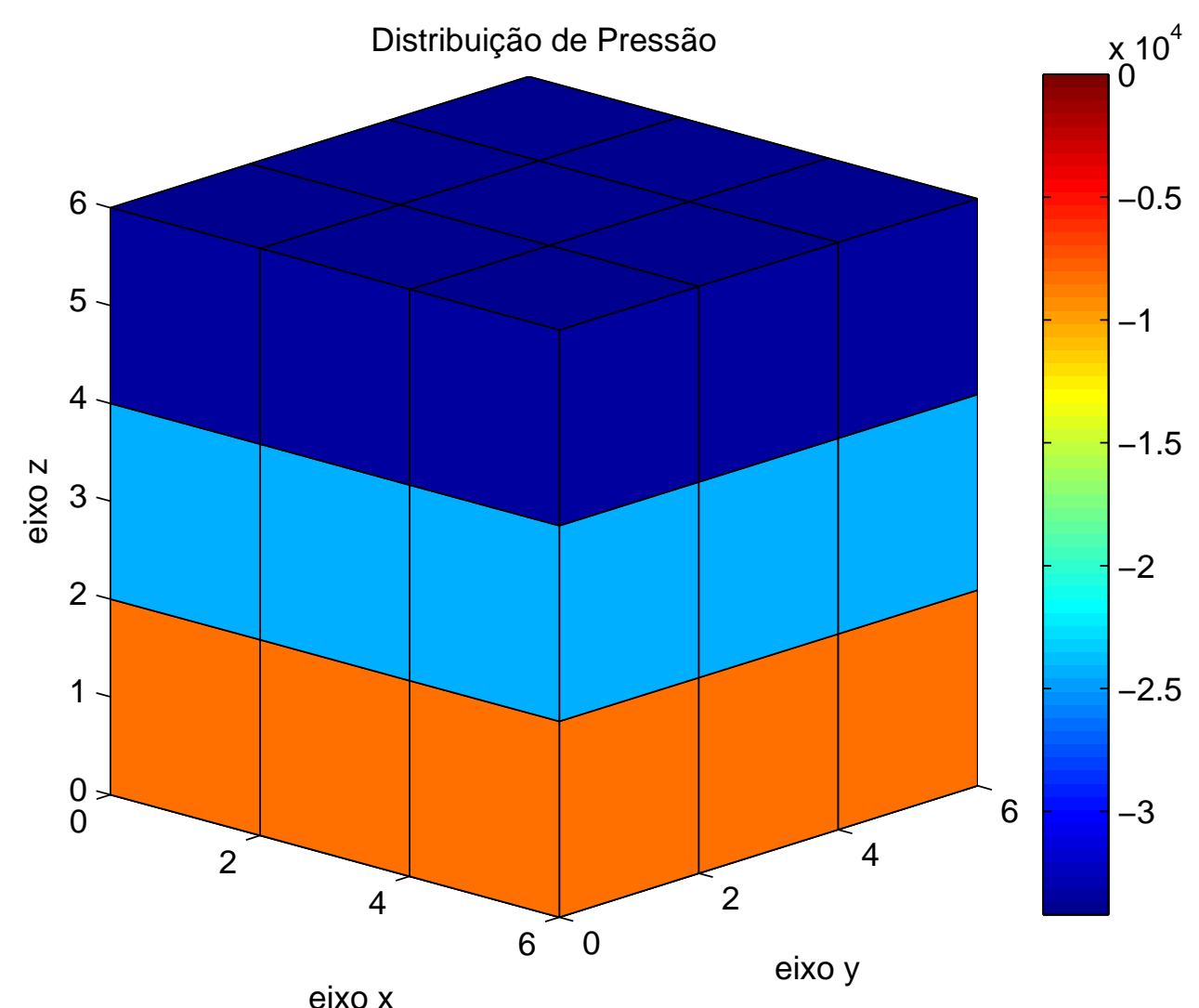

Figura 5.15: Modo identificado para a cavidade (v) 3D cúbica aberta-fechada

\subsubsection{Cavidade 3D longa fechada-fechada - Caso (vi)}

A cavidade (vi) é a representação tridimensional da cavidade (i) fechada em todos os lados unidimensional. A geometria pode ser descrita como a geometria da cavidade (i) com a inclusão de uma dimensão física de lado $1 \mathrm{~m}$. As condições de contorno para o gradiente de pressão são de parede fechada para todos os lados. A solução analítica para uma cavidade unidimensional fechada em todos os lados é dada por

$$
f_{\text {fechado-fechado }}=\frac{(2 \cdot \pi \cdot n) \cdot c}{2 \cdot L_{\text {tubo }}}, n=0,1,2,3, \ldots
$$

em que $c$ é a velocidade de propagação da onda, $n=0,1,2,3, \ldots$ são os números naturais e $L_{t u b o}$ é o comprimento do tubo estudado. A unidade de frequência é radianos por segundo $[\mathrm{rad} / \mathrm{s}]$. O primeiro modo, referente ao índice $n=0$, também chamado de modo de corpo rígido, não será mostrado neste trabalho. A figura 5.16 mostra a resposta em frequência obtida para as formas modais mostradas na figura 5.17. 


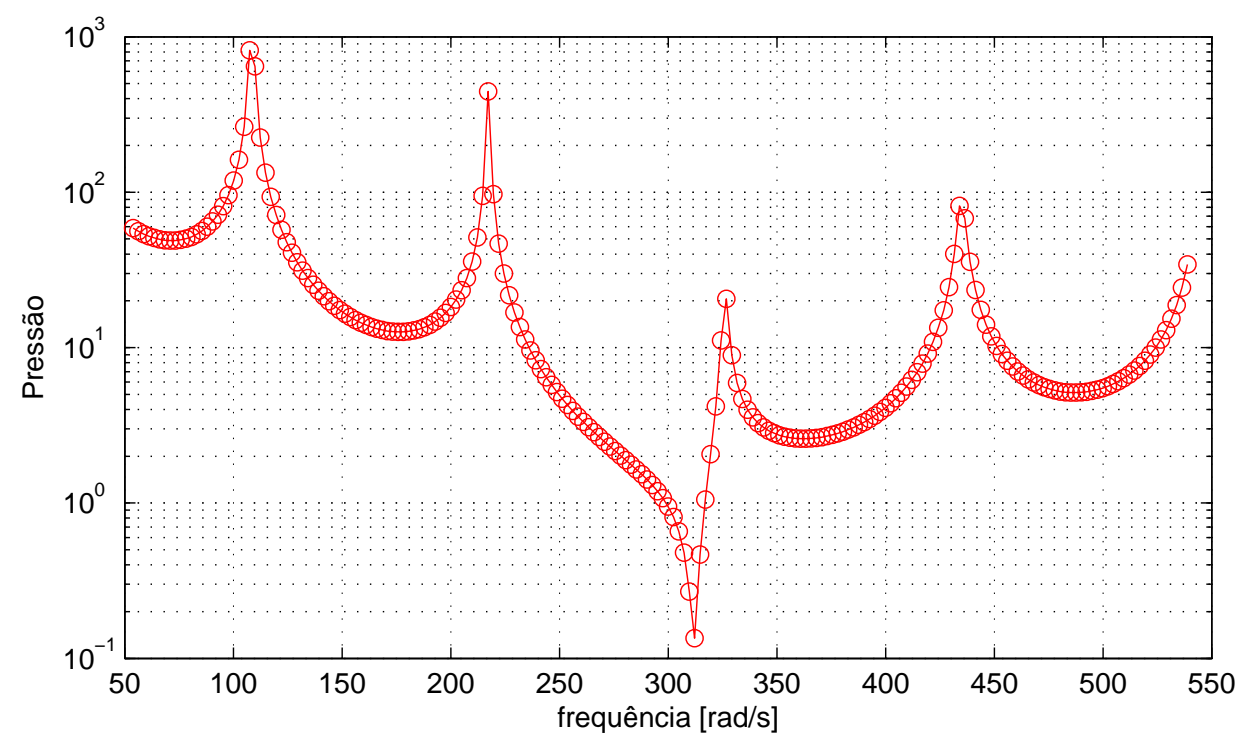

Figura 5.16: Resposta em frequência para a cavidade (vi) 3D longa fechada-fechada

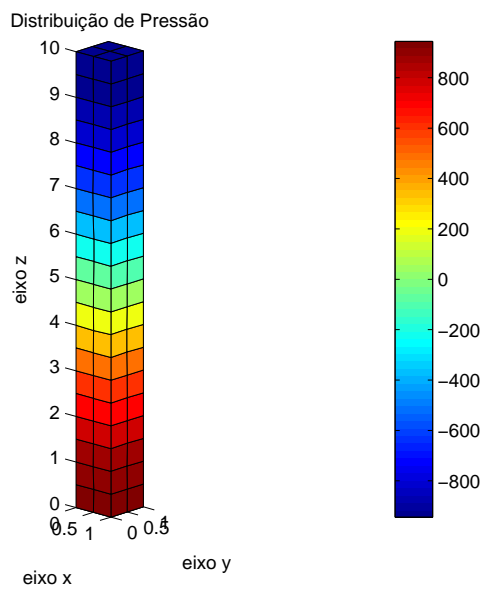

(a) Modo 1

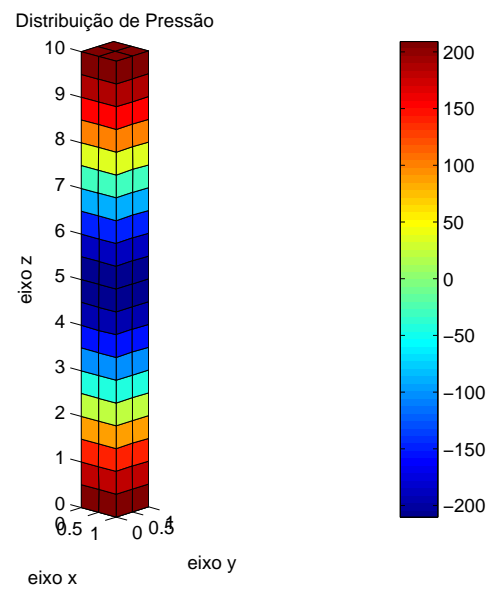

(b) Modo 2

Figura 5.17: Duas primeiras formas modais para a cavidade (vi) 3D longa fechada-fechada 


\section{Capítulo 6 CASOS ESTUDADOS}

Este capítulo apresenta os resultados numéricos obtidos para modelagem de geometria complexa. Esses casos referem-se a problemas acústicos ensaiados experimentalmente no Laboratório de Vibração do Grupo de Dinâmica de Sistemas (UnB - FT/EnM/GDS) e a resultados experimentais da literatura. Quando possível estes resultados são comparados a soluções analíticas.

\subsection{Cavidade de Auralização}

A cavidade de auralização para o estudo modal de cavidades é descrito por Tourinho (2011) mostrada na figura 6.1. Os resultados experimentais utilizados para a validação das soluções numéricas desenvolvidas são descritas em Melo (2013).

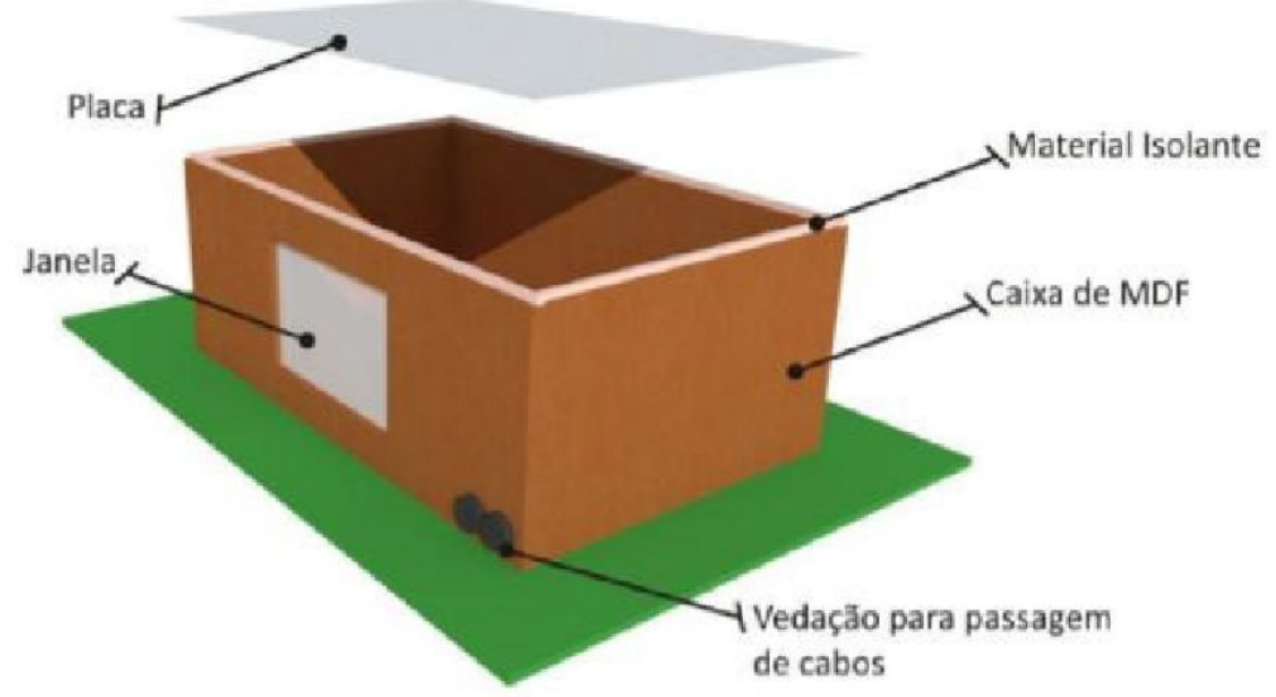

Figura 6.1: Cavidade de auralização

As dimensões da cavidade (tabela 6.1) (Fonseca et al., 2010) são função da razão áurea entre os eixos da cavidade garantindo uma melhor distribuição dos modos normais. Correspondente ao caso de cavidade rígida ensaida por Melo (2013), as condições de contorno da simulação estipula que todas as faces possuam condição de parede fechada $\left(\partial_{n} p=0\right)$. A 
fonte de excitação acústica localiza-se na abertura de passagem dos cabos, veja figura 6.1. Para modelar a excitação da cavidade, impõe-se uma condição de pistão $\left(\partial_{n} p=10\right)$ em um único elemento de contorno correspondente à abertura da passagem cabos.

Tabela 6.1: Dimensões da Cavidade de Auralização

\begin{tabular}{ll}
\hline Altura (eixo x) & $800 \mathrm{~mm}$ \\
\hline Largura (eixo y) & $500 \mathrm{~mm}$ \\
\hline Profundidade (eixo z) & $330 \mathrm{~mm}$ \\
\hline
\end{tabular}

O modelo tridimensional do MEF e uma solução analítica (Kinsler, 1982; Ferreira, 2012) serão comparadas ao presente modelo tridimensional do MEC. A solução analítica é mostrada na equação 6.1 .

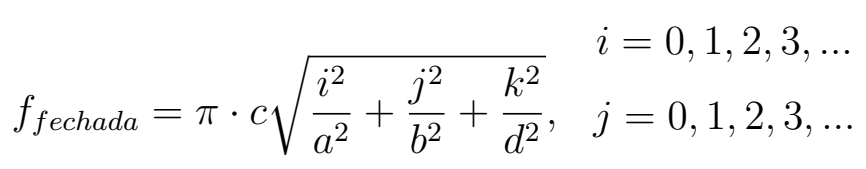

$$
\begin{aligned}
& k=0,1,2,3, \ldots
\end{aligned}
$$

Em que $a, b$ e $d$ são as dimensões da cavidade, $c$ é a velocidade de propagação de onda, $i=$ $0,1,2,3, \ldots$ são os números naturais e determinam o modo na direção de $a, j=0,1,2,3, \ldots$ são os números naturais e determinam o modo na direção de $b$, e $k=0,1,2,3, \ldots$ são os números naturais e determinam o modo na direção de $d$. Neste trabalho, os modos de corpo rígido, que correspondem a $i=0, j=0$ e $k=0$ não serão abordados.

Uma malha tridimensional do contorno da cavidade foi obtida utilizando o programa comercial GiD 11.0.7. A malha resultante possui 158 elementos quadrilaterais constantes (figura 6.3). A identificação modal foi realizada utilizando a resposta em frequência da cavidade, figura 6.2.

Uma extração modal foi realizada utilizando a resposta em frequência da cavidade acústica. Os primeiros modos foram comparados com a solução analítica e com os resultados experimentais (Melo et al., 2013). A primeira e segunda formas modais são mostradas nas figuras 6.4 e 6.5 respectivamente.

A tabela 6.2 resume os resultados de frequência natural do problema. 


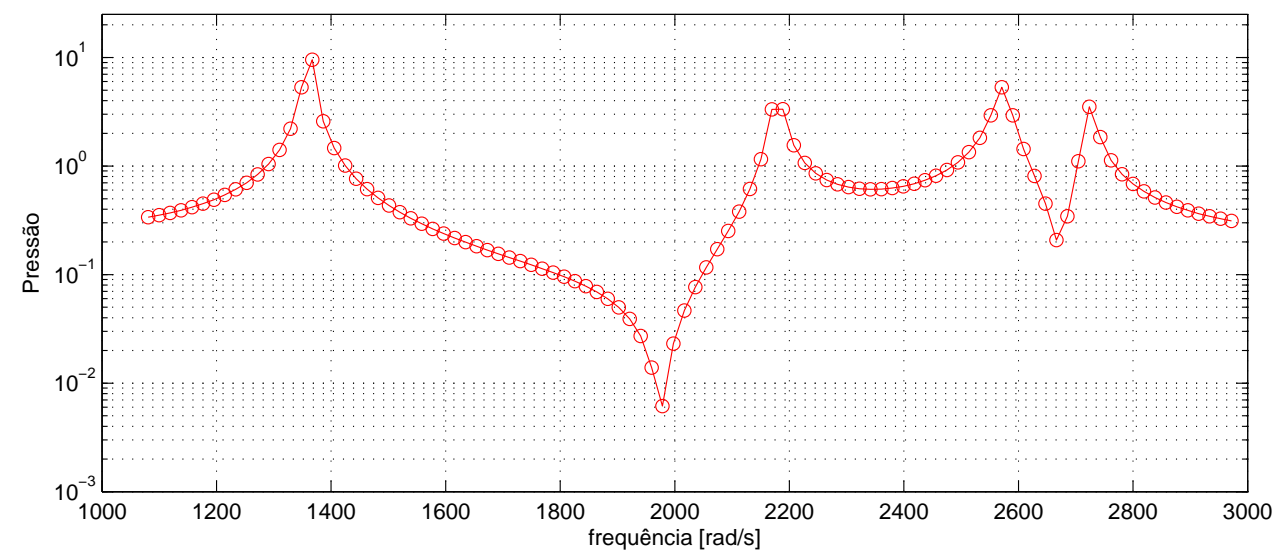

Figura 6.2: Resposta em frequência da cavidade de auralização discriminando os quatro primeiros modos de ressonância
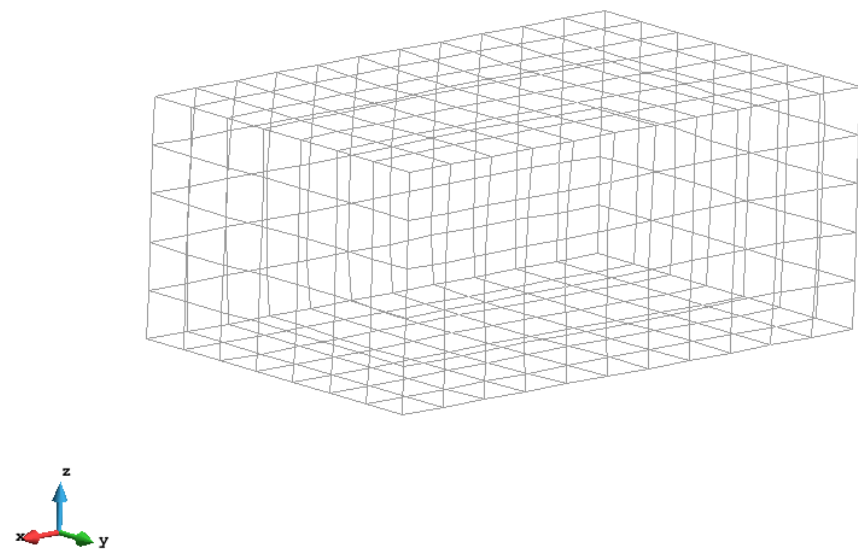

Figura 6.3: Malha em elementos de contorno para a cavidade de auralização

Tabela 6.2: Frequências de Ressonância da Cavidade de Auralização (Hz)

\begin{tabular}{lcccc}
\hline Modo & Solução Analítica & Experimental & MEF & MEC \\
\hline Primeiro & 215,6 & 213,4 & 215,9 & 217,6 \\
\hline Segundo & 345,0 & 346,8 & 345,4 & 348,3 \\
\hline Terceiro & 406,8 & 407,9 & 407,3 & 409,2 \\
\hline Quarto & 431,3 & 431,5 & 433,0 & 433,5 \\
\hline
\end{tabular}




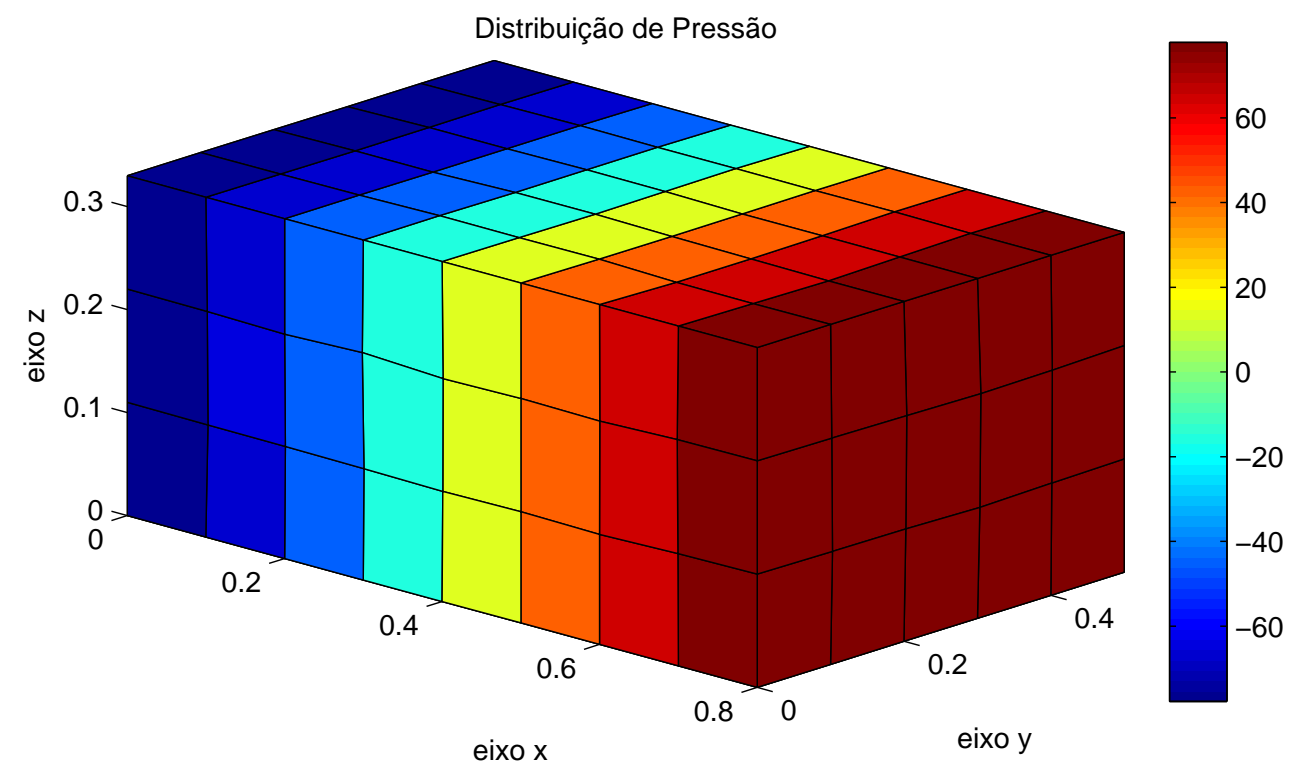

Figura 6.4: Primeira forma modal acústica da cavidade de auralização obtida por MEC

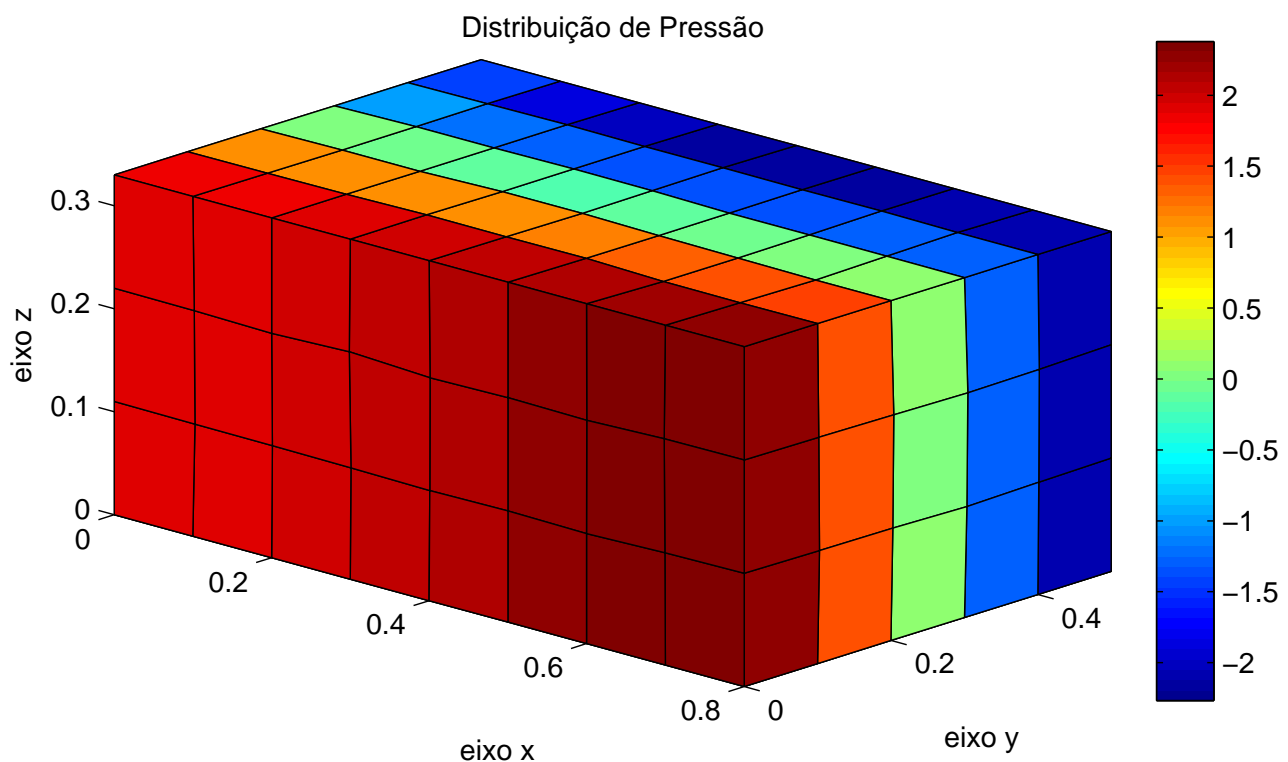

Figura 6.5: Segunda forma modal acústica da cavidade de auralização obtida por MEC 


\subsection{Acústica do trato vocal}

A acústica do trato vocal é uma área de estudo de grande importância para profissionais que usam a voz como instrumento de transmissão de ideias, tal como professores, oradores, cantores e profissionais do teatro. Uma voz ressonante (Titze, 2001) é uma característica desejável para obtenção de amplitude do som fonado com a ausência ou diminuição de um esforço excessivo nas pregas vocais. Tal característica ressonante da voz já é conhecida pelos estudantes do bel-canto e pelos profissionais do teatro. Mas sua produção ainda se baseia em sensações no corpo do agente fonador. Um estudo das propriedades acústicas do trato vocal e das características da chamada voz ressonante são um passo essencial para o avanço da tecnologia vocal e do ensino da voz falada para os profissionais que a utilizam. A figura 6.6 mostra um modelo esquemático para o sistema fonador, incluindo o trato vocal. Apenas a porção entre a glote e a boca serão abordados neste trabalho.

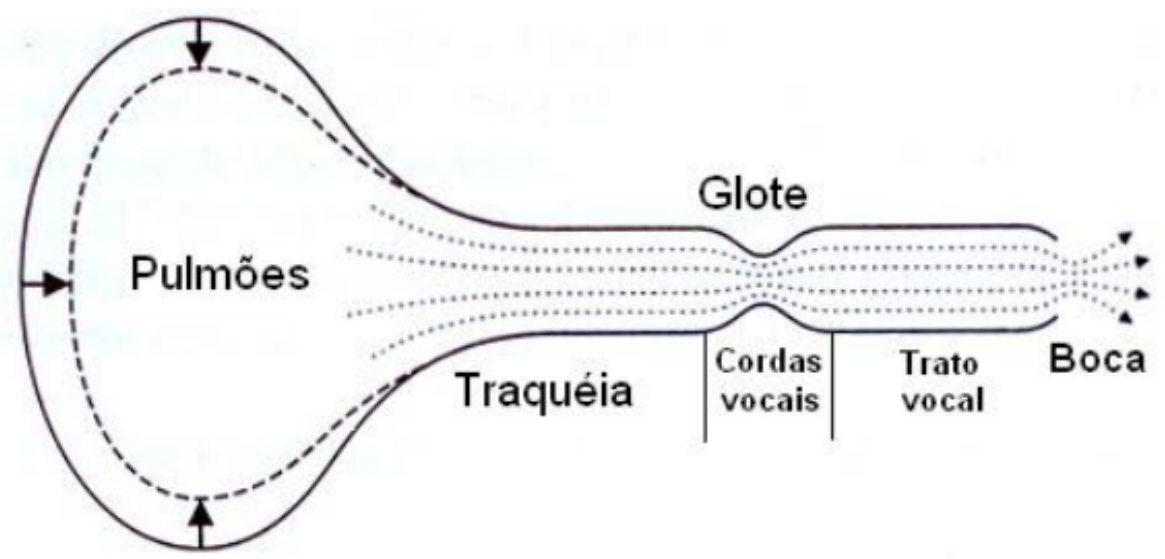

Figura 6.6: Modelo esquemático para o aparelho fonador (Cataldo et al., 2004)

A inertância é uma propriedade acústica de uma massa de ar, geralmente uma coluna de ar em um tubo, sendo acelerada por pressão acústica. Devido às características do fenômeno acústico, essa aceleração é oscilatória. Na vibração das pregas vocais, a coluna de ar acima da glote é acelerada pela pressão supraglotal. Apenas quando o harmônico fundamental (F0) da nota fonada está abaixo do primeiro formante que todas as partículas da coluna de ar se movem na mesma direção, com velocidades diferentes. Caso a fundamental (F0) esteja acima do primeiro formante, o ajuste com algum outro formante pode trazer a característica de inertância da coluna de ar de volta. A inertância ajuda tanto na fase de fechamento como na abertura das pregas vocais pois o movimento da coluna de ar está em fase com o movimento das pregas vocais, efeito esse que pode ser confundido com o efeito Bernoulli nas 
pregas vocais. Complacência é a propriedade da massa de ar de apresentar uma direção contrária na aceleração no volume de ar próximo da glote ao movimento das pregas vocais, que corresponde à porção fechada do trato vocal. Essa alteração dinâmica prejudica o movimento das pregas vocais e dificulta a adução, aumentando limiar de pressão para a fonação. Isso acontece principalmente por que essa alteração não está em fase com o movimento das pregas.

A inertância da voz pode ser alterada alterando-se a vogal fonada. Uma outra estratégia que não altera a vogal ou consoante fonada é a constrição do vestíbulo laríngeo (tubo epilaríngeo). Titze (2001) implementou um algoritmo para fazer aproximações de tratos vocais com diferentes configurações do tubo epilaríngeo, aberto e constrito, e da boca, aberta e fechada. O autor notou que a constrição do tubo epilaríngeo resultou em um aumento na faixa de inertância do trato vocal e diminuiu as faixas de complacência do trato. Um produto também dessa constrição foi o aparecimento de uma inertância maior na faixa associada ao formante do cantor $(\approx 3000 \mathrm{~Hz})$. O caso de forma de boca oclusa (boca fechada), o aumento da inertância na faixa de $300-1000 \mathrm{~Hz}$ mostra eficiente a adoção dessa posição para treinar as sensações do uso da inertância para auxiliar na adução das pregas. A conclusão final é a de manter F0 abaixo de F1 (boca aberta) ou muito acima de F1 e próxima de F2 (boca fechada) além de sempre manter o estreitamento do tubo epilaríngeo.

Um resultado semelhante foi obtido ao utilizar-se para o cálculo analítico dos formantes funções de área para vogais e fricativos bilabiais (Story et al., 2000). O trabalho procura identificar características acústicas do trato vocal para um modelo em semi-oclusão posterior e inferior do trato vocal, uso de fricativos bilabiais e uso de um tubo de pequeno diâmetro para auxiliar na fonação. Os resultados foram obtidos utilizando funções de área por unidade de comprimento do trato vocal para o cálculo das frequências de ressonância e o autor conclui que o uso desses tratos semi-oclusos com o uso de fricativos bilabiais ou constringidos e com comprimento aumentado artificialmente através do uso de tubos de pequeno diâmetro aumenta a impedância do trato e diminui o primeiro formante, o que ajuda a manter o trato vocal inertante durante a fonação e auxilia o agente fonador a manter o trato vocal inertante mesmo após a remoção desses auxílios. Esse resultado é corroborado com uma análise das características vocais e da geometria do trato vocal em Guzman et al. (2013). Um cantor treinado foi avaliado ao produzir uma vogal $\backslash a \backslash$ em uma nota confortável e foi analisado 
em uma tomografia computadorizada. Após quinze minutos de silêncio, o cantor produziu a vogal em um tubo de ressonância e depois produziu a vogal na máquina de tomografia novamente. Depois de outros quinze minutos de silêncio, o cantor fez exercícios utilizando o canudo e produziu a vogal novamente na máquina de tomografia. Durante e depois da fonação dentro do tubo de ressonância e do canudo, o velum fechou a passagem nasal melhor, a posição da laringe abaixou e a área da hipofaringe aumentou. O formante do cantor foi identificado mais proeminentemente após os exercícios no tubo e no canudo. O coeficiente de contato (contact quotient) diminuiu durante e depois dos exercícios com tubo e canudo, medido com um EGG (eletroglotograma). A pressão subglótica aumentou durante a fonação com o canudo e permaneceu alta depois. Nesse estudo, o autor chega à conclusão de que um aumento na impedância acústica durante a realização de exercícios levam a um aumento de eficiência e economia durante a fonação depois dos exercícios. Os resultados foram mais proeminentes com o uso do canudo.

O estudo da acústica de tratos vocais durante a fonação de vogais é abordada por Hannukainen et al. (2007) e Takemoto et al. (2010), em que os métodos de elementos finitos e de diferenças finitas foram utilizados, respectivamente, para resolver a equação da onda. Cavidades com geometria aproximada à geometria dos tratos vocais foram utilizadas. As figuras $6.7 \mathrm{a}$ e $6.7 \mathrm{~b}$ mostram a distribuição de pressão normalizada para o primeiro modo de ressonância das vogais $\backslash o \backslash \mathrm{e} \backslash a \backslash$ respectivamente.

O estudo de uma geometria aproximada para o trato vocal pode ser realizado utilizando imagens obtidas através de máquinas de ressonância magnética. Em Clement et al. (2007), o autor tem como objetivo avaliar se o uso de imagens obtidas com o uso de Ressonância Magnética (Magnetic Resonance Imaging - MRI) na obtenção da geometria da cavidade do trato vocal com o objetivo de simular as características acústicas de vogais, principalmente na identificação dos três primeiros formantes, que alteram mais proeminentemente a vogal fonada. Como a teoria para a ressonância do trato vocal é unidimensional, apenas duas dimensões são essenciais para a obtenção das características acústicas do trato vocal: comprimento do trato e função de área para o cálculo do volume do tubo (área transversal do tubo). 


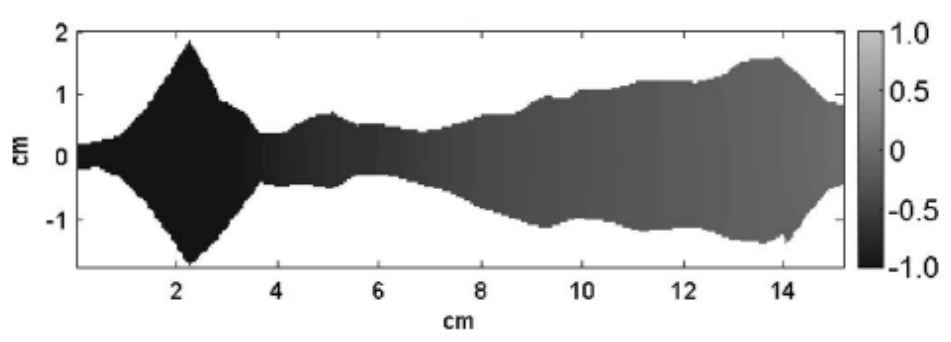

(a) Vogal $\backslash o \backslash$ Hannukainen et al. (2007)

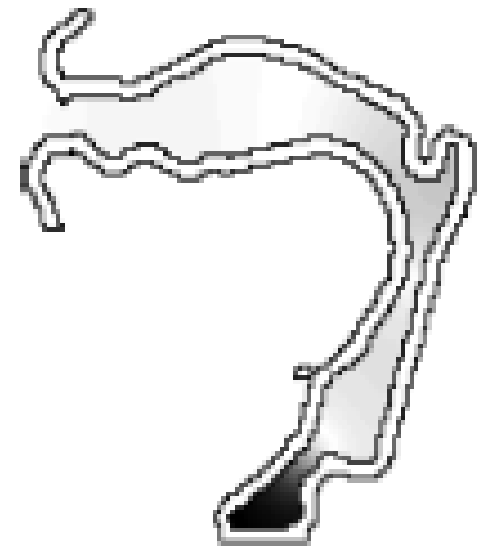

(b) Vogal $\backslash a \backslash$ Takemoto et al. (2010)

Figura 6.7: Distribuição de pressão normalizada para o primeiro modo das vogais $\backslash o \backslash \mathrm{e} \backslash a \backslash$ obtidas respectivamente por Hannukainen et al. (2007) e Takemoto et al. (2010)

A partir das informações obtidas para a geometria do trato vocal de Clement et al. (2007), os resultados dos modelos do MEC e do método da Matriz de Transferência foram obtidos para caracterizar a cavidade do trato vocal e avaliar as formas modais e as frequências de ressonância acústica do mesmo. Duas vogais foram caracterizadas no presente trabalho: $\backslash a \backslash$ e $\backslash u \backslash$. Uma malha tridimensional foi obtida utilizando o pacote comercial GiD versão 11.0.7 contendo 292 elementos constantes quadrilaterais correspondendo à geometria descrita para a vogal $\backslash a \backslash$. A malha pode ser visualizada na figura 6.8. A malha para a vogal $\backslash u \backslash$ foi construída de forma semelhante, possui 619 elementos constantes quadrilaterais e pode ser visualizada na figura 6.9 .

Para construir as malhas, o comprimento total do trato vocal foi estimado como descrito no artigo, em que cada seção transversal correspondia a um corte com um centímetro de distância do anterior. As áreas foram aproximadas por seções quadradas, então cada lado possui o valor da raiz quadrada do valor da área mostrado na tabela 6.3.

A tabela 6.4 compara as primeiras frequências naturais obtidas para os três exemplos de cavidade com relação aos resultados de Clement et al. (2007) e a solução analítica por Matriz de Transferência. Para a vogal $\backslash a \backslash$ primeira forma modal pode ser observada na figura 6.11 para a frequência de $f_{1} \approx 816 \mathrm{~Hz}$. O segundo modo $f_{2} \approx 1766 \mathrm{~Hz}$ é apresentado na figura 6.12. O terceiro modo é mostrado na figura 6.13. O gráfico de resposta em frequência para vogal $\backslash a \backslash$ pode ser visto na figura 6.10 . 
Tabela 6.3: Área da seção transversal do trato vocal para diferentes vogais $\left[\mathrm{cm}^{2}\right]$

\begin{tabular}{crrr}
\hline Número do corte & $\backslash a \backslash$ & $\backslash i \backslash$ & $\backslash u \backslash$ \\
\hline 1 & 1.8 & 3.0 & 1.4 \\
2 & 1.8 & 3.7 & 3.4 \\
3 & 2.8 & 4.5 & 6.6 \\
4 & 1.5 & 6.6 & 8.7 \\
5 & 0.8 & 9.3 & 9.8 \\
6 & 1.3 & 10.3 & 9.2 \\
7 & 1.5 & 9.4 & 7.6 \\
8 & 1.7 & 7.5 & 5.8 \\
9 & 2.8 & 4.5 & 4.4 \\
10 & 4.5 & 1.4 & 2.3 \\
11 & 7.1 & 0.6 & 0.7 \\
12 & 9.3 & 0.4 & 1.5 \\
13 & 13.5 & 0.3 & 3.9 \\
14 & 15.5 & 2.2 & 8.6 \\
15 & 7.8 & & 6.9 \\
16 & & & 1.5 \\
17 & & & 1.3 \\
\hline
\end{tabular}
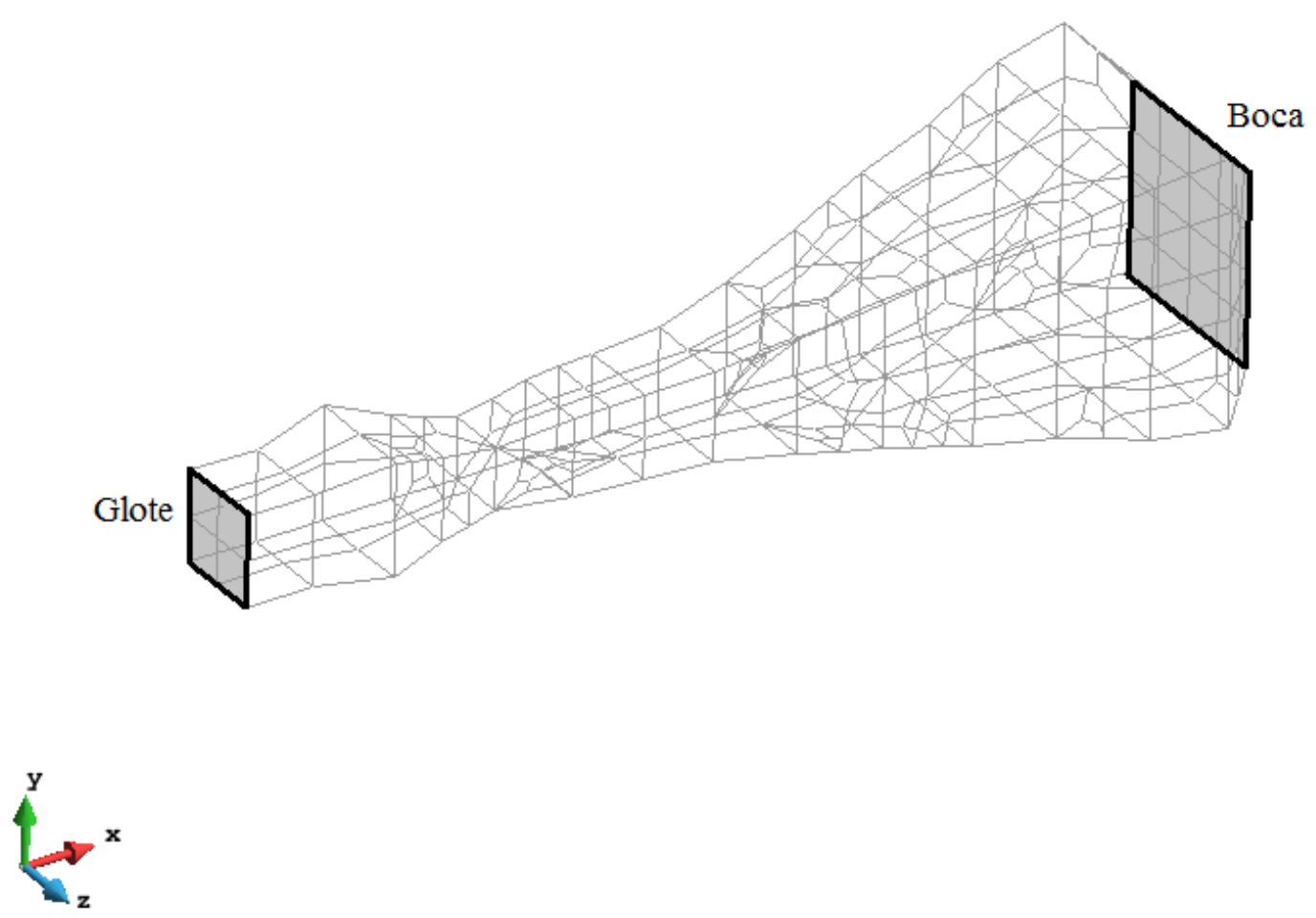

Figura 6.8: Malha desenvolvida para a cavidade do trato vocal durante a fonação da vogal $\backslash a \backslash$ 


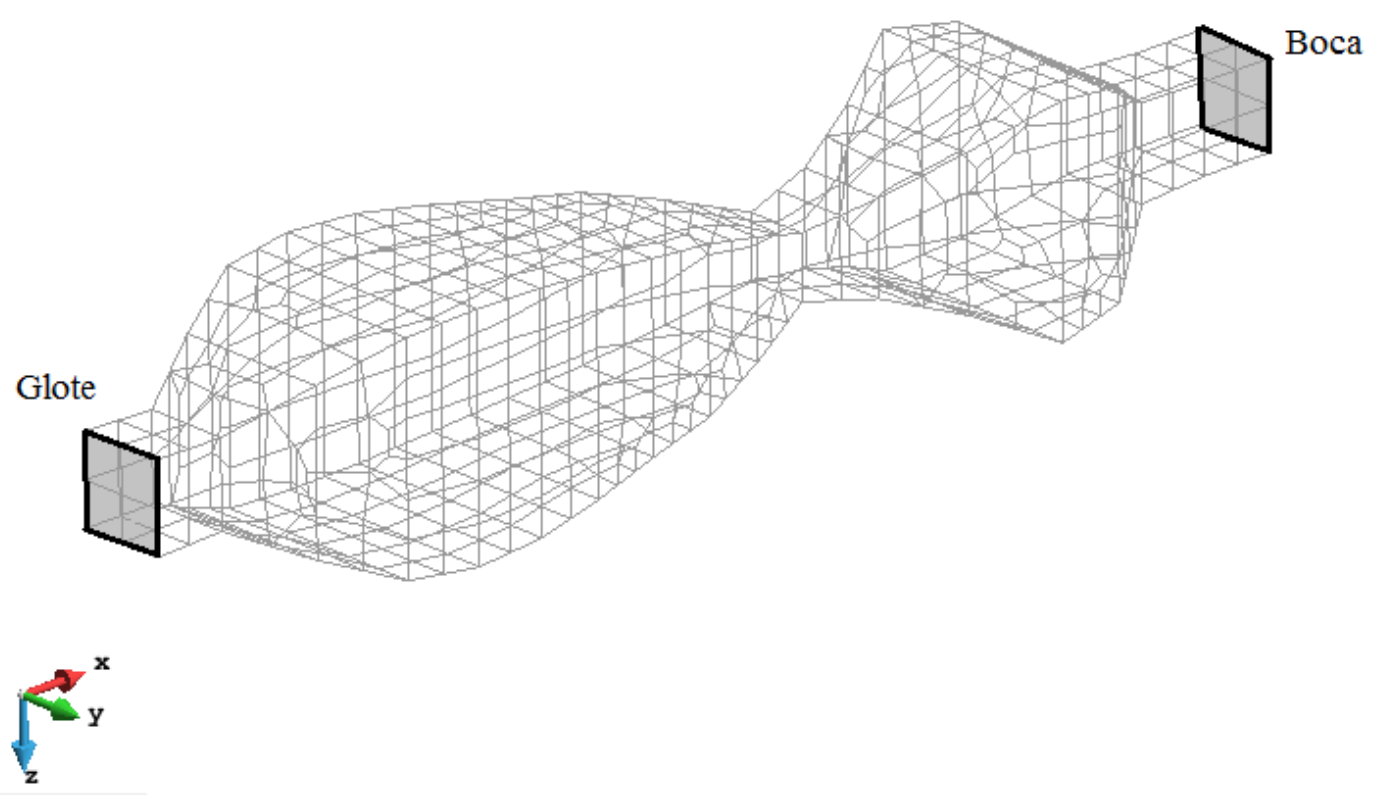

Figura 6.9: Malha desenvolvida para a cavidade do trato vocal durante a fonação da vogal $\backslash u \backslash$

Tabela 6.4: Frequências Naturais para os modos de Ressônancia do trato vocal para diferentes vogais

\begin{tabular}{lrrr}
\hline \multicolumn{5}{c}{ Primeiro Modo } \\
\hline \multicolumn{5}{c}{ Clement [Hz] } & Matriz de Trasnferência [Hz] & MEC [Hz] \\
Vogal $\backslash a \backslash$ & 774 & 774 & 804 \\
Vogal $\backslash u \backslash$ & 340 & 323 & 320 \\
\hline \multicolumn{4}{c}{ Segundo Modo } \\
\hline \multicolumn{5}{c}{ Clement [Hz] } & Matriz de Transferência [Hz] & MEC [Hz] \\
Vogal $\backslash a \backslash$ & 1300 & 1580 & 1767 \\
Vogal $\backslash u \backslash$ & 1114 & 1182 & 1145 \\
\hline \multicolumn{5}{c}{ Terceiro Modo } \\
\hline Vogal $\backslash a \backslash$ & Clement [Hz] & Matriz de Transferência [Hz] & MEC [Hz] \\
Vogal $\backslash u \backslash$ & 2724 & 2852 & 2814 \\
\hline
\end{tabular}




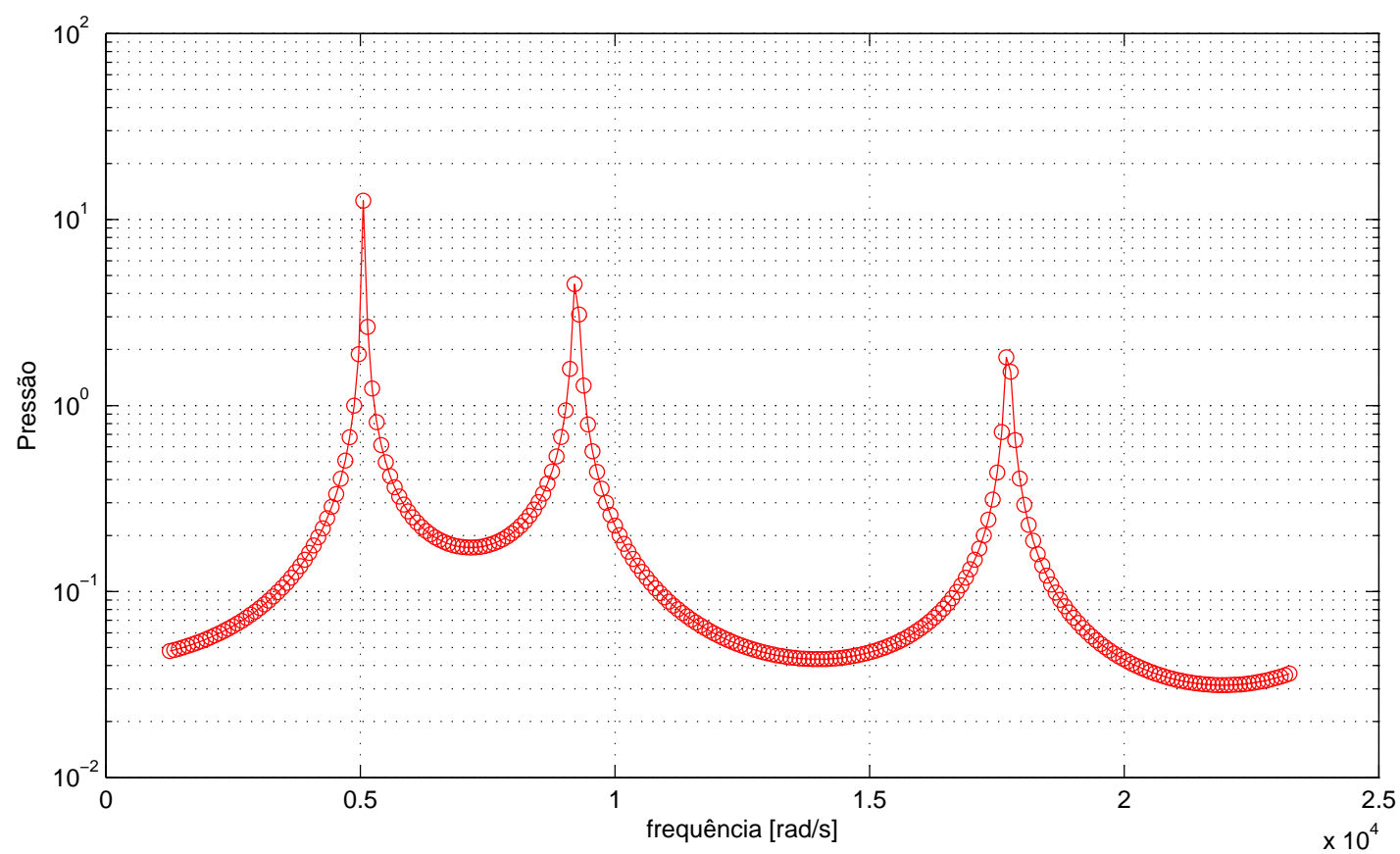

Figura 6.10: Resposta em frequência para a cavidade do trato vocal durante a fonação da vogal $\backslash a \backslash$ identificando os três primeiros modos de ressonância

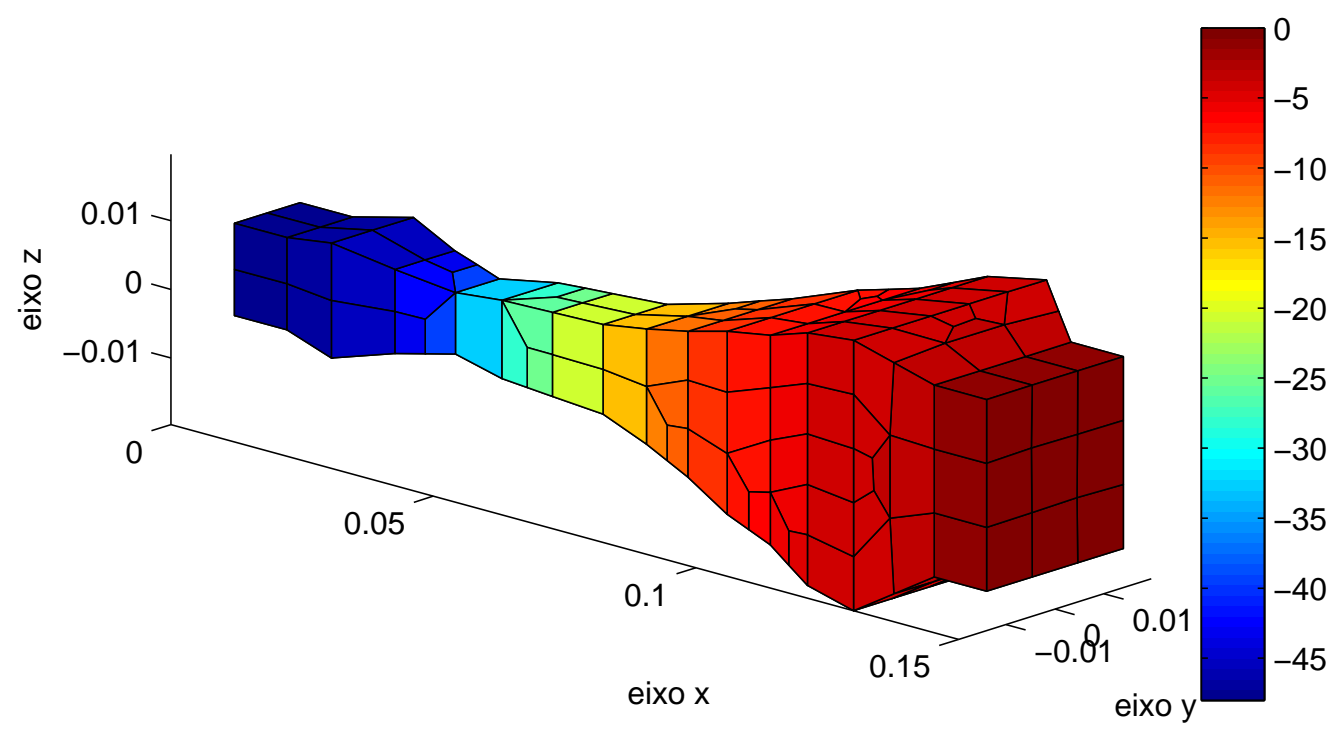

Figura 6.11: Primeira forma modal para a cavidade do trato vocal durante a fonação da vogal $\backslash a \backslash$ 


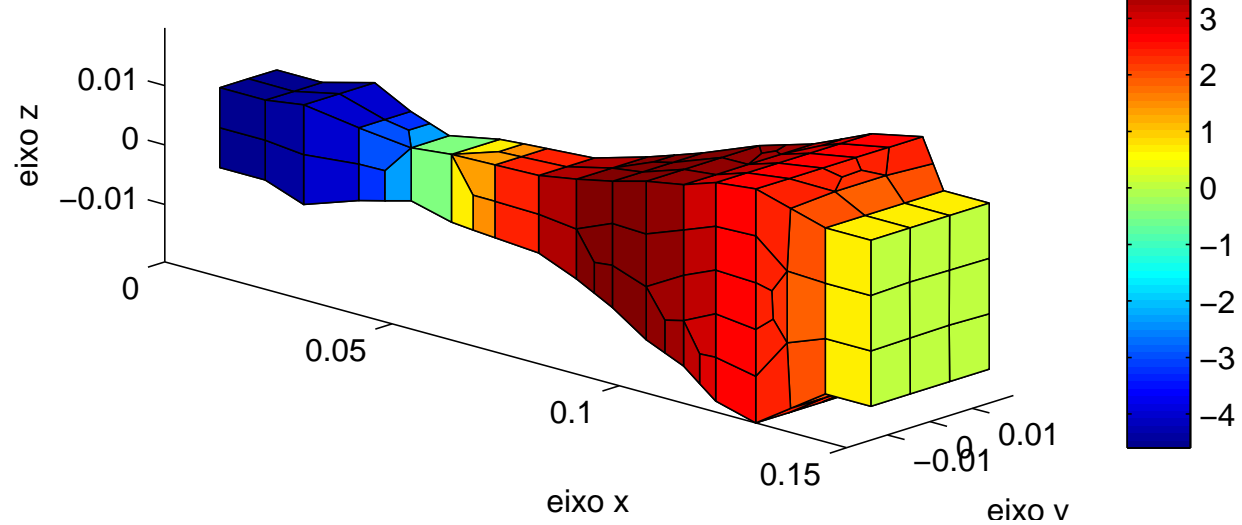

Figura 6.12: Segunda forma modal para a cavidade do trato vocal durante a fonação da vogal $\backslash a \backslash$

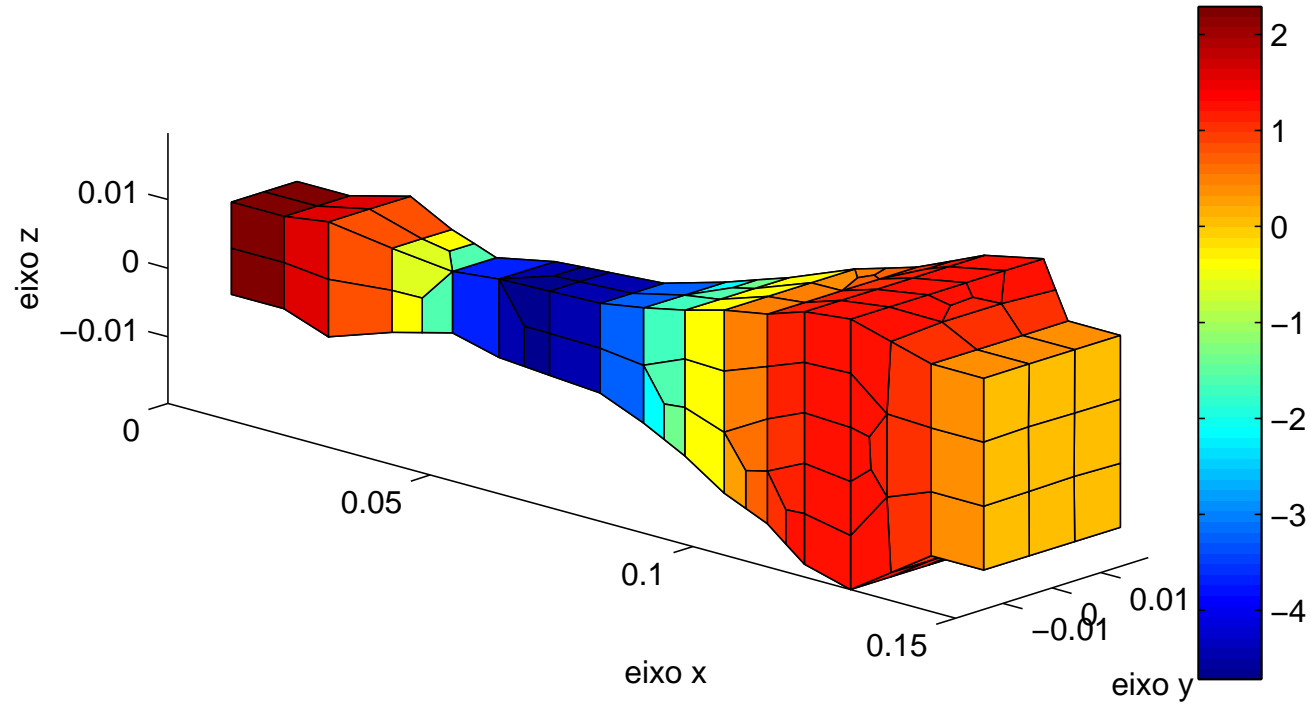

Figura 6.13: Terceira forma modal para a cavidade do trato vocal durante a fonação da vogal $\backslash a \backslash$ 
O gráfico de resposta em frequência para a vogal $\backslash u \backslash$ é apresentado na Figura 6.17 e a forma modal dos três primeiros modos são mostradas na figuras $6.14-6.16$.

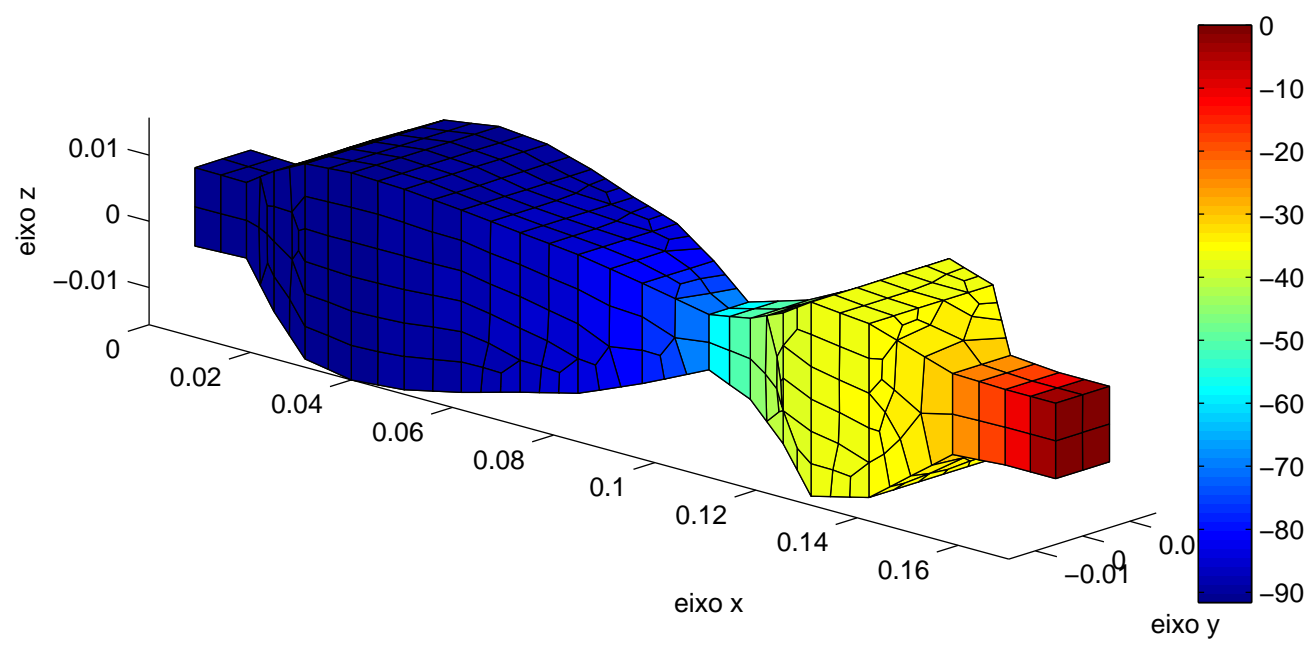

Figura 6.14: Primeira forma modal para a cavidade do trato vocal durante a fonação da vogal $\backslash u \backslash$

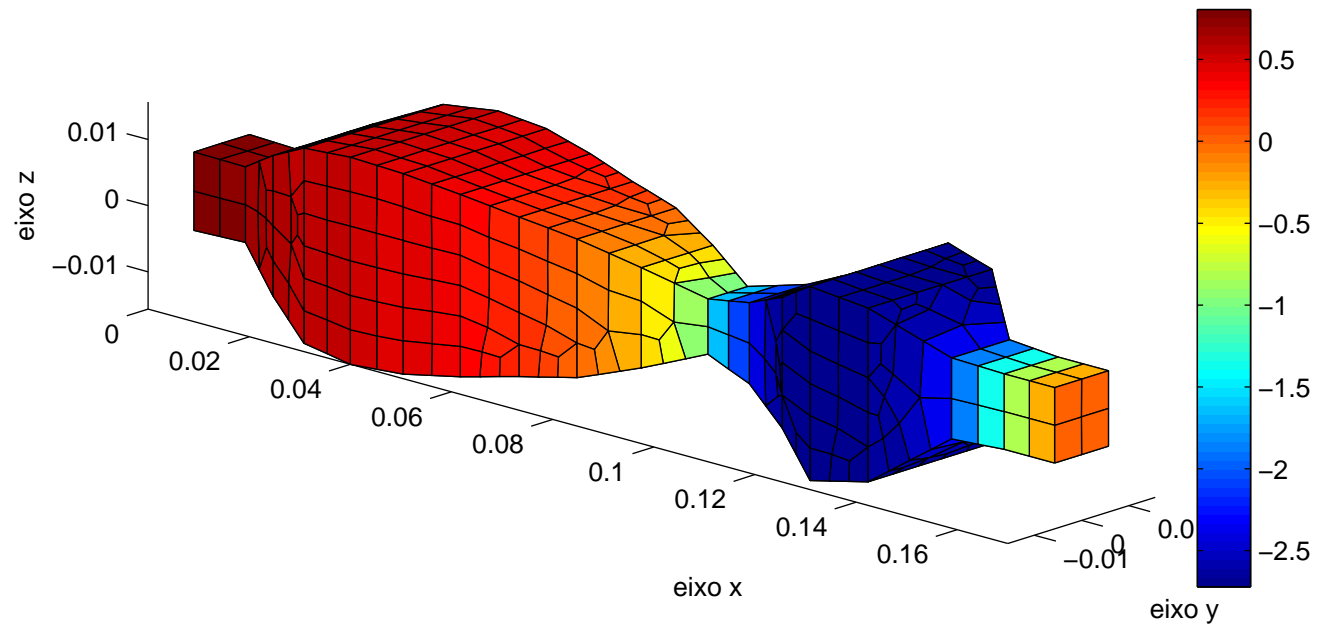

Figura 6.15: Segunda forma modal para a cavidade do trato vocal durante a fonação da vogal $\backslash u \backslash$ 


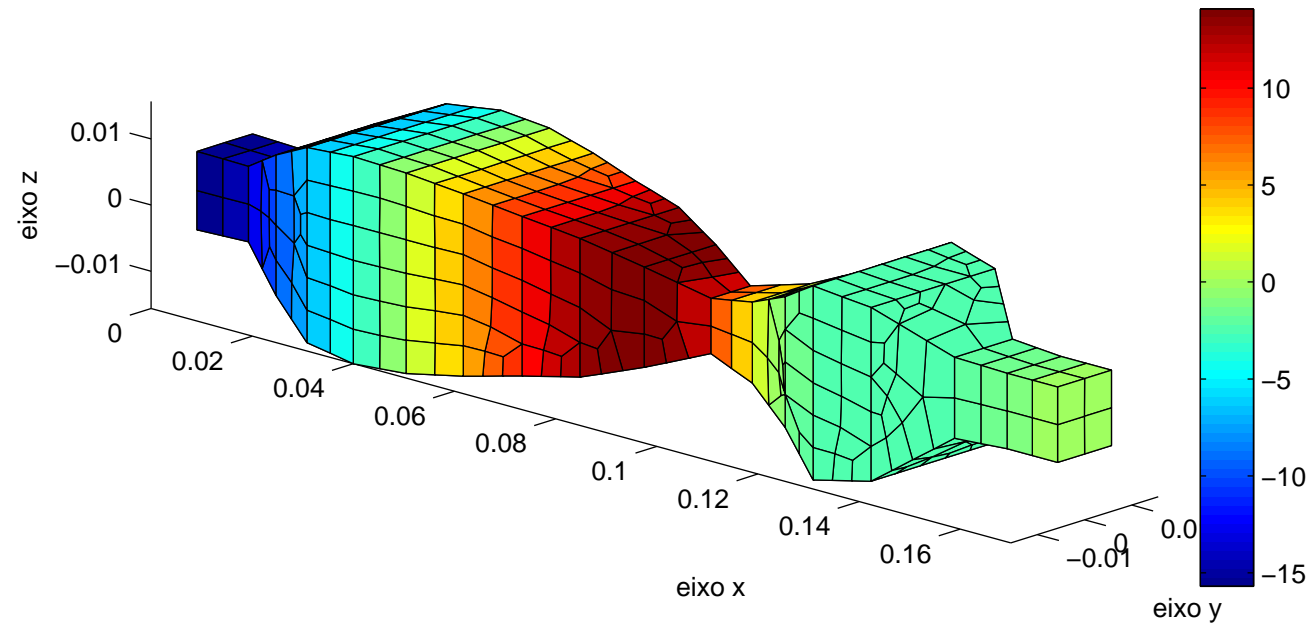

Figura 6.16: Terceira forma modal para a cavidade do trato vocal durante a fonação da vogal $\backslash u \backslash$

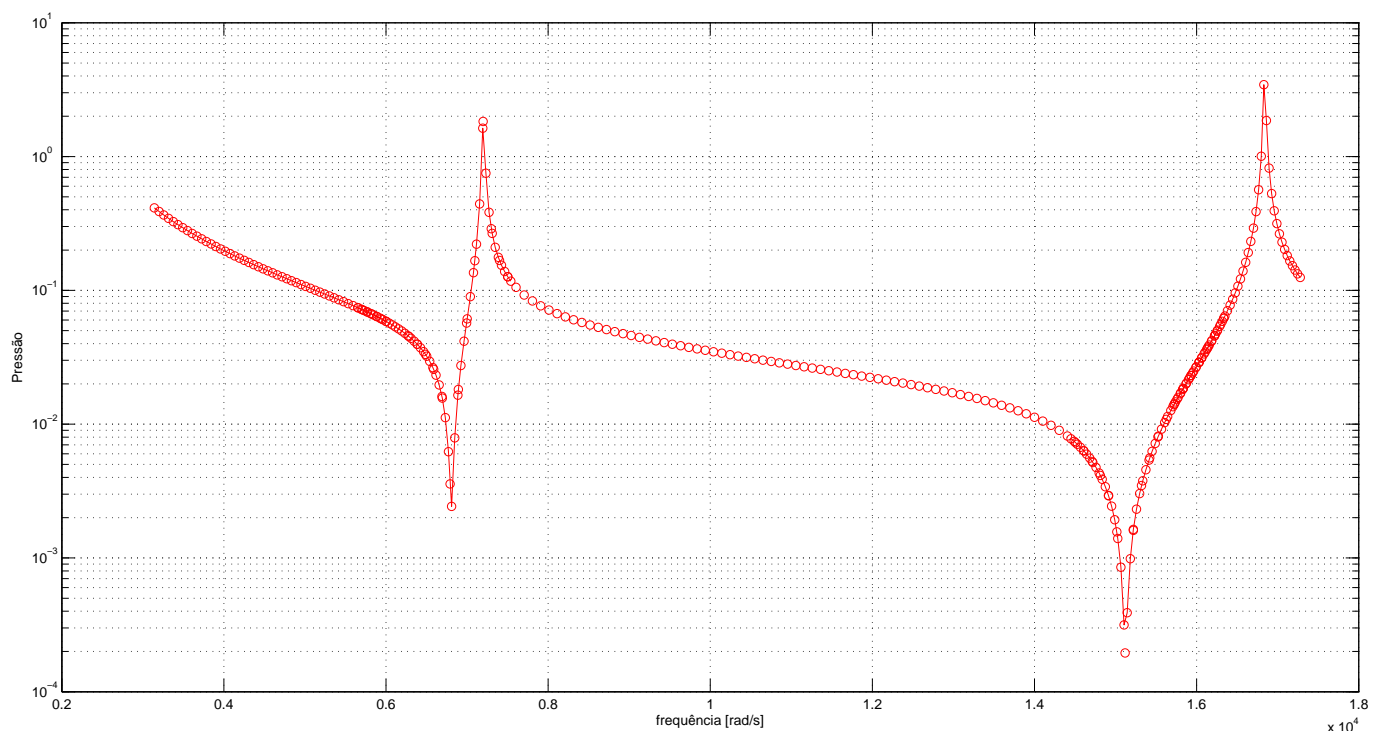

Figura 6.17: Resposta em frequência para a cavidade do trato vocal durante a fonação da vogal $\backslash u \backslash$ 


\subsection{Cavidade de um Motor de Foguete Híbrido}

Foguetes de propulsão híbrida tem o potencial de serem mais seguros, flexíveis e de menor custo comparado com outros tipos de propulsão líquida. Esse tipo de motor pode ser acionado, parado e reiniciado. As vantagens do foguete híbrido em comparação com seus concorrentes deriva do fato de que motores híbridos utilizam um sistema de propulsão de duas fases, o que também traz alguns desafios que devem ser abordados para evitar suas instabilidades. Motores de propulsão híbrida utilizam combustível na fase sólida e oxidantes de fase gasosa ou líquida. Como o fluxo do oxidante pode ser controlado separadamente do combustível, esse tipo de motor é dotado de flexibilidade e segurança.

A amplitude das oscilações (instabilidade) de pressão observados nesse tipo de foguete são delimitadas. Essas oscilações geram taxas de queima imprevisíveis e introduzem oscilações no torque do foguete. M. Stoia-Djeska (2011) sugerem que a interação entre ondas acústicas e a combustão causa uma instabilidade de oscilação acústica retroalimentada.

Para verificar essa assertiva, um estudo das características acústicas de um motor de propulsão híbrida é proposto utilizando o MEC e o MEF, além de soluções analíticas de modelos aproximados utilizando o método de matriz de transferência. Essa caracterização vai considerar inicialmente a cavidade com ar frio, ou seja, com a velocidade do som tal qual em condições ambientes. Caracterizações com cavidades em ar quente, tal como o foguete opera, não são desenvolvidas neste trabalho, mas são sugeridas como trabalhos futuros.

A figura 6.18 expõe as dimensões principais do motor utilizado. A partir do modelo do motor híbrido realizam-se estudos numéricos, analíticos e experimentais. Os componentes principais do motor podem ser observados na figura 6.19 : (1) Tubeira, (2) Parafusos para junção das flanges, (3) Flange do injetor, (4) Flange da tubeira, (5) Envelope do motor, (6) Sistema de injeção. Mais informações sobre o motor podem ser encontradas em Câmara et al. (2013).

Os ensaios experimentais foram feitos utilizando um falante Driver JBL Selenium D220T I8 $\Omega$ com uma frequência de banda larga (frequency broadband) de $20-20000 \mathrm{~Hz}$, um gerador de sinal senoidal HP 33120A e dois microfones Brüel \& Kjaer 194537 conectado a um 
amplificador de sinal Brüel \& Kjaer NEXUS. A aquisição de dados foi realizada utilizando as placas National Instruments CompactDAQ NI 9174 e NI 9234 interfaceadas por uma rotina LabView. Para determinar a frequência máxima observada, a existência de apenas ondas planas foi considerada, uma vez que o uso de uma fonte calibrada considera que a fonte seja um monopolo (Rossetto, 2001). O valor da coêrencia do sinal foi utilizado para definir a frequência mínima observada.

Os modelos de elementos de contorno foram desenvolvidos incialmente para uma cavidade com diâmetro de $140 \mathrm{~mm}$ acoplado a uma tubeira cuja geometria é conhecida. A malha gerada possui 992 elementos quadráticos constantes. Uma varredura de frequência foi realizada para obter as frequências de ressonância e o gráfico de resposta em frequência pode ser visto na figura 6.20. A primeira forma modal de ressonância é mostrada na figura 6.21, a segunda forma modal na figura 6.22, e a terceira forma modal na figura 6.23. A frequência encontrada para a primeira forma modal por MEC foi de $f_{1} \approx 76.55 \mathrm{~Hz}$. Os resultados obtidos analiticamente, através da matriz de transferência, numericamente, através do MEF e do MEC foram comparados com os resultados experimentais (Ferreira et al., 2013) na tabela 6.5. Como podemos observar, os resultados obtidos utilizando o MEC foram satisfatórios, mesmo considerando que o modelo criado não obedece a característica circular uniforme da geometria real.

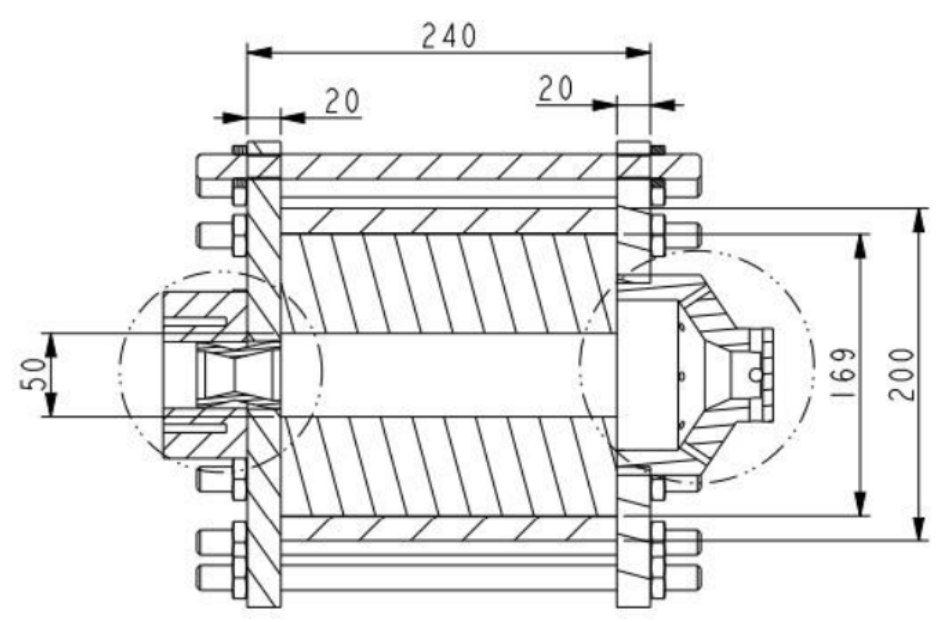

Figura 6.18: Dimensões principais do motor híbrido estudado 


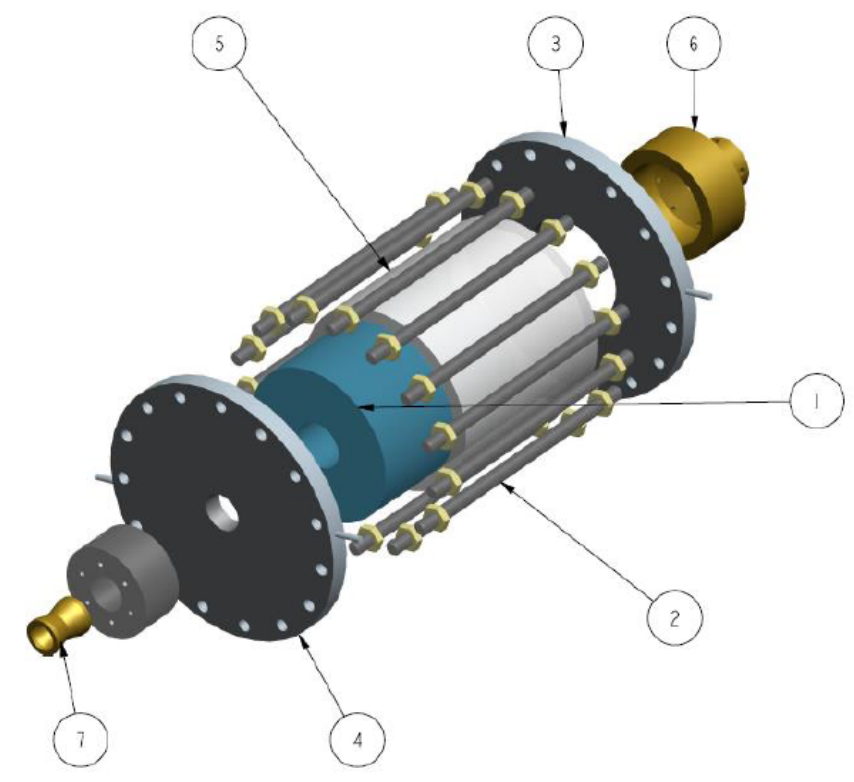

Figura 6.19: Vista explodida mostrando os componentes principais do motor híbrido estudado

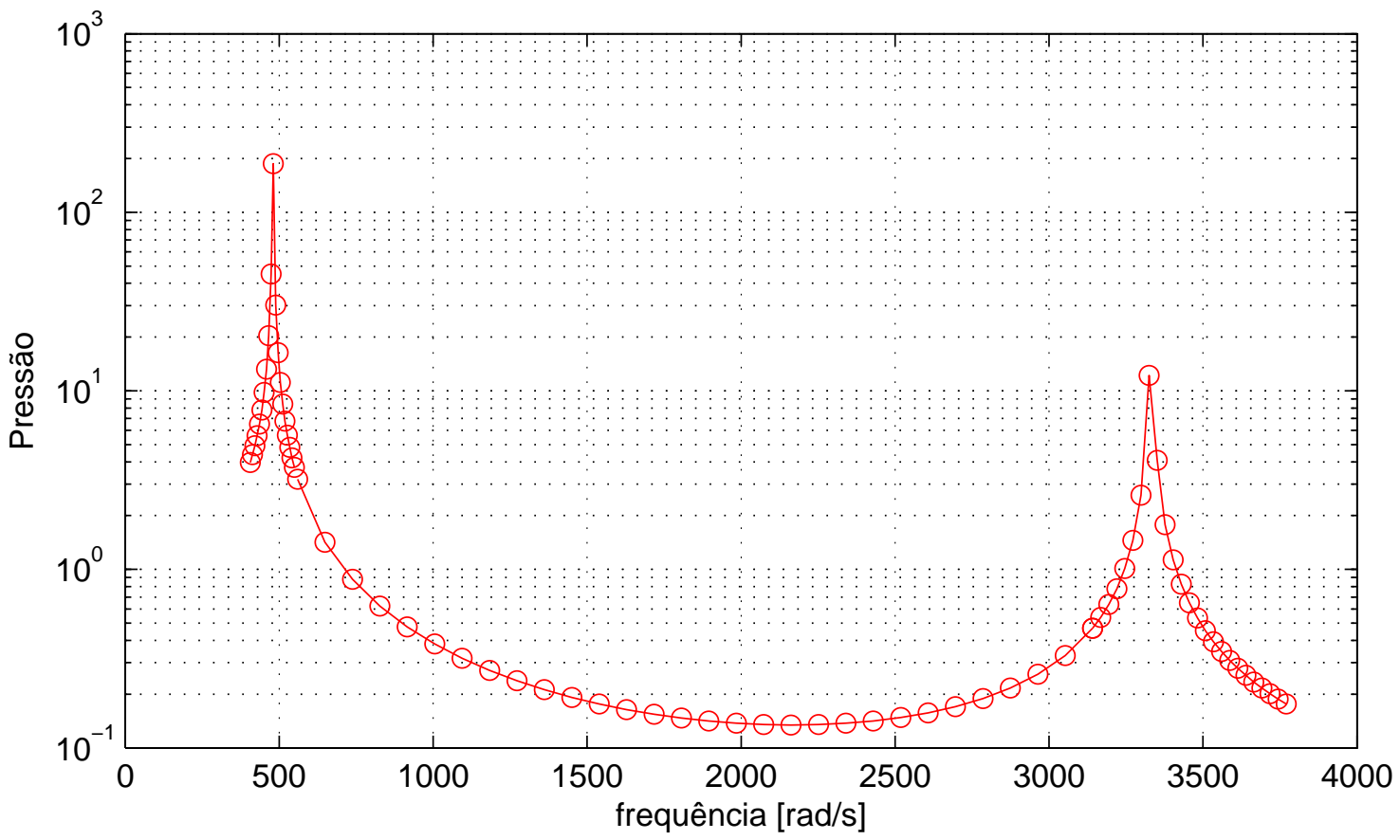

Figura 6.20: Resposta em frequência para a cavidade do motor de foguete híbrido 


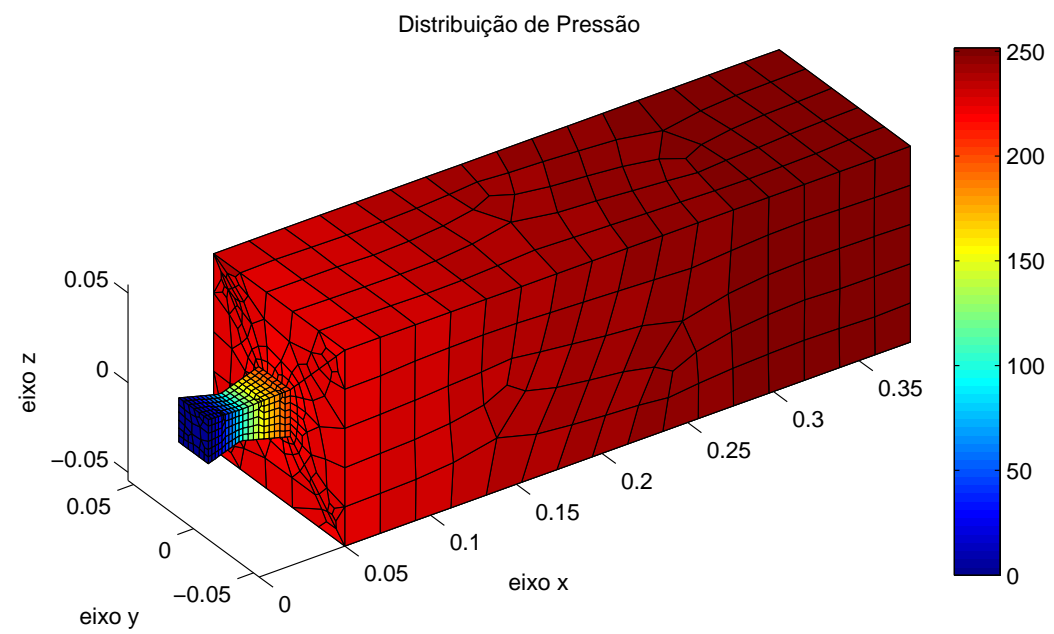

Figura 6.21: Primeira forma modal para a cavidade do motor de foguete híbrido

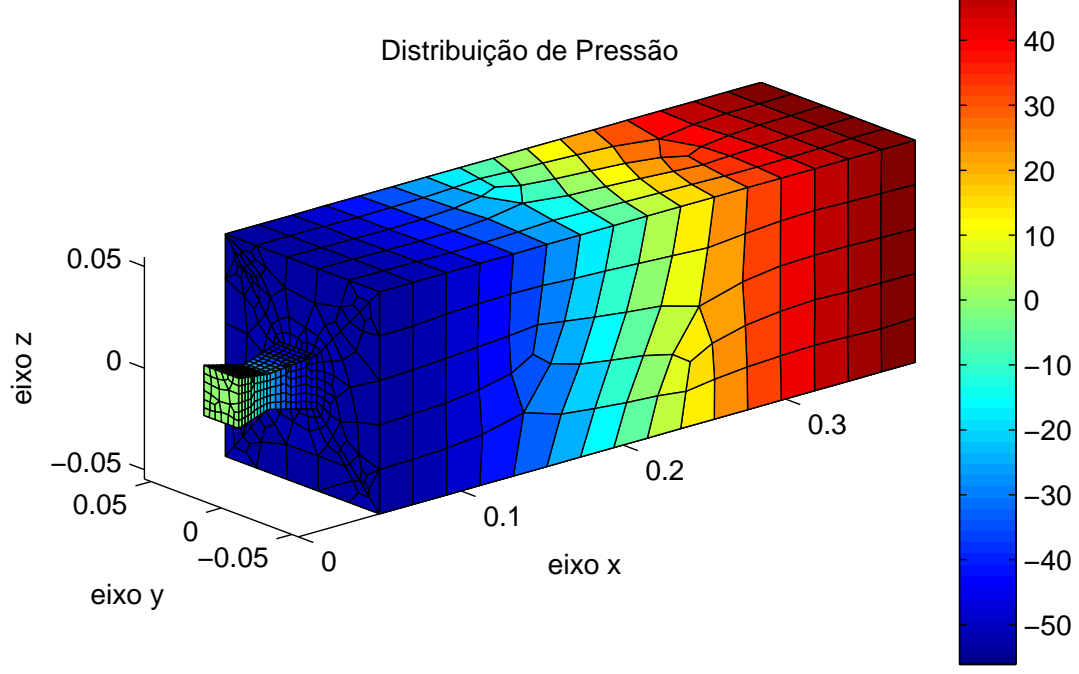

Figura 6.22: Segunda forma modal para a cavidade do motor de foguete híbrido 


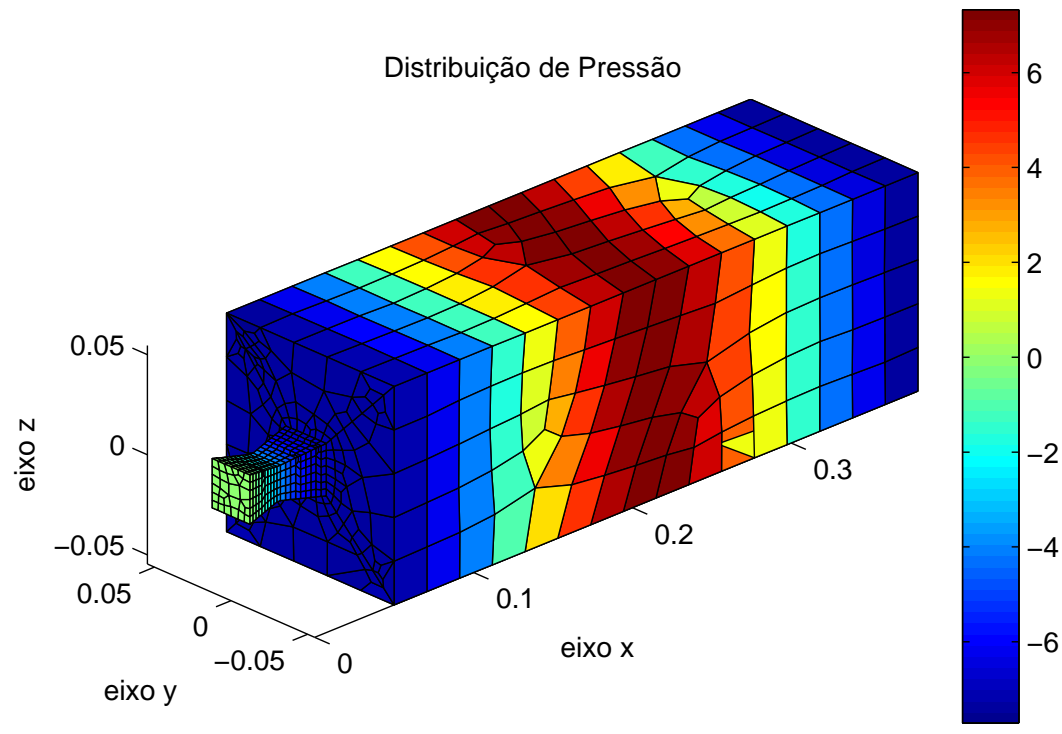

Figura 6.23: Terceira forma modal para a cavidade do motor de foguete híbrido

Tabela 6.5: Primeiras três frequências naturais do motor híbrido

\begin{tabular}{|c|c|c|c|}
\hline \multicolumn{4}{|c|}{ Diâmetro d = 140} \\
\hline & Primeiro Modo & Segundo Modo & Terceiro Modo \\
\hline Solução Analítica (Helmholtz) $[\mathrm{Hz}]$ & 59,57 & - & - \\
\hline Matriz de Transferência (Strip) $[\mathrm{Hz}]$ & 78,99 & 531,14 & 1043,2 \\
\hline Matriz de Transferência (Uniforme) [Hz] & 66,98 & 527,98 & 1042,5 \\
\hline MEF $[\mathrm{Hz}]$ & 55,11 & 524,74 & 1040,4 \\
\hline $\mathrm{MEC}[\mathrm{Hz}]$ & 76,55 & 529,19 & 1042,6 \\
\hline Experimental $[\mathrm{Hz}]$ & $\approx 66$ & 664,05 & 1175,2 \\
\hline \multicolumn{4}{|c|}{ Diâmetro d = 73} \\
\hline & Primeiro Modo & Segundo Modo & Terceiro Modo \\
\hline Solução Analítica (Helmholtz) $[\mathrm{Hz}]$ & 105,82 & - & - \\
\hline Matriz de Transferência (Strip) $[\mathrm{Hz}]$ & 113,82 & 544,97 & 1048,1 \\
\hline Matriz de Transferência (Uniforme) [Hz] & 97,89 & 538,23 & 1046,4 \\
\hline $\operatorname{MEF}[\mathrm{Hz}]$ & 94,69 & 535,35 & 1042,5 \\
\hline $\operatorname{MEC}[\mathrm{Hz}]$ & 109,47 & 541,82 & 1042,6 \\
\hline Experimental $[\mathrm{Hz}]$ & 103,44 & 554,74 & 1127,6 \\
\hline
\end{tabular}




\section{Capítulo 7 CONCLUSÕES E PERSPECTIVAS}

\subsection{Conclusões}

O presente trabalho apresentou o Método de Elementos de Contorno Direto aplicado a problemas de acústica. O método apresentado resolve problemas no domínio da frequência. Uma revisão bibliográfica foi realizada visando a compreensão do Método de Elementos de Contorno direto assim como dos métodos para melhorar seu custo computacional.

O método foi implementado na linguagem MATLAB 12.0 com o objetivo de criar uma ferramenta numérica que pudesse ser utilizado posteriormente no Laboratório de Vibrações na Universidade de Brasília. O método é apresentado para casos bidimensionais e tridimensionais.

O código foi validado através de comparações com casos em que existe solução analítica, obtidos através do método de separação de variáveis (Kinsler, 1982) e do método da matriz de transferência (Gibert, 1988). Nesses casos o Método de Elementos de Contorno foi capaz de reproduzir a física dos sistemas de forma satisfatória. O programa implementado foi utilizado então para resolver problemas de acústica de cavidades complexas, em estudo pelo Grupo de Dinâmica de sistemas. Os resultados obtidos numericamente foram então comparados com os resultados obtidos experimentalmente, com soluções analíticas aproximadas e com resultados numéricos obtidos através do Método de Elementos Finitos.

Existem muitas vantagens óbvias de se utilizar um método em que apenas o domínio deve ser discretizado. A primeira é a maior facilidade de modelagem dos problemas. Como apenas o contorno do domínio deve ser discretizado, o processo de criação de malhas se torna mais rápido e eficiente. As malhas construídas para os modelos de geometria complexa foram obtidas utilizando o programa GiD 12.0. Apesar dessas vantagens o método apresenta uma grande desvantagem com relação ao custo computacional. O Método de Elementos de Contorno Direto produz matrizes cheias e não-simétricas para a solução das equações 
diferenciais. Isso significa que, para resolver o problema da multiplicação matriz $\times$ vetor são necessárias $O\left(N^{2}\right)$. Isso diminui muito a eficiência do programa, principalmente quando a geometria é complexa e o número de nós é alto. É por isso que dizia-se que o Método de Elementos de Contorno está limitado a algumas dezenas de milhares de graus de liberdade, enquanto seus concorrentes podiam resolver dezenas de milhões de graus de liberdade. Muitas técnicas foram desenvolvidas para a solução desse problema, dentre elas os métodos de Adaptive Cross-Approximation e Expansão em Multi Pólos Rápidos (Fast Multipole Expansion) são as mais evidentes e promissoras para implementação posterior pois ambas conseguem diminuir o número de operações para $O(N)$.

\subsection{Perspectivas}

O Método de Elementos de Contorno (MEC) é adequado para resolver uma gama abrangente de problemas de acústica, mas seu custo computacional é mais alto do que métodos concorrentes como o Método de Elementos Finitos (MEF). Apesar das vantagens de modelagem do MEC em comparação com métodos em que o domínio inteiro do problema deve ser modelado e não apenas o contorno, o MEC ainda não consegue ser eficiente o suficiente para ser adotado em grande escala na indústria, principalmente por conta da necessidade de resolver matrizes cheias e não-simétricas (Dhandole and Modak, 2007). Uma das soluções para esse problema é o uso da expansão em multipólos rápida (Fast Multipole Expansion) que reduz o custo computacional da solução do problema e aumenta a competitividade do método com relação às outras ferramente numéricas disponíveis (Liu, 2009). 


\section{REFERÊNCIAS BIBLIOGRÁFICAS}

Azevedo, C. A. C. (2007). Formulação alternativa para análise de domínios não homogêneos e inclusões anistotrópicas via mec. Master's thesis, Escola de Engenharia de São Carlos.

Bergen, B., Pluymers, B., Genechten, B. V., Vandepitte, D., and Desmet, W. (2012). A trefftz based method for solving helmholtz problems in semi-infinitedomains. Engineering Analysis with Boundary Elements, 36:30-38.

Braga, L. M. (2012). Método dos elementos de contorno rápido com expansão em multipólos aplicado a problemas de condução de calor. Master's thesis, Universidade de Brasília.

Brancati, A. (2010). Boundary Element Method for Fast Solution of Acoustic Problems: Active and Passive Noise Control. PhD thesis, Imperial College London.

Campa, G. and Camporeale, S. (2010). Application of transfer matrix method in acoustics. Proceedings of the COMSOL Conference 2010 Paris.

Cataldo, E., Sampaio, R., and Nicolato, L. (2004). Uma discussão sobre modelos mecânicos de laringe para síntese de vogais. ENGEVISTA, 6(1):47-57.

Cheng, A. H. and Cheng, D. T. (2005). Heritage and early history of the boundary element method. Engineering Analysis with Boundary Elements, 29(3):268-302.

Clement, P., Hans, S., Hartl, D. M., Maeda, S., Vaissiere, J., and Brasnu, D. (2007). Vocal tract area function for vowels using three-dimensional magnetic resonance imaging. a preliminary study. Journal of Voice, 21(5):522 - 530.

Câmara, G. Z., Inglez, T. M. D., Bertoldi, A. E. M., and Veras, C. A. G. (2013). Development and testing of alternative paraffin-based hybrid rocket fuel. 22nd International Congress of Mechanical Engineering (COBEM).

Dhandole, S. D. and Modak, S. V. (2007). Review of vibro-acoustics analysis procedures for prediction of low frequency noise inside a cavity. IMAC-XXV: Conference and Exposition on Structural Dynamics.

Dominguez, J. (1993). Boundary Elements in Dynamics. Escuela Superior de Ingenieros Industriales Universidad de Sevilla, Av. Reina Mercedes, s/n, 41012 Seville, Spain.

Estorff, O. (2008). Challenges in technical acoustics: What can be computed today. 7.LSDYNA Awenderforum.

Ferreira, A. C. (2012). Comparação analítica numérica de cavidades acústicas e vibroacústicas. Technical report, Projeto de Graduação. Brasília: Departamento de Engenharia Mecânica (UnB/FT/EnM).

Ferreira, A. C., de Morais, M. V. G., de Morais Bertoldi, A. E., Júnior, M. N. D. B., and Veras, C. A. G. (2013). Modal identification of hybrid rockets acoustic cavities: Experimental and numerical evaluation. 22nd International Congress of Mechanical Engineering (COBEM 2013).

Fonseca, W. D., Masiero, B. S., Bistafa, S. R., Dietrich, P., Quiqueto, G. S., Chamon, L. F., Vorländer, M., and Gereges, S. N. Y. (2010). Medição de uma plataforma acústica con- 
ceitual desenvolvida por diferentes instituições de pesquisa. XXIII Encontro da Sociedade Brasileira de Acústica.

Gerges, S. N. Y. (2001). Ruídos e Vibrações Veiculares. Samir Nagi Yousri Gerges.

Gibert, R. J. (1988). Vibrations des structures - Interactions avec les fluides - Sources d'excitation aléatoires. Eyrolles.

Gilat, V. S. A. (2008). Métodos Numéricos para Engenheiros e Cientistas. Bookman.

Guzman, M., Laukkanen, A.-M., Krupa, P., Horacek, J., Svec, J. G., and Geneid, A. (2013). Vocal tract and glottal function during and after vocal exercising with resonance tube and straw. Journal of Voice, 27(4):523.e19 - 523.e34.

Hannukainen, A., Lukkari, T., Malinen, J., and Palo, P. (2007). Vowel formants from the wave equation. Journal of the Acoustical Society of America, 122(1):EL 1 - 7.

Kinsler, L. (1982). Fundamentals of Acoustics. John Wiley and Sons, third edition.

Kirkup, S. M. (2007). The Boundary Element Method in Acoustics. Integrated Sound Software.

Kurz, S., Rain, O., and Rjasanow, S. (2002). The adaptive cross-approximation technique for the 3-d boundary-element method. IEEE TRANSACTIONS ON MAGNETICS, 38(2):421424.

Liu, Y. (2009). Fast Multipole Boundary Element Method Theory and Applications in Engineering. Campridge University Press.

Liu, Y. J. and Nishimura, N. (2006). The fast multipole boundary element method for potential problems: A tutorial. Engineering Analysis with Boundary Elements, 30:371-381.

M. Stoia-Djeska, F. M. (2011). A mathematical and numerical model for the analysis of hybrid rocket motors. INCAS Bulletin, 3(4):113-125.

MATLAB (2010). MATLAB R2010a User's Guide. The MathWorks Inc.

Melo, N. G. R. (2013). Análise modal experimental de cavidade acústica com fonte calibrada. Master's thesis, Universidade de Brasília.

Melo, N. G. R., Ferreira, A. C., de Morais, M. V. G., and de Carvalho, M. O. M. (2012). Experimental modal identification of vibro-acoustic cavities with calibrated acoustic source. SAE Technical Paper 2012-36-0619.

Melo, N. G. R., Ferreira, A. C., de Morais, M. V. G., and de Carvalho, M. O. M. (2013). Experimental modal identification of vibro-acoustic cavities with calibrated acoustic source. 22nd International Congress of Mechanical Engineering (COBEM 2013).

Morais, M. V. G. (2000). Modelagens numéricas pelo método dos elementos finitos em problemas de interação fluido-estrutura. Master's thesis, Universidade de Brasília.

Partridge, P. W. and Brebbia, C. A. (1990). Computer implementation of the bem dual reciprocity method for the solution of general field equations. Communications in Applied Numerical Methods, 6(2):83-92.

Rokhlin, V. (1985). Rapid solution of integral equations of classical potential theory. $J$ Comput Phys, 60:187-207.

Rossetto, D. G. (2001). Contribution to the theory and practice of experimental acoustical modal analysis. Master's thesis, State University of Campinas.

Story, B. H., Laukkanen, A.-M., and Titze, I. R. (2000). Acoustic impedance of an artificially lengthened and constricted vocal tract. Journal of Voice, 14(4):455-469. 
Takemoto, H., Parham, and Mokhtari (2010). Acoustic analysis of the vocal tract during vowel production by finite-difference time-domain method. Journal of the Acoustical Society of America, 128(6):3724-3738.

Titze, I. (2001). Acoustic interpretation of resonant voice. Journal of Voice, 15(4):519-528.

Tourinho, A. (2011). Construção de modelo para análise de funções de transferência de sistemas vibro-acústicos. Technical report, Projeto de Graduação. Brasília: Departamento de Engenharia Mecânica (UnB/FT/EnM). 


\section{APÊNDICES}




\section{Solução Analítica para Cavidades Unidimensionais Não-Uniformes}

Ao estudarmos acústica de cavidades, muitas vezes podemos nos deparar com casos de cavidades longas, com características unidimensionais, que não possuem uma geometria uniforme. Esse é o caso de escapamentos de veículos, tubulações de ar e o trato vocal humano. Nesses casos, uma solução interessante para o problema encontra-se na Matriz de Transferência (Gibert, 1988). Métodos de Matriz de Transferência são ferramentas matemáticas muito poderosas pois podem dividir o sistema analisado em uma rede de subsistemas. A construção dessas matrizes pode ser obtida utilizando métodos analíticos, numéricos ou experimentalmente Campa and Camporeale (2010). No caso de uma cavidade acústica unidimensional, podemos definir as variáveis pressão e fluxo de pressão em cada um dos lados que compõem a cavidade. A matriz de transferência é a matriz que determina a relação entre os valores de pressão e fluxo de pressão no início e final da cavidade. Ao dispormos de ao menos um valor de pressão ou fluxo de pressão em cada extremidade, podemos encontrar as outras variáveis através da matriz de transferência.

Considere a equação da onda unidimensional homogênea no domínio da frequência 7.1.

$$
\frac{\partial^{2} p}{\partial x^{2}}=\frac{1}{k^{2}} p
$$

onde $k=c / \omega$ é denominado o número de onda.

A solução da equação diferencial ordinária 7.1 pode ser escrita como mostrado na equação 7.2 .

$$
p(x, \omega)=A \operatorname{sen}\left(\frac{\omega}{c} x\right)+B \cos \left(\frac{\omega}{c} x\right)
$$

Podemos definir a vazão mássica $q$ através de um cilindro de área $S$ e altura $H$ como mostrado na equação 7.3 . 


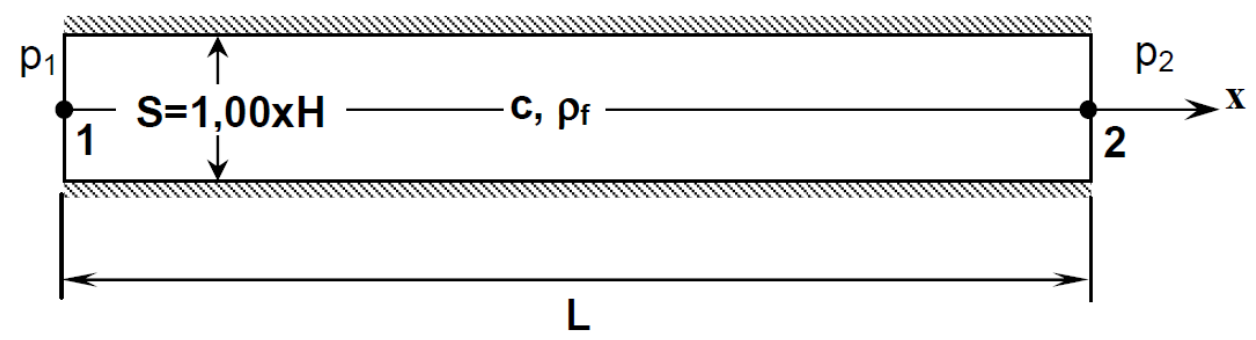

Figura 7.1: Esquema do conduto reto (Morais, 2000)

$$
q=\rho_{f} V_{f}=\rho_{f} S \dot{X}_{f}
$$

onde $V_{f}=V_{f}(x, t)$ e $X_{f}=X_{f}(x, t)$ são a velocidade e o deslocamento de uma partícula no domínio do tempo e $S$ é a seção transversal do conduto reto. Um esquema do modelo físico pode ser encontrado na figura 7.1 .

A partir do equilíbrio dinâmico de forças de uma partícula do fluido $\Delta x$ que tende a zero,

$$
\frac{\partial p}{\partial x}+\rho \ddot{X}_{f}=0
$$

Ao substituir 7.3 em 7.4 e realizar algumas manipulações algébricas, é possível obter a equação 7.6.

$$
\frac{\partial p}{\partial x}+\frac{\dot{q}}{S}=0
$$

que resulta em

$$
q=\frac{i S}{\omega} \frac{\partial p}{\partial x}
$$

para o caso em que $q=q(x) e^{i \omega t}$

A partir da equação 7.2 e da equação 7.6, a vazão acústica apresenta a forma seguinte:

$$
q=\frac{i S}{c}\left(A \cos \left(\frac{\omega}{c} x\right)-B \operatorname{sen}\left(\frac{\omega}{c} x\right)\right)
$$

A partir das relações dadas por 7.2 e 7.7, aplicando as condições de contorno para os pontos 
$1(x=0)$ e $2(x=L)$, podemos obter uma relação entre a pressão e a vazão da pressão no conduto reto mostrado. A equação correspondente, para extremidades 1 e 2 de uma cavidade unidimensional é mostrado na equação 7.8 .

$$
\left\{\begin{array}{l}
p_{2} \\
q_{2}
\end{array}\right\}=\left[\begin{array}{cc}
\cos (\gamma) & \frac{c}{i S} \sin (\gamma) \\
\frac{-i S}{c} \sin (\gamma) & \cos (\gamma)
\end{array}\right]\left\{\begin{array}{l}
p_{1} \\
q_{1}
\end{array}\right\}
$$

Em que $c$ é a velocidade de propagação da onda, $p_{i}$ e $q_{i}$ são, respectivamente, os valores de pressão e fluxo de pressão para o ponto $i, S$ é a área transversal da cavidade no comprimento $L, k=\frac{\omega}{c}$ é o número de onda e $\gamma=L \cdot k$ é o comprimento de onda.

A mesma técnica pode ser utilizada para cavidades irregulares, acoplando cada cavidade por uma matriz de transferência diferente. Essa técnica é também utilizada para obter as formas modais em cavidades irregulares. Cada cavidade pode ter um comprimento $L$ e área transversal $S$ arbitrários. Nesse caso, considere 2 cavidades acopladas de tal forma que a pressão final da cavidade é a pressão inicial da próxima cavidade, podemos montar uma matriz de transferência que corresponde à matriz mostrada na Equação 7.9.

$$
\left\{\begin{array}{l}
p_{3} \\
q_{3}
\end{array}\right\}=A_{(3)(1)}\left\{\begin{array}{l}
p_{1} \\
q_{1}
\end{array}\right\}
$$

Em que $A_{(3)(1)}$ é a matriz de transferência do ponto 1 ao 3 . Podemos escrever agora a matriz de transferência do ponto 1 ao 2 como mostrado na Equação 7.10.

$$
\left\{\begin{array}{l}
p_{2} \\
q_{2}
\end{array}\right\}=A_{(2)(1)}\left\{\begin{array}{l}
p_{1} \\
q_{1}
\end{array}\right\}
$$

Como não existe restrição na montagem das matrizes quanto aos pontos iniciais e finais, é possível escrever uma terceira equação que prevê o comportamento acústico do ponto 2 ao 3, mostrada na Equação 7.11.

$$
\left\{\begin{array}{l}
p_{3} \\
q_{3}
\end{array}\right\}=A_{(3)(2)}\left\{\begin{array}{l}
p_{2} \\
q_{2}
\end{array}\right\}
$$

Em que $A_{(3)(2)}$ é a matriz de transferência do ponto 2 ao 3 . 
A partir das equações 7.9, 7.10 e 7.11, é possível escrever a equação 7.12.

$$
\left\{\begin{array}{l}
p_{3} \\
q_{3}
\end{array}\right\}=A_{(3)(2)} \cdot A_{(2)(1)}\left\{\begin{array}{l}
p_{1} \\
q_{1}
\end{array}\right\}
$$

Expandindo pra $N$ cavidades arbitrárias, podemos escrever a equação 7.13.

$$
\left\{\begin{array}{l}
p_{N} \\
q_{N}
\end{array}\right\}=A_{(N)(N-1)} \cdot A_{(N-1)(N-2)} \cdot A_{(N-2)(N-3) \ldots A_{(3)(2)}} \cdot A_{(2)(1)}\left\{\begin{array}{l}
p_{1} \\
q_{1}
\end{array}\right\}
$$

Cada matriz $A_{(i)(i-1)}$ prevê o comportamento acústico do trecho contido entre os pontos $i$ e $i-1$. A área transversal $S$ e o comprimento $L$ podem assumir qualquer valor arbitrário para cada cavidade. Uma varredura de frequências é realizada para obter a resposta da cavidade para cada número de onda $k=\frac{\omega}{c}$.

As condições de contorno são determinadas pela pressão e fluxo de pressão nos pontos finais da cavidade, pontos $N$ e 1. É possível modelar cavidades aberta-aberta, fechada-aberta, aberta-fechada e fechada-fechada. Para encontrarmos as frequências de ressonância é necessário montar a equação modelada pelo conjunto de matrizes de transferência. Sabendo que a matriz $A_{(N)(1)}$ é a multiplicação matricial $A_{(N)(N-1)} \cdot A_{(N-1)(N-2)} \cdot A_{(N-2)(N-3)} \ldots A_{(3)(2)}$. $A_{(2)(1)}$, nota-se que ela mantém o tamanho $2 \times 2$ da Equação 7.8. Podemos reescrever a equação 7.13 após ter realizado as sucessivas multiplicações de tal forma que obtemos a equação 7.14 .

$$
\left\{\begin{array}{l}
p_{N} \\
q_{N}
\end{array}\right\}=\left[\begin{array}{ll}
A_{11} & A_{12} \\
A_{21} & A_{22}
\end{array}\right]\left\{\begin{array}{l}
p_{1} \\
q_{1}
\end{array}\right\}
$$

Em que $A_{11}, A_{12}, A_{21}$ e $A_{22}$ são os termos obtidas pela multiplicação matricial. Podemos escrever as equações resultantes como mostrado nas equações 7.15 e 7.16.

$$
p_{N}=A_{11} \cdot p_{1}+A_{12} \cdot q_{1}
$$




$$
q_{N}=A_{21} \cdot p_{1}+A_{22} \cdot q_{1}
$$

Sabemos que as condições de contorno para superfície aberta é a de pressão nula $p=0$, e a de superfície fechada é a de fluxo nulo $q=0$, finalmente podemos determinar que o número de onda $k=\frac{\omega}{c}$ que obedece as relações mostradas na Tabela 7.1.

Tabela 7.1: Relações necessárias para encontrar as frequências de ressonância utilizando a matriz de transferência

\begin{tabular}{|l|l|}
\hline Condição de Contorno & Condição necessária \\
\hline Aberta-Aberta & $A_{12}=0$ \\
\hline Aberta-Fechada & $A_{22}=0$ \\
\hline Fechada-Aberta & $A_{11}=0$ \\
\hline Fechada-Fechada & $A_{21}=0$ \\
\hline
\end{tabular}

Conhecendo as condições mostradas na Tabela 7.1, podemos encontrar os valores das frequências de ressonância para as condições de contorno desejadas. Dessa forma é possível encontrar as frequências de ressonância do modo unidimensional de qualquer cavidade de geometria arbitrária.

Para obter as formas modais dadas pelas frequências de ressonância $\omega_{r}$, basta aplicar a equação 7.8 para cada cavidade com o valor da frequência encontrada $\omega_{r}$. Assim é possível encontrar o valor da pressão e fluxo da pressão para cada cavidade. Essa forma modal corresponde ao modo de ressonância para a frequência $\omega_{r}$.

\section{Programas para o cálculo da matriz de transferência}

O programa apresentado a seguir corresponde à formulação para a matriz de transferência apresentado anteriormente. O programa é dividido em duas partes, um programa principal transfer_matrix.m e o programa de entrada de dados dad_teste.m.

\section{- transfer_matrix.m}

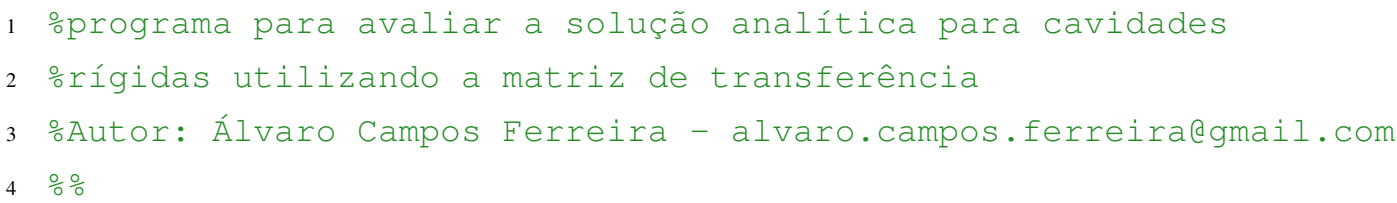




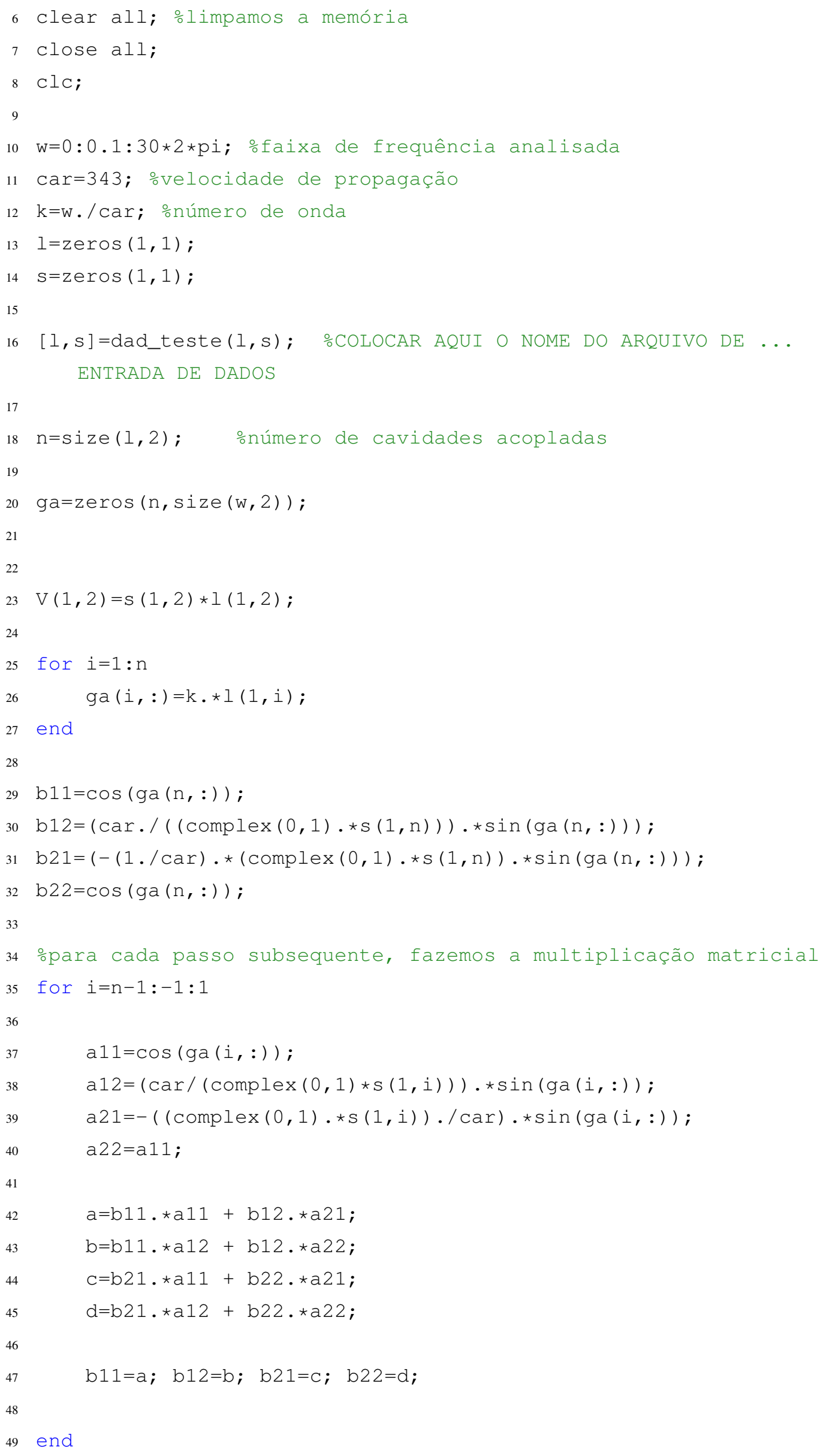




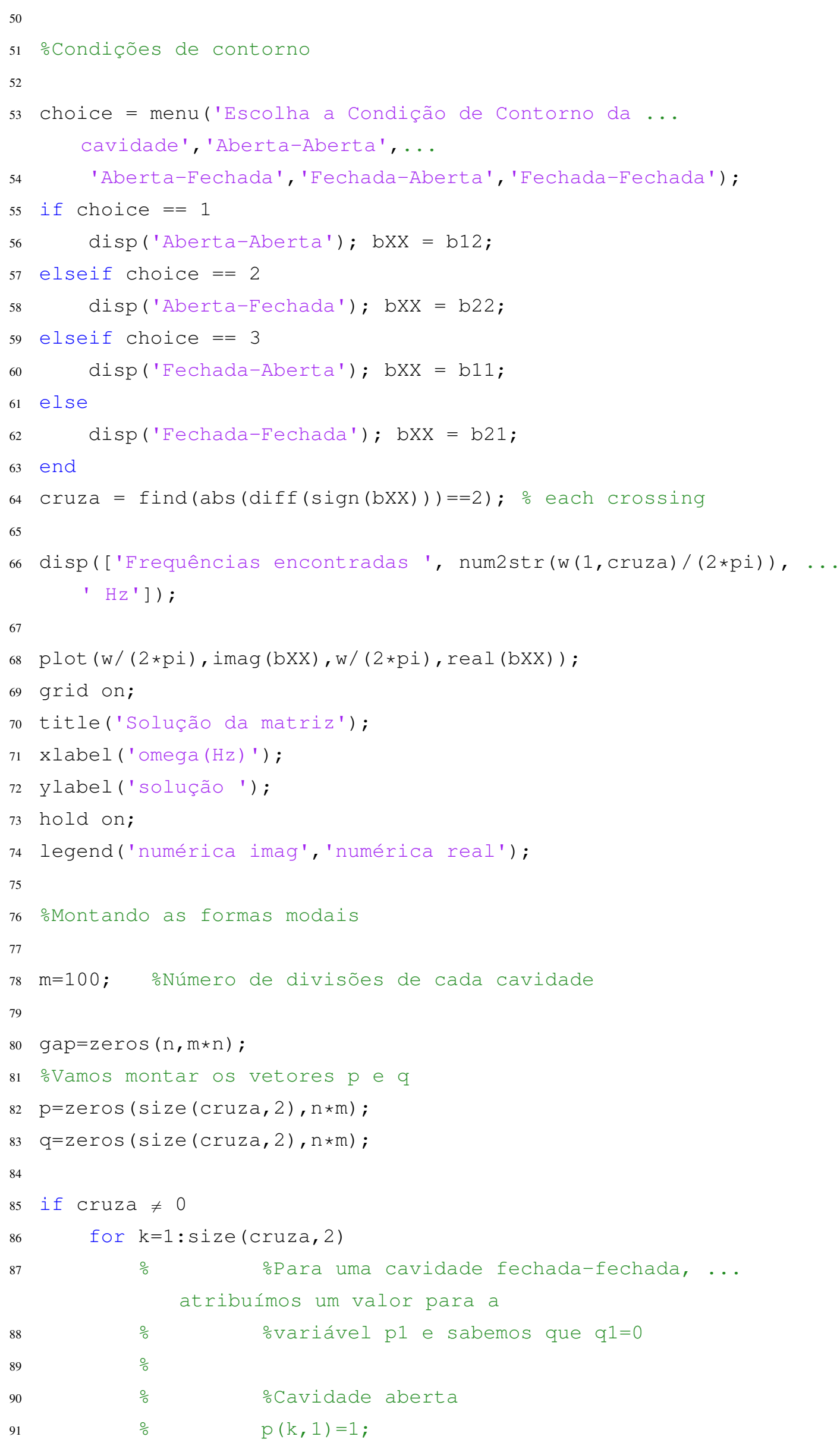




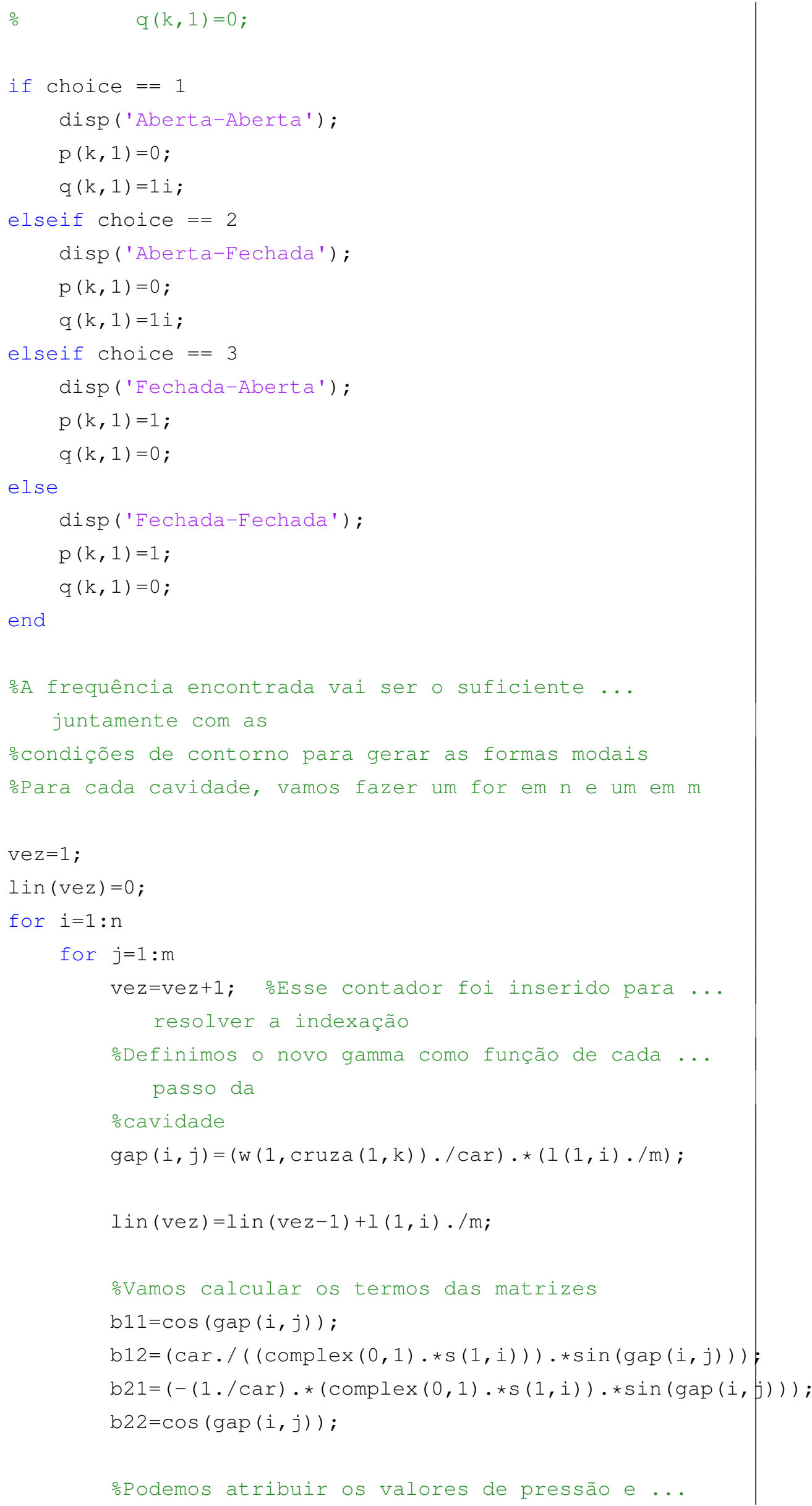




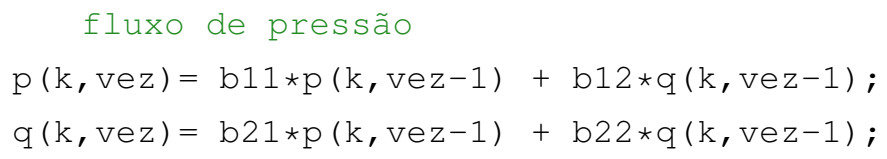

end

end

figure (2)

plot (lin, (p(k, :)));

grid on;

title('Forma modal');

xlabel ('Posição [m] ') ;

ylabel ('Forma modal');

\%legend('numérica imag', 'numérica real');

pause

$151 \quad$ end

52 end

153

154

155 save('dad_teste_res', 'l','s', 'n', 'm', 'p', 'lin');

\section{- dad_teste.m}

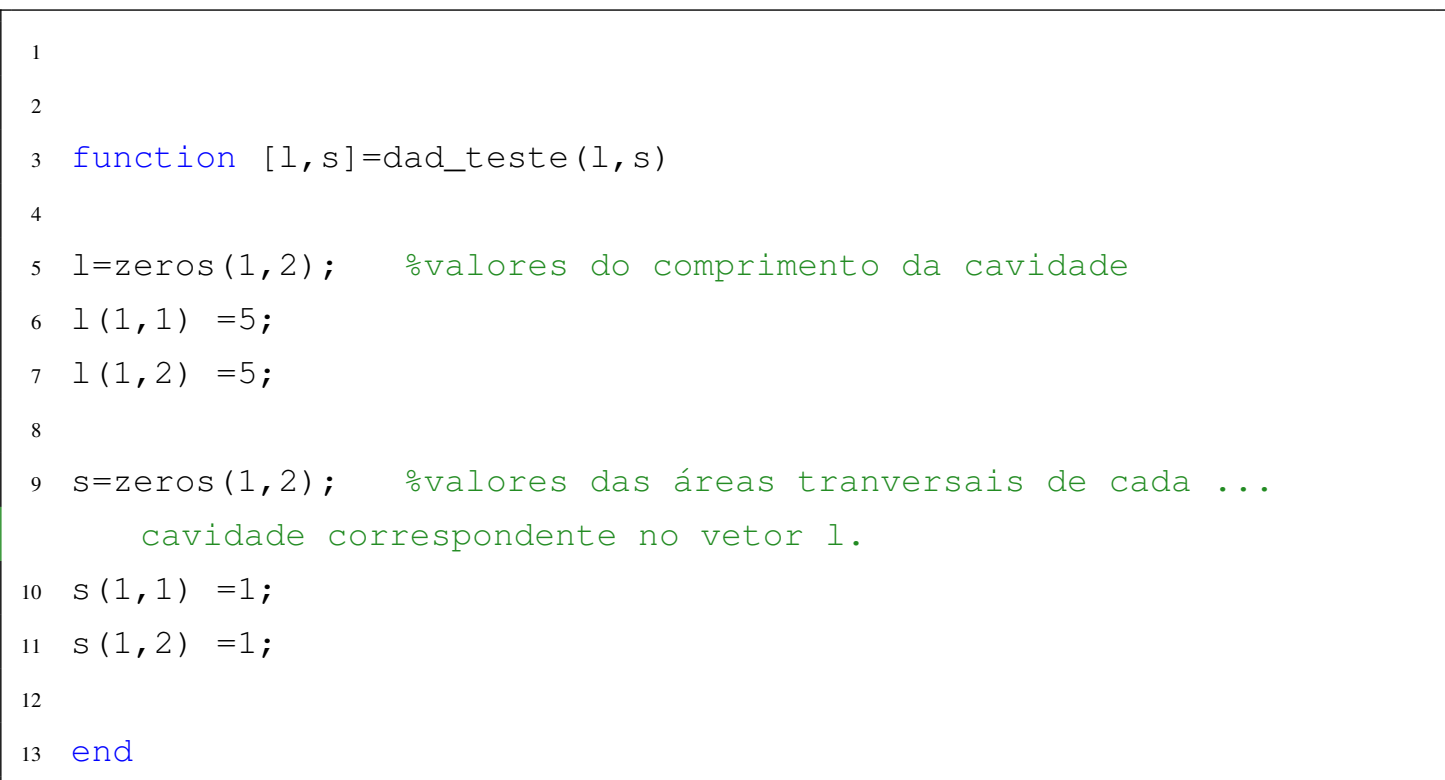




\section{Método da Integração Radial - RIM}

O Método da Integração Radial (Radial Integration Method - RIM) pode ser utilizado para transformar integrais de domínio em integrais de contorno. No caso da equação de Helmholtz, o método pode ser utilizado incorporando uma função de interpolação para os valores de pressão e fluxo de pressão, como mostrado no capítulo a seguir. A formulação a seguir é a mesma descrita em

Para resolver o problema da equação da onda, iremos considerar o problema de Laplace com uma fonte que depende da pressão em cada ponto. A equação resultante é a equação de Helmholtz, como mostrada na equação 7.1. A solução fundamental considerada para a equação 7.1 é a solução fundamental para a equação de Laplace bidimensional, considerando o termo de inércia como uma força de campo, ou seja:

$$
\nabla^{2} p+b=0
$$

onde $b=\left(\frac{\omega}{c}\right)^{2} p$. Desta forma, a equação integral correspondente será dada por 7.5. Neste caso, as soluções fundamentais são as soluções fundamentais da equação de Laplace que, para o caso bidimensional é a solução da equação diferencial:

$$
\nabla^{2} p=-\delta\left(x-x_{d}\right)
$$

onde $\delta\left(x-x_{d}\right)$ é o delta de Dirac para o ponto de colocação $x_{d}$. As soluções fundamentais são:

$$
\begin{gathered}
p^{*}=\frac{-1}{2 \pi} \ln r \\
\frac{\partial p^{*}}{\partial n}=\frac{1}{2 \pi r}\left(r_{x} n_{x}+r_{y} n_{y}\right)
\end{gathered}
$$

onde $r=x-x_{d}$ é a distância entre o ponto de integração e o ponto de colocação (ponto campo e ponto fonte, respectivamente). Note que agora existe uma integral de área na 
equação 7.5 correspondente à força de corpo $b$. Para evitar a discretização do domínio, esta integral de área precisa ser transformada em integrais de contorno. Nesta seção, é descrita esta transformação usando o método da integração radial.

$$
C(\xi) p(\xi)+\int_{S} p \frac{\delta p^{*}}{\delta n} d S-\int_{S} \frac{\delta p}{\delta n} p^{*} d S+\left(\frac{\omega}{c}\right)^{2} \int_{A} p^{*} p d A=0
$$

Considere um domínio $A$ de contorno $S$. Podemos escrever, sem perda de generalidade, as relações mostradas na Figura 7.1.

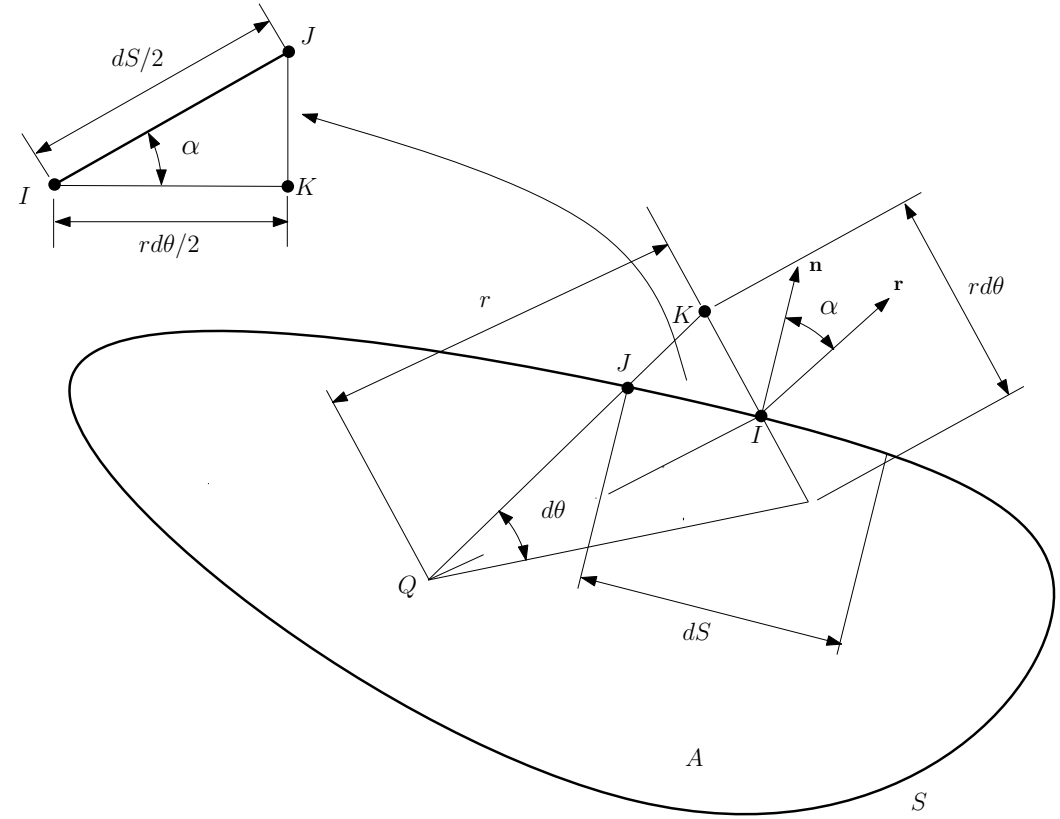

Figura 7.1: Transformação da integral de domínio em integral de contorno.

$$
\cos \alpha=\frac{r \frac{d \theta}{2}}{\frac{d S}{2}}
$$

$\mathrm{ou}$

$$
d \theta=\frac{\cos \alpha}{r} d S
$$

Usando as propriedades do produto interno dos vetores unitários $\mathbf{n}$ e $\mathbf{r}$, indicados na Figura 7.1, podemos escrever: 


$$
d \theta=\frac{\mathbf{n} \cdot \mathbf{r}}{r} d S
$$

O RIM aproxima a pressão $p$ como uma soma de $M$ produtos de funções de aproximação $f^{m}$ e coeficientes a determinar $\gamma^{m}$, ou seja:

$$
\begin{gathered}
p(x)=\sum_{m=1}^{M} \gamma^{m} f^{m} \\
I(\xi)=\int_{A} p^{*} p d A=\sum_{m=1}^{M} \gamma^{m} \int_{A} f^{m} p^{*}(\xi, x) \rho d \rho d \theta
\end{gathered}
$$

em que $\xi$ é o ponto fonte e $x$ o ponto de integração (ponto campo). Podemos também escrever:

$$
I(\xi)=\sum_{m=1}^{M} \gamma^{m} \int_{\theta} \int_{0}^{r} f^{m} p^{*}(\xi, x) \rho d \rho d \theta
$$

onde $r$ é o valor de $\rho$ em um ponto no contorno $S$ (ver Figura 7.1):

Definindo $F^{m}(\xi)$ como:

$$
F^{m}(\xi)=\int_{0}^{r} f^{m} p^{*}(\xi, x) \rho d \rho
$$

pode-se escrever:

$$
I(\xi)=\sum_{m=1}^{M} \gamma^{m} \int_{\theta} F^{m}(\xi) d \theta
$$

Substituindo a equação (7.8) na equação (7.13), a equação integral de domínio da equação (7.5) pode ser escrita na seguinte integral de contorno: 


$$
I(\xi)=\sum_{m=1}^{M} \gamma^{m} \int_{S} \frac{F^{m}(\xi)}{r} \mathbf{n} \cdot \mathbf{r} d S
$$

Assim, a integral de domínio da equação (7.5) pode ser escrita como:

$$
I(\xi)=\left[\begin{array}{llll}
\int_{S} \frac{F_{1}(\xi)}{r} \mathbf{n} \cdot \mathbf{r} d S & \int_{S} \frac{F_{2}(\xi)}{r} \mathbf{n} \cdot \mathbf{r} d S & \ldots & \int_{S} \frac{F_{M}(\xi)}{r} \mathbf{n} \cdot \mathbf{r} d S
\end{array}\right]\left\{\begin{array}{c}
\gamma_{1} \\
\gamma_{2} \\
\vdots \\
\gamma_{M}
\end{array}\right\} .
$$

Para calcular $\gamma_{m}$, é necessário considerar a força de corpo em $M$ pontos do domínio e do contorno. No caso deste trabalho, estes pontos são os nós do contorno e alguns pontos internos. Assim, a equação (7.9) pode ser escrita como:

$$
\mathbf{p}=\mathbf{F} \gamma
$$

e $\gamma$ pode ser calculado como:

$$
\gamma=\mathbf{F}^{-1} \mathbf{p}
$$

Substituindo (7.17) na equação (7.15), tem-se:

$$
I(\xi)=\left[\begin{array}{llll}
\int_{S} \frac{F_{1}(\xi)}{r} \mathbf{n} \cdot \mathbf{r} d S & \int_{S} \frac{F_{2}(\xi)}{r} \mathbf{n} \cdot \mathbf{r} d S \quad \ldots \quad \int_{S} \frac{F_{M}(\xi)}{r} \mathbf{n} \cdot \mathbf{r} d S
\end{array}\right] \mathbf{F}^{-1} \mathbf{p} .
$$

ou, para todos os pontos fontes $\xi_{1}, \xi_{2}, \ldots, \xi_{N}$, tem-se 


$$
\mathbf{I}=\mathbf{S F}^{-1} \mathbf{p}
$$

onde

$$
\mathbf{S}=\left[\begin{array}{cccc}
\int_{S} \frac{F_{1}\left(\xi_{1}\right)}{r} \mathbf{n} \cdot \mathbf{r} d S & \int_{S} \frac{F_{2}\left(\xi_{1}\right)}{r} \mathbf{n} \cdot \mathbf{r} d S & \ldots & \int_{S} \frac{F_{M}\left(\xi_{1}\right)}{r} \mathbf{n} \cdot \mathbf{r} d S \\
\int_{S} \frac{F_{1}\left(\xi_{2}\right)}{r} \mathbf{n} \cdot \mathbf{r} d S & \int_{S} \frac{F_{2}\left(\xi_{2}\right)}{r} \mathbf{n} \cdot \mathbf{r} d S & \ldots & \int_{S} \frac{F_{M}\left(\xi_{2}\right)}{r} \mathbf{n} \cdot \mathbf{r} d S \\
\vdots & \vdots & \ddots & \vdots \\
\int_{S} \frac{F_{1}\left(\xi_{N}\right)}{r} \mathbf{n} . \mathbf{r} d S & \int_{S} \frac{F_{2}\left(\xi_{N}\right)}{r} \mathbf{n} \cdot \mathbf{r} d S & \ldots & \int_{S} \frac{F_{M}\left(\xi_{N}\right)}{r} \mathbf{n} \cdot \mathbf{r} d S
\end{array}\right]
$$

Escrevendo a equação (7.18) para todos os pontos do domínio, isto é, todos os nós do contorno e pontos internos, tem-se:

$$
\begin{gathered}
\mathbf{H} \mathbf{p}-\mathbf{G q}+\left(\frac{\omega}{c}\right)^{2} \mathbf{S F}^{-1} \mathbf{p}=0 \\
{\left[\mathbf{H}+\left(\frac{\omega}{c}\right)^{2} \mathbf{S F}^{-1}\right] \mathbf{p}-\mathbf{G q}=0} \\
\mathbf{H}_{2} \mathbf{p}=\mathbf{G q}
\end{gathered}
$$

onde

$$
\mathbf{H}_{2}=\left[\mathbf{H}+\left(\frac{\omega}{c}\right)^{2} \mathbf{S F}^{-1}\right]
$$

As funções de aproximação $f^{m}$ serão funções de base radial escritas em termos de $R$, onde $R$ é a distância entre o centro $T$ da função de base radial e o ponto de integração $P$. Da Figura 7.2, pode-se escrever: 


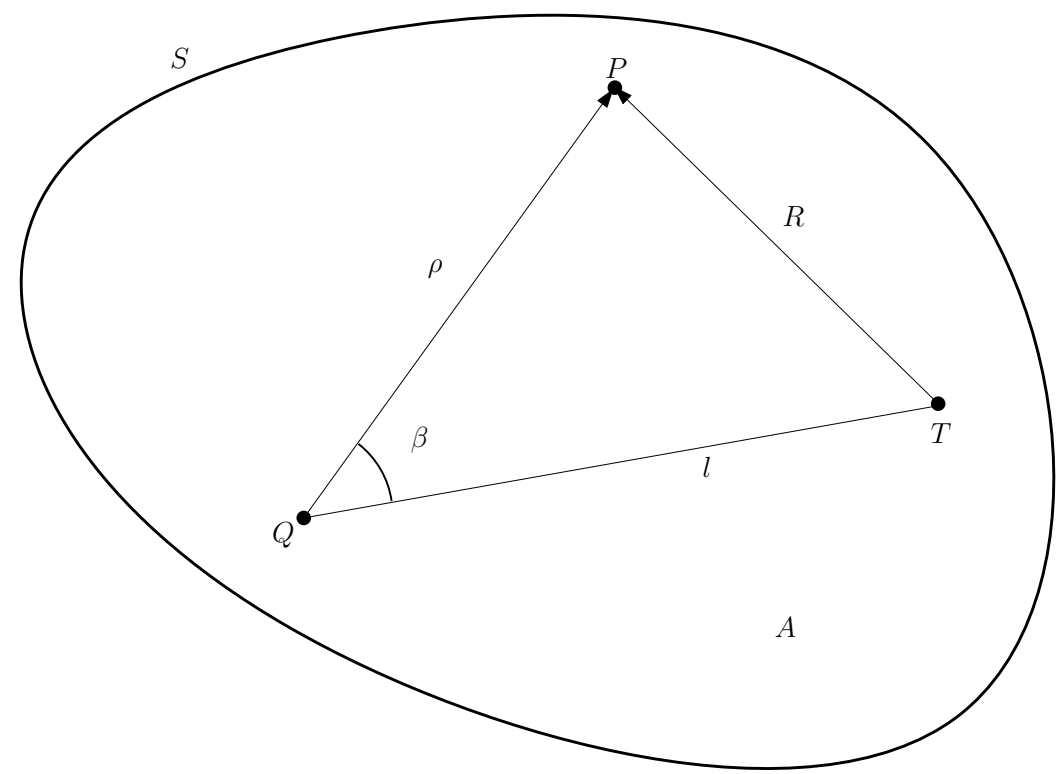

Figura 7.2: Posição dos pontos no domínio.

$$
R=\sqrt{\rho^{2}+l^{2}-2 \rho l \cos \beta}
$$

onde $l$ é a distância entre os pontos $T$ e $Q$ e $\beta$ é o ângulo entre $\rho$ e $l$, conforme observado na Figura 7.2. A integral (15) é escrita como

$$
F^{m}(Q)=\int_{0}^{r} \frac{1}{2 \pi}\left(\sqrt{\rho^{2}+l^{2}-2 \rho l \cos \beta}+1\right) \log (\rho) \rho d \rho
$$

A integral da equação (7.25) não pode ser calculada analiticamente. O cálculo numérico desta integral torna mais alto o custo computacional do RIM em comparação com o DRM, uma vez que no DRM não se faz nenhuma integração numérica na transformação da integral de domínio em integrais de contorno.

Neste trabalho foi usada como função de aproximação de base radial, a função dada por:

$$
f=1+R
$$

O DRM foi implementado em MATLAB assim como o RIM, mas sua formulação foge do escopo deste trabalho não será apresentada, podendo ser encontrada em Partridge and Brebbia (1990). A única consideração que deve ser feita para obter a equação da onda a 


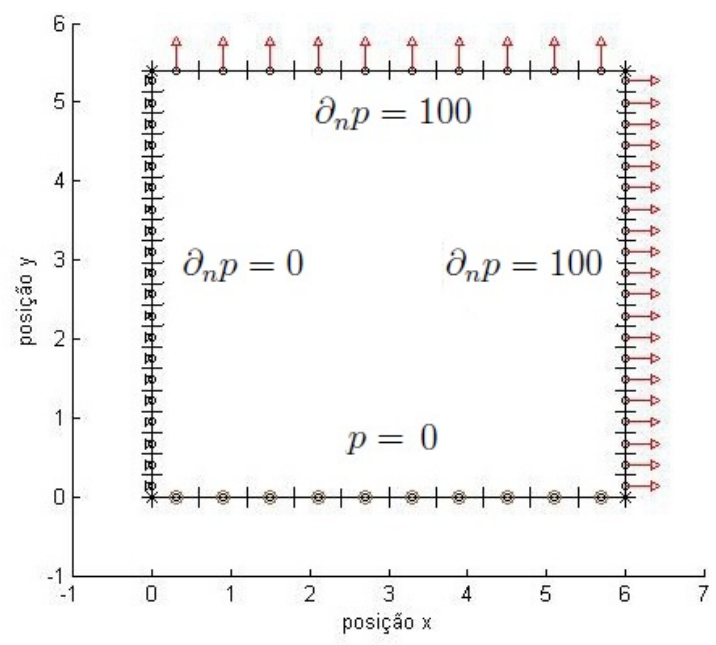

Figura 7.3: Condições de contorno do exemplo 1

partir de uma equação de Laplace com um fonte que dependa da pressão é considerar a constante que multiplica a fonte como o quadrado do número de onda, como mostrado em 7.1 .

Para se verificar a performance do método proposto, foi analisado um problema que possui uma solução analítica. O caso estudado foi o mesmo do exemplo 1 apresentado em Dominguez (1993) na seção 2.19, página 197. As condições de contorno podem ser observadas na figura 7.3, em que as setas que terminam com um triângulo correspodem a áreas em que o fluxo de pressão é conhecido e setas que terminam com círculos são áreas em que a pressão é conhecida. O modelo corresponde a um caso unidimensional de propagação de ondas planas. A solução analítica do problema apresentada é dada pela equação 7.27. A primeira forma modal obtida utilizando este método pode ser vista na Figura 7.4.

$$
f_{\text {aberto-fechado }}=\frac{[2 \cdot \pi \cdot(2 \cdot n-1)] \cdot c}{4 \cdot L_{\text {tubo }}}, n=0,1,2,3, \ldots
$$

O DRM foi capaz de obter os mesmos resultados para uma cavidade fechada que o RIM e as formas modais encontradas foram as mesmas para o RIM. 


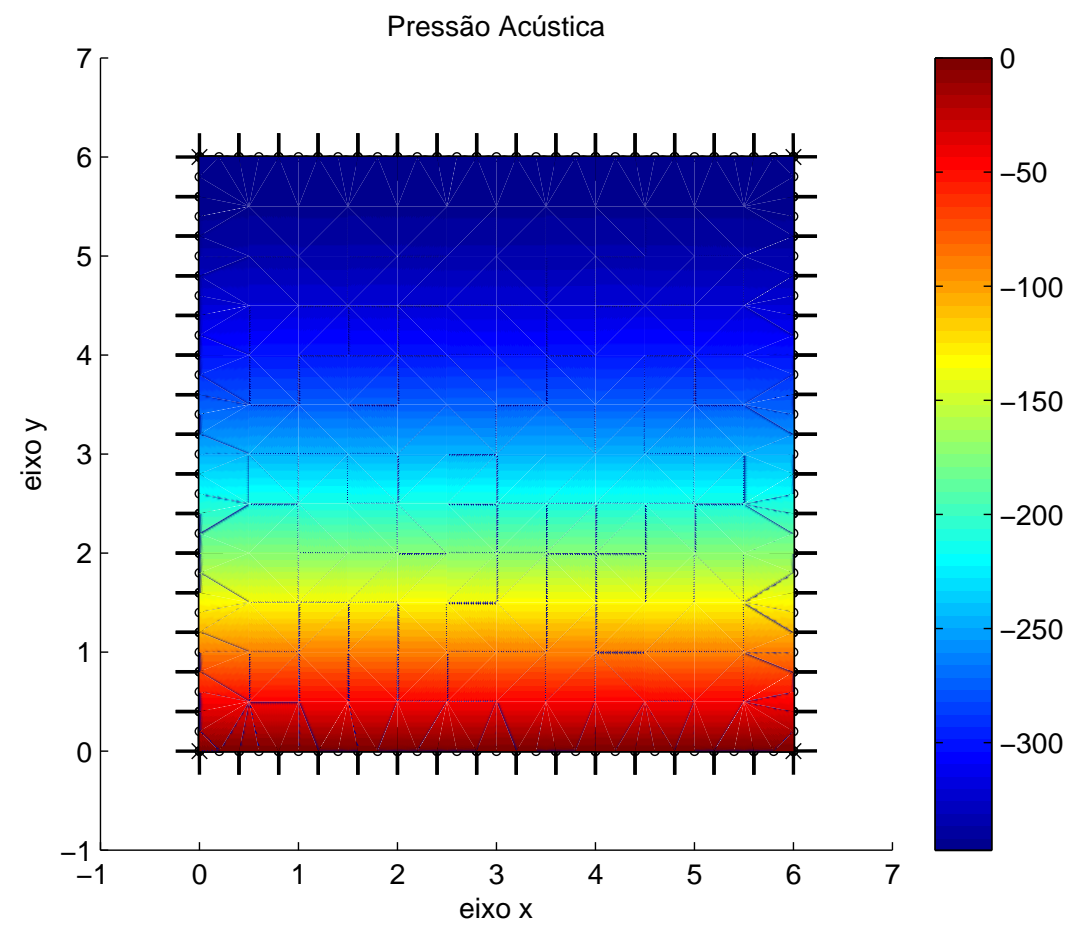

Figura 7.4: Primeira forma modal para o exemplo 1, obtido utilizando o RIM 